\title{
Exploring the side effect profile of 16-Ethynyl Salvinorin A
}

\section{Stephen George Mathew}

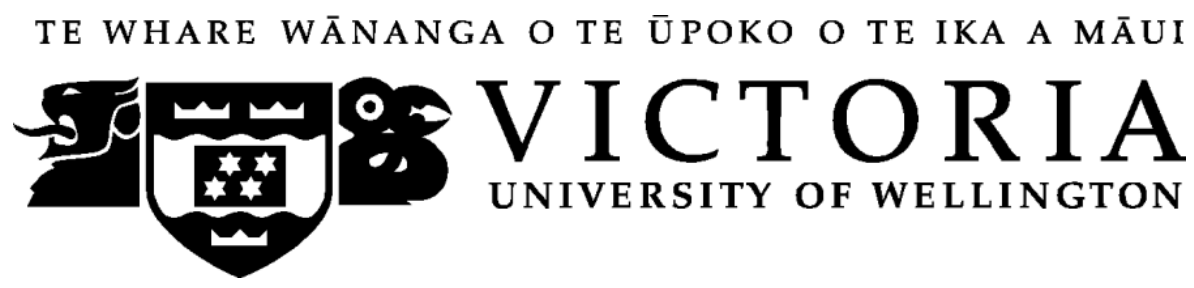

School of Biological Sciences

Te kura Matauranga Koiora

A thesis submitted to Victoria University of Wellington in fulfilment of the requirements of the degree of Master of Biomedical Science 



\section{Abstract}

Introduction: Drug addiction is a chronic and relapsing disorder that has widespread socioeconomic and health consequences. Globally, there are over 29.5 million people who are drug dependent, and New Zealand has one of the highest rates of drug use rates in the developed world. Currently, there are no Food and Drug Administration (FDA) approved pharmacotherapies that target psychostimulant addiction. Kappa opioid receptor (KOPr) agonists are being studied as a potential pharmacotherapy as it utilizes the brain's own mechanism for controlling reward, however, KOPr agonists have unwanted side effects such as dysphoria and sedation. This thesis explores the KOPr agonists Salvinorin A (Sal A), a naturally-occurring, highly potent and short-acting non-nitrogenous $\mathrm{KOPr}$ agonist and a structural analogue, 16-Ethynyl Salvinorin A (16-Ethy). KOPr agonists, such as Sal A have known preclinical anti-addictive and anti-reward effects, therefore, this thesis focuses on evaluating Sal A and 16-Ethy in preclinical tests of reward and side effects

Methods: Male Sprague-Dawley rats were used in preclinical tests to evaluate common KOPrmediated side-effects including anxiety (elevated plus maze), depression (forced swim test) sedation (locomotor activity) and aversion (conditioned place aversion). The anti-cocaine effects were also examined using self-administration, dose-response and drug-behavioural sensitisation tests. 16-Ethy was tested at $2 \mathrm{mg} / \mathrm{kg}$ in all experiments.

Results: Acute pre-treatment of 16-Ethy induced sedative effects in non-habituated locomotor activity but when rats were habituated prior to administration, no sedation was observed. In contrast, Sal A (2 mg/kg) had sedative effects in habituated, but not in nonhabituated locomotor activity $(p=0.0037)$. Compared to vehicle-treated rats, 16 -Ethy and Sal A did not display pro-depressive effects in the forced swim test, show anxiogenic or aversive properties or modulate behavioural sensitisation to cocaine. Cocaine selfadministration and dose-response tests were not successfully completed.

Conclusion: At $2 \mathrm{mg} / \mathrm{kg}, 16$-Ethy was found to display sedative effects in non-habituated locomotor activity but not in a habituated paradigm. Compared to vehicle-treated rats, 16Ethy did not display pro-depressive effects in the forced swim test, or display anxiogenic or aversive properties and did not show significant cocaine sensitisation. Cocaine self- 
administration and dose-response tests were not successfully completed and will need to be repeated to ascertain the effects of 16-Ethy on them. However, 16-Ethy has shown glimpses of promise as a potential pharmacotherapy against addiction. 


\section{Acknowledgements}

They say it takes a village to raise a child. This thesis has taken a metropolis of individuals who have helped me formulate it, bin it and ultimately create what it is now. I am thankful for the opportunity to immortalise my gratitude to you all in this acknowledgement section.

Firstly, I would like to thank my Lord and Saviour, Jesus Christ. If I had not been raised with my faith, I would have lost all hope, especially during the toughest 13 months of my life doing the self-admin experiment. To my beloved parents, I am honoured to be your son and have always wanted to make you proud. Thank you for always encouraging and believing in me, I could never have done this without you, love you. To Samuel and Thomas, I am proud of you both, you have infinite potential, may this thesis provide you with some sort of inspiration to pursue excellence in your lives, if I could complete this, you guys can achieve anything. To Billie, I'm so glad we got you, best pupper ever. To all my family in India and around the world, thank you for your thoughts and prayers, rest in peace Yeroor Ammachi. To my Church family, it's been an honour serving and leading you in my capacity.

Dr Bronwyn Kivell, I was humbled when you took me in for the summer scholarship so long ago. I never thought this sort of thing would be possible yet you believed in me enough to entrust me with this project. You're one of the most ambitious and driven people I've had the opportunity to witness, it was inspiring and I know you will achieve whatever you set your goals on. One of the highlights of my postgraduate study was being able to point you out as my supervisor while I presented my research in parliament. Thank you. Dr Tom Prisinzano, thank you for making all the compounds our lab tests, hopefully we'll find one that changes the world.

To my lab mates, being with you all has made this all worthwhile. Kelly, you have been the one constant since undergrad. Thank you for always being there, answering every dumb question and my constant pop-ups. You are one of the most hardworking people ever, I wish you every success and reap the rewards of all that work. To Diana, thank you for every single thing you've done for me, none of this would have happened without your help, I will forever be grateful for you, God bless for your future. To my sister from another mister Afnan, thanks for all your support, I hope I have impacted you the same way you have for me, all love. Amy, thankfully I finally got to confirm my accurate memory when we first met, thanks for the laughs (by that I mean, you and Kelly hysterically laughing at your own jokes) and also warming me up to the idea of cats. Andy, thanks for your guidance, it was nice to have at least one dude around in the lab. Susan, thanks for the sweet treats and always being the chatterbox, definitely filled the silence. Janine, never forget to skip, it's the only way to go. To everyone that has been in the lab, it's been a swell time; Caiti, Amy E, Adam, Aimee C, Samantha, Ricky, Nikki, Phyllida, Lisa, Harvier, Isobel, Zinmar and Kendra. Varun, you have been there since year one of my undergrad, since then you've been an amazing support. You bring value to everyone, and I'm sure you're the MVP of SBS, I wish you nothing but the very best. 
To David and Karmella, thank you for being my Awhina mentors and pushing me to pursue post-grad, your student has done it. Sandra, thank you for passing my name forward to Bronwyn after that fateful career evening, it all started with you.

To the administration team; Mary, you have been like a loving aunty, we're all lucky to have you. To Charlotte, thank you for introducing me to Trade Aid chocolate powder, my weetbix has never been the same. Stephen, thanks for promptly getting every problem fixed. Thanks Mark and Paul. To Patricia, you have been amazing to me, thank you for your empathy and willingness to help, I certainly couldn't have handed this in without you. Thank you Sushila for all the encouragement. Thank you to all the technicians; Neville, Craig, Shaun. Paul, thank you for the laughs, advice and stories of Punkey, it's made every walk up the Terrace fun. Thank you Stacey and Aimee for managing the new animal facility, good luck.

Thank you to Te Puni, for all the fun last year, I really enjoyed my time as an RA.

To my mentors, you have brought value to my life and my successes are a testament to your input. Ms Sauvao, thank you for always believing and guiding me. Jerram, thank you for your inspiration, prayers and encouragement. Mrs McDonald, Sashi Meanager Dr, Diane Ormsby and Dr Darren Day, you have all inspired me to be a better communicator and teacher of my knowledge base.

Dear Nick Linney, rest in peace brother, I wouldn't have done my undergrad degree without your diagnosis. I didn't know it would lead to neuroscience but here it is, a thesis completed.

I would like to finish by thanking my dear friends, I am the sum total of my experiences with you, I love you all.

Daniel, you are my brother, thank you for your lasting encouragement and lasting friendship. To Michael, you are the man, every meeting has been inspirational. Patrick, Josh, Lee, Braedyn and Daini, I love seeing how we're all evolving in our individual lives, more life.

To my dear friends; Reigh, John, Alex, Rory, Holly, Sam, Madge. I have been blessed with the best. What an amazing group of loving, funny, charismatic, beautiful and smart people. My time at uni has been some of the best years of my life simply because you came into my life. I am grateful for you and love you. Reigh and John, thank you for being with me through the thick and the thin, you inspire me to be better. I can't mention you lot without thanking Chloe for bringing us all together, who knew life would turn out this way, proud of you and your family Chloe. Cedric, you are the sort of guy I want to grow to become, God bless. Kef and Regan, I'm lucky to have met you guys. Alison, it was a fond memory, thank you.

Victoria University of Wellington, it's been a great few years and I'm glad I got to have studied here especially now before the name change. Finally, to all the rats hopefully our addiction research will go on to benefit humanity and thereby your lives are honoured. 


\section{Table of Contents}

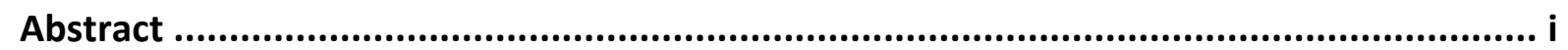

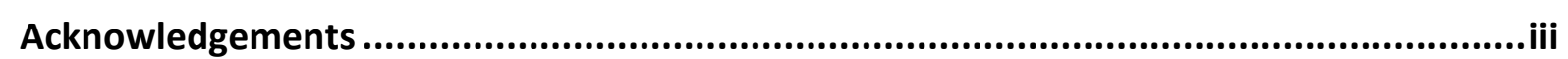

List of Figures ......................................................................................................... vii

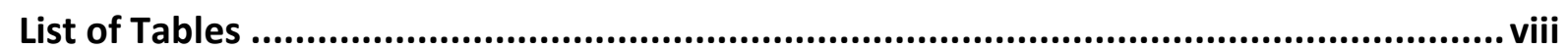

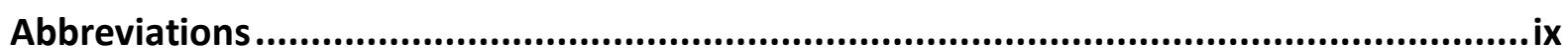

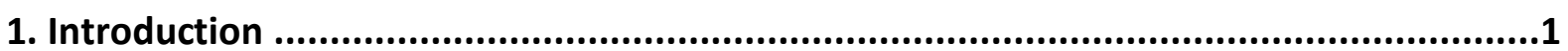

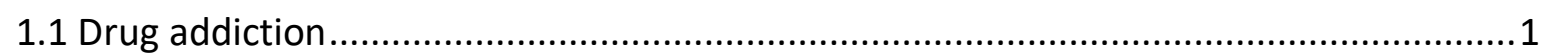

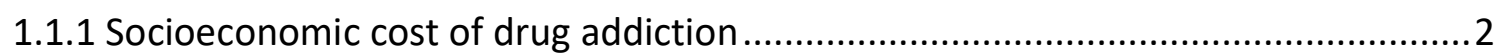

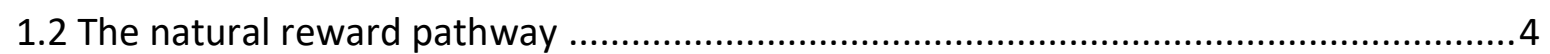

1.3 Changes in the reward pathway following drug abuse ............................................ 8

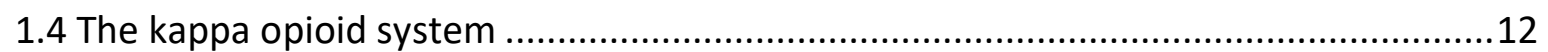

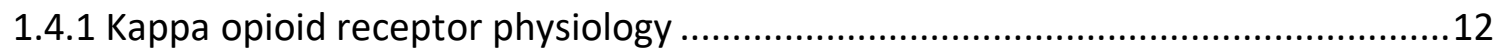

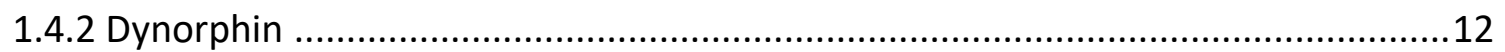

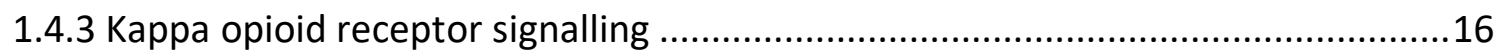

1.5 Kappa opioid receptor agonists in addiction research .............................................19

1.5.1 Acute administration of kappa opioid receptor agonists .....................................19

1.5.2 Chronic administration of kappa opioid receptor agonists ...................................21

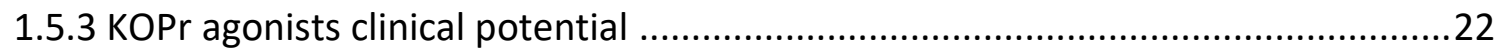

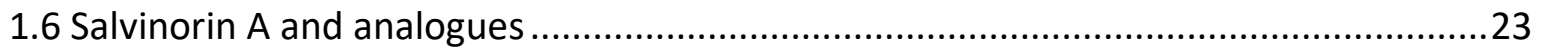

1.7 Animal models of kappa opioid receptor-mediated side effects ................................28

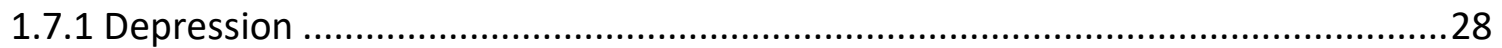

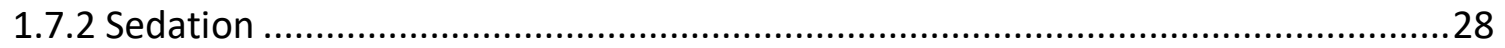

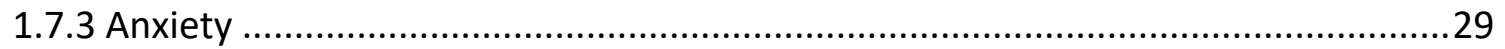

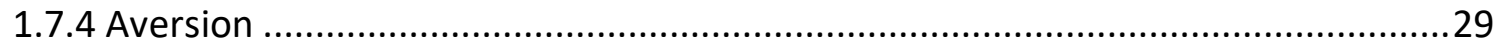

1.8 Self administration - a preclinical behavioural model of addiction .............................30

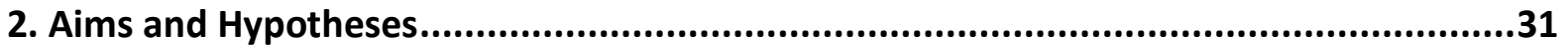

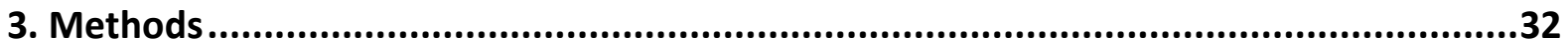

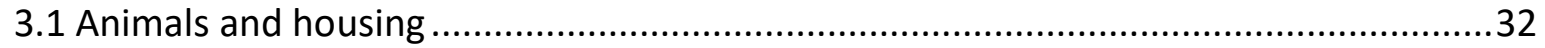

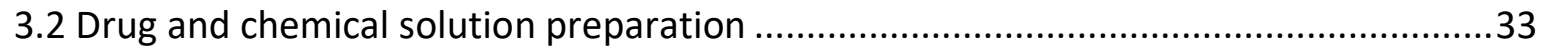

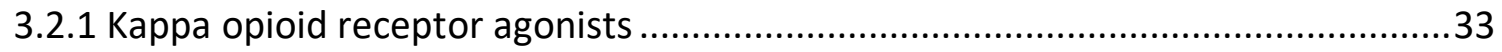

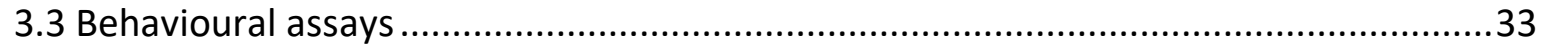

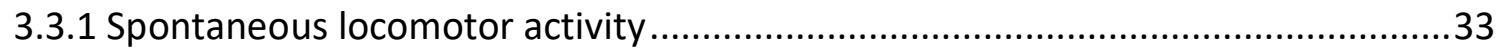

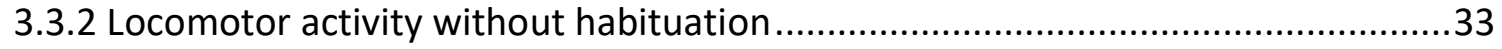

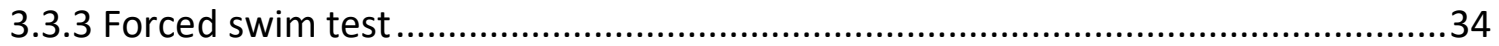




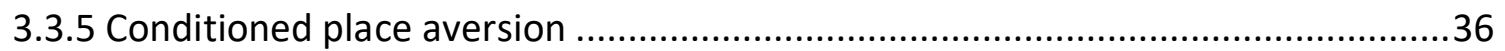

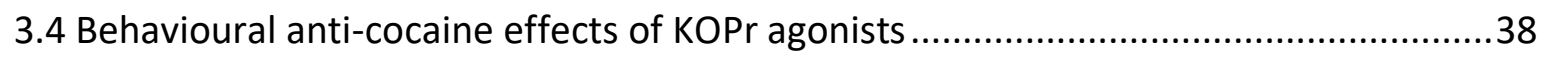

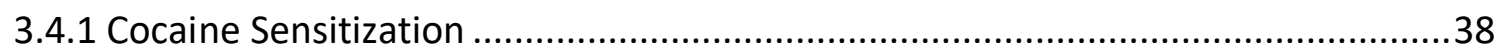

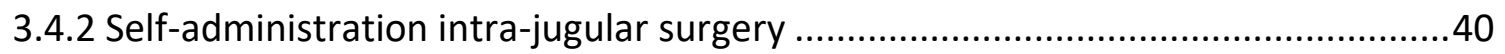

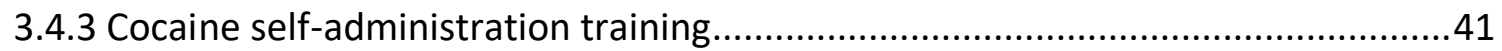

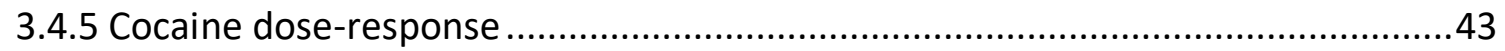

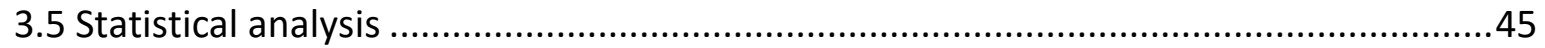

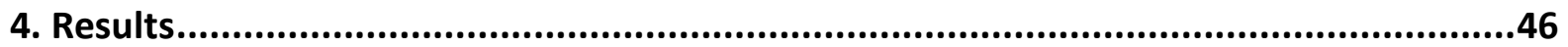

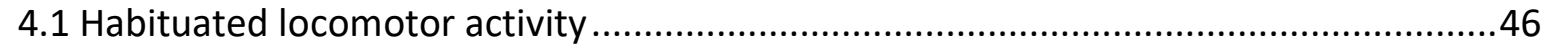

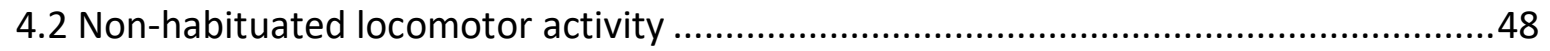

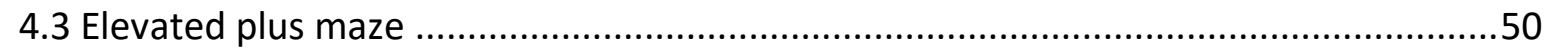

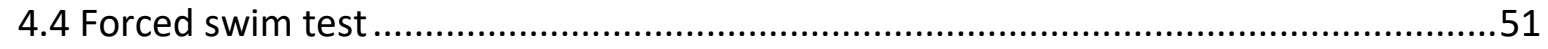

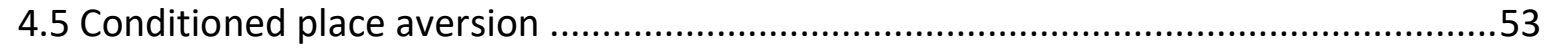

4.6 Behavioural sensitisation to cocaine with acute KOPr treatment..............................55

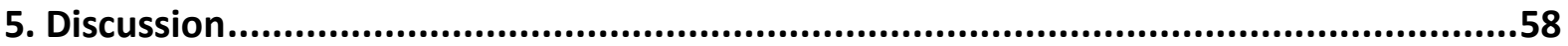

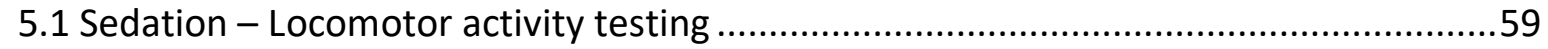

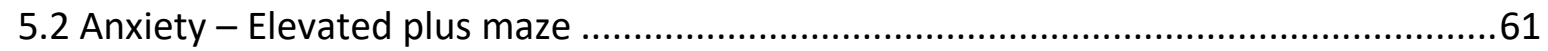

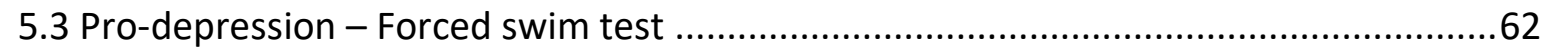

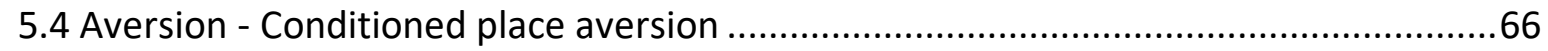

5.5 Cocaine locomotor effects - Behavioural sensitisation .........................................67

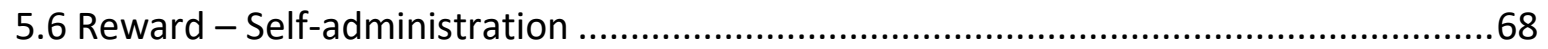

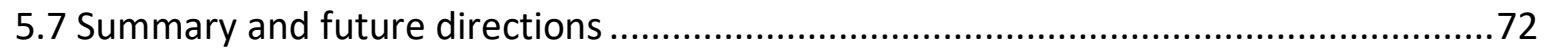

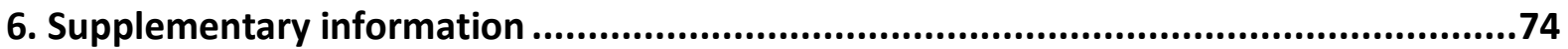

Appendix 1: Setup and use of SMART software for FST video analysis............................74

Appendix 2: Chemicals and solutions for self-administration .........................................76

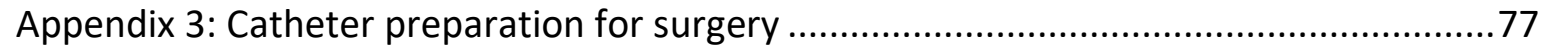

Appendix 4: Self-administration intra-jugular surgery (Headpiece system) ......................78

Appendix 5: Self-administration intra-jugular surgery (Backpack system) .........................81

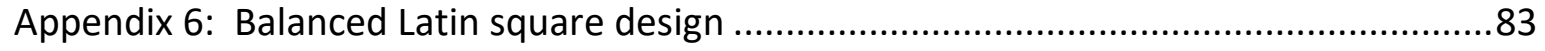

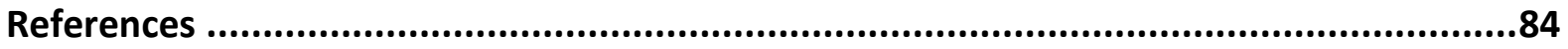




\section{List of Figures}

Figure 1: The reward pathway and the expression of kappa opioid receptor (KOPr) and

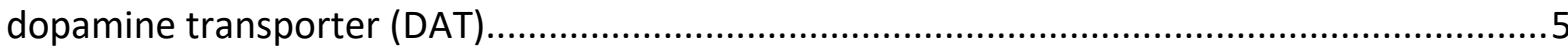

Figure 2: Comparison of a normal synapse and a synapse in the presence of cocaine ........... 7

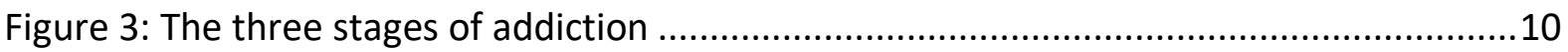

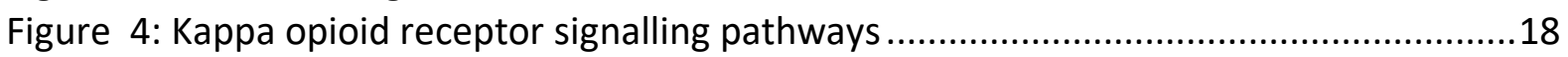

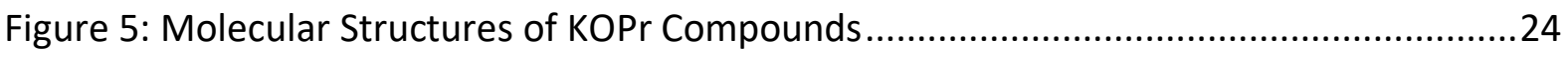

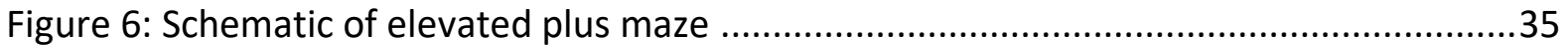

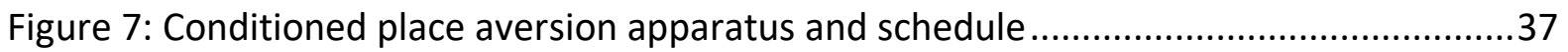

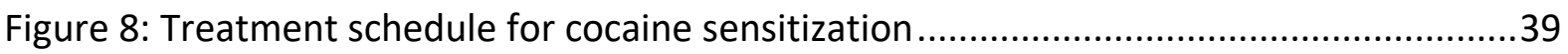

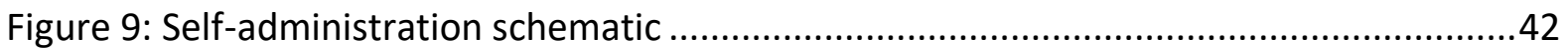

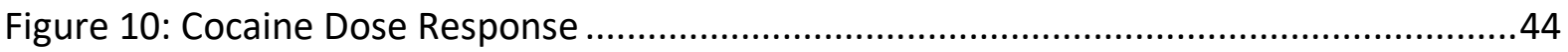

Figure 11: Effects of Sal A and 16-Ethy on habituated locomotor activity...........................47

Figure 12: Effects of Sal A and 16-Ethy on non-habituated locomotor activity ......................49

Figure 13: Neither Sal A nor 16-Ethy change time open arm time in the elevated plus maze50

Figure 14: Forced swim test with acute KOPr agonist treatment .....................................52

Figure 15: Comparison of time spent in the preferred chamber pre- and post-conditioning 54

Figure 16: Comparison of locomotor activities recorded on Days 1 and 10 of the cocaine

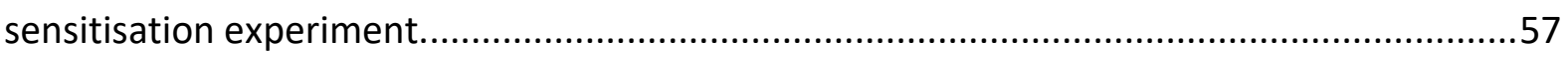

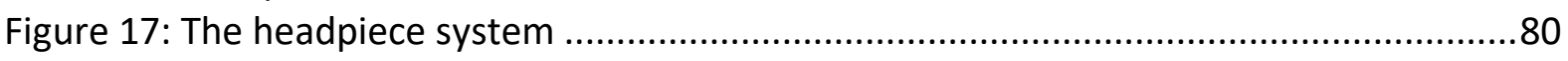

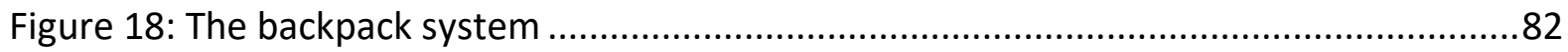




\section{List of Tables}

Table 1: Behavioural models for the three stages of addiction ...........................................11

Table 2: Behavioural effects of acute KOPr agonist and antagonist treatment ......................15

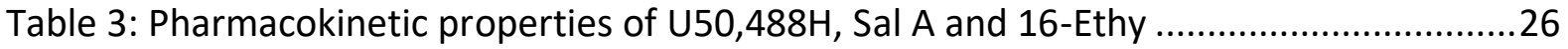

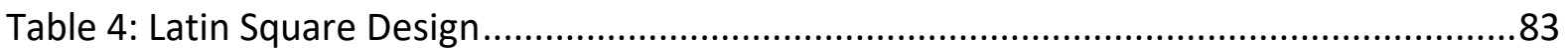




\section{Abbreviations}

\begin{tabular}{|c|c|}
\hline 16-Ethy & 16-Ethynyl Salvinorin A \\
\hline ANOVA & analysis of variance \\
\hline Br-Sal A & 16-Bromo Salvinorin A \\
\hline CAMP & cyclic adenosine monophosphate \\
\hline CPA & conditioned place aversion \\
\hline CPP & conditioned place preference \\
\hline CREB & CAMP response element-binding protein \\
\hline D1 & dopamine 1 receptor \\
\hline D2 & dopamine 2 receptor \\
\hline DA & dopamine \\
\hline DAT & dopamine transporter \\
\hline DMSO & dimethyl sulfoxide \\
\hline $\mathrm{DOPr}$ & delta opioid receptor \\
\hline EOM-SalB & 2-ethoxymethyl Salvinorin B \\
\hline EPM & elevated plus maze \\
\hline ERK $1 / 2$ & extracellular signal-regulated kinases 1 and 2 \\
\hline FDA & Food and Drug Administration \\
\hline FST & forced swim test \\
\hline GPCR & G-protein coupled receptor \\
\hline GRK3 & G-protein coupled receptor kinase 3 \\
\hline i.p. & intraperitoneal \\
\hline i.v. & intravenous \\
\hline $\mathrm{KOPr}$ & kappa opioid receptor \\
\hline MAPK & mitogen-activated protein kinase \\
\hline Me-SalA & 16-methyl Salvinorin A \\
\hline MOM-Sal B & 2-methoxymethyl Salvinorin B \\
\hline MOPr & mu opioid receptor \\
\hline NAC & Nucleus accumbens \\
\hline nor-BNI & nor-binaltorphimine \\
\hline NZ & New Zealand \\
\hline $\mathrm{pFC}$ & Prefrontal cortex \\
\hline Sal A & Salvinorin A \\
\hline Sal B & Salvinorin B \\
\hline s.c. & subcutaneous \\
\hline SD & standard deviation \\
\hline SEM & standard error of the mean \\
\hline USA & United States of America \\
\hline VTA & Ventral tegmental area \\
\hline
\end{tabular}




\section{Introduction}

\subsection{Drug addiction}

Drug addiction is considered a chronic and relapsing disease where an individual seeks and uses drugs despite adverse consequences, leading to long-lasting effects on the brain (Rinaldi et al., 1988). The use of drugs does not necessarily mean an individual will become addicted. However, over 29.5 million people worldwide that use drugs are thought to be in the caught in the vicious cycle of drug abuse and addiction (UNODC., 2016).

The United States of America (USA) is currently in the grips of an opioid epidemic that has claimed 72,000 lives due to overdose in 2017 alone; nearly 30,000 of which were as a result of synthetic opioids such as fentanyl (NIDA., 2018). The opioid crisis in the USA has shone a spotlight on healthcare practices globally, New Zealand (NZ) being no exception. In 10 years the number of prescription opioids (daily doses) dispensed had a dramatic 4-fold increase from 2 million units per annum during 2001-03 to 8 million in 2011-13 (Berterame et al., 2016). Unfortunately, information regarding drug use in NZ has been limited over the last decade. In 2010, it was estimated that there were 9,142 chronic opioid drug users in NZ, half of whom were not receiving opioid substitution therapy (Adamson et al., 2012). There were an estimated 29,200 people who used opioid or sedative drugs in NZ (Morrow., 2018). Drug overdose statistics have not been released officially to the NZ public through the coroner's court, however, under the Official Information Act 1982, the coroner revealed, that between 1 July 2007 to 30 January 2018 there were 18 Fentanyl related mortalities, 6 cases were still under active investigation (Powell J, personal communication., 13 August 2018). Although this emerging information is concerning, the NZ drug use landscape is distinctly different from that seen in the USA. Perhaps due to the geographical isolation of NZ, drugs such as cocaine have a much greater barrier of entry, therefore pricing alone limits its use. NZ is the most expensive country in the world to purchase cocaine with a price tag over $€ 211.7$ per gram (\$370 NZD) compared to $€ 55.3$ per gram in the USA (\$97 NZD) (Global Drug Survey., 2018). According to the Global Drug Survey (2018), in the last year, 4.3\% of NZ respondents used cocaine, $3.1 \%$ used methamphetamine and $38.6 \%$ of NZ respondents used cannabis. NZ has largely avoided the opioid epidemic sweeping the rest of the world, however substance abuse 
and drug addiction itself has still left an indelible mark on our country, decimating the lives of those in its grips and generating substantial national socioeconomic costs.

\subsubsection{Socioeconomic cost of drug addiction}

There is a large socioeconomic cost of drug addiction. Unsurprisingly, there is a strong interrelationship between drug use and crime. Alcohol and drug use have been implicated in approximately $80 \%$ of offences that lead to incarceration in the USA such as intoxicated driving, domestic violence and other drug-related crimes (NCADD., 2015). A large majority of inmates are in prison due to substance abuse, of which nearly $50 \%$ of the prison population are believed to be clinically addicted (Karberg \& James., 2005). Over the last 10 years, the number of inmates incarcerated for violent, sexual or serious drug-related offences greatly increased from 65\% to 74\% (Department of Corrections., 2018). An older survey conducted on the three major NZ cities, Auckland, Wellington and Christchurch, to identify an association with drug use and criminal activity found that $38 \%$ of those who regularly used illicit drugs were themselves drug dealers, $16 \%$ had engaged in theft and $6 \%$ had committed violent crimes (Wilkins et al., 2008).

In 2016, the total social cost of drug abuse in New Zealand was estimated to be $\$ 1.8$ billion, this accounted for personal and community harm as well as the cost of intervention (McFadden Consultancy., 2016). On average, the cost of intervention alone, including the price associated with healthcare, police, customs, courts and corrections, had a total sum of \$351.4 million NZD per annum (McFadden Consultancy., 2016). The overall social cost of drug abuse in the USA is considerably greater, with over $\$ 740$ billion USD annually spent on crime and health care costs, as well accounting for the loss of workplace productivity due to drug abuse (NIDA., 2017).

The cost of drug abuse is substantial and devastating, not only in NZ but on a global scale. In the past year, 247 million people have been estimated to use illegal drugs. As previously stated 29.5 million of which suffer drug use disorders, of these only 1 in 6 people are undergoing treatment (UNODC., 2017). Cannabis is the most widely used drug in the world (183 million users as of 2014) followed by amphetamines (UNODC., 2016). There are 33 million users of opiates and prescription opiates globally (UNODC., 2016). However, opioids 
were found overall, to be the most harmful type of drug with $70 \%$ of the global burden of disease that's attributed to drug use disorders associated with opioids (UNODC., 2017). 


\subsection{The natural reward pathway}

All drugs of abuse activate the brain's natural reward pathway, which encompasses the mesolimbic and mesocortical dopaminergic pathways (Figure 1A). The structures making up these pathways are the ventral tagmental area (VTA) the nucleus accumbens (NAC) and the prefrontal cortex (Phillips \& Fibiger, 1978). The cornerstone of the reward pathway is the neurotransmitter dopamine (DA). DA is synthesized in the VTA by dopaminergic neurons, these extend out to the NAC and the prefrontal cortex, thus forming the mesolimbic and mesocortical pathways respectively (Swanson, 1982; Wood \& Rao, 1991). Dopaminergic neurons also extend from the VTA to the striatum, those that extend to the ventral striatum belong to the mesolimbic pathway and those that project from the substantia nigra compacta to the dorsal striatum are part of the nigrostriatal pathway (Hull \& Dominguez., 2015).

When an individual partakes in an activity that provides them pleasure, the VTA is stimulated, releasing DA from presynaptic terminals located in the NAC and the prefrontal cortex. The DA that is in the synapse binds to its receptors on the postsynaptic terminal, activating the postsynaptic neuron to transmit the action potential. The release of DA and its subsequent transmission throughout dopaminergic pathways provides the experience of euphoria (Figure 2). The source of such events can be as a result of varied stimuli from the ingestion of food and drink to sex and is a natural survival mechanism (Yoshida et al., 1992; Pfaus et al., 1990).

When DA is released into the synapse, it migrates across the synapse and binds onto DA receptors. These DA receptors (D1-D5) are part of a large rhodopsin-like, seven transmembrane superfamily of G-protein coupled receptors (GPCRs). The five different mammalian receptor subtypes are classified into either being part of the D1-like receptors 


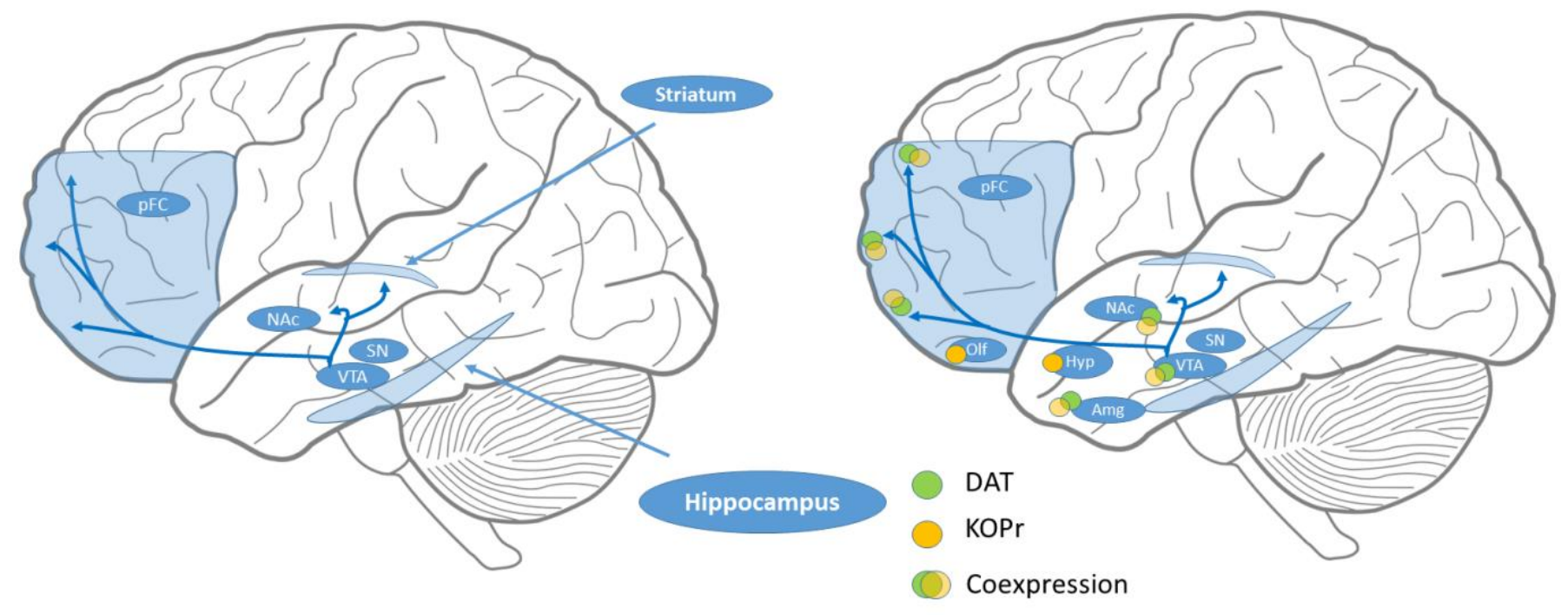

Figure 1: The reward pathway and the expression of kappa opioid receptor (KOPr) and dopamine transporter (DAT)

A) The reward pathway in the human brain is composed of three main regions, the ventral tagmental area (VTA) the nucleus accumbens (NAc) and the prefrontal cortex (pFC). Dopaminergic neurons that project from the VTA to the NAC make up the mesolimbic pathway. Dopaminergic neurons that project form the VTA to the pFC make up the mesocortical pathway. The nigrostriatal pathway is composed of dopaminergic neurons that extend from the substantia nigra (SN) to the dorsal striatum.

B) It was discovered that the reward regions of the brain co-expressed both the dopamine transporter (DAT) and the kappa opioid receptor (KOPr) through the characterisation of brain tissue in immunoblot, immunoprecipitation and immunocytochemistry assays (Ciliax et al., $1995,1999)$. This suggested that the regulation of DAT by KOPr may play an important function in regulating both mood and reward states in the brain. 
(D1 and D5) or part of the D2-like receptors (D2, D3 and D4). The two subfamilies represent opposing downstream effects upon activation (Kebabian., 1978; Self et al., 1996). Those that belong to the D1 receptor family, stimulate neuronal signalling by activating adenylyl cyclase and thereby increasing cyclic adenosine monophosphate levels (cAMP) levels (Graham et al., 2007; Surmeier et al., 2010).

Dopamine receptors that belong to the D2-like subfamily exert inhibitory effects (Durieux et al., 2009). When activated, they couple to $\mathrm{G} \mathrm{i}_{\mathrm{i}}$ to inhibit adenylyl cyclase and inhibit calcium channels whilst also activating the inhibitory G-protein inwardly rectifying potassium channels. Following its release into the synapse, clearance of DA is primarily undertaken by the dopamine transporter (DAT) (Figure 2A). The activation of D2-like receptors facilitates the inhibition of reward by increasing the cell surface expression of DAT (Mayfield and Zahniser, 2001) and through changes in voltage-dependent uptake of DAT (Sonders et al., 1997). An increase in DAT activity via D2-like receptors results in increased levels of DA uptake (Cass and Gerhardt, 1994, Dickinson et al., 1999, Mayfield and Zahniser, 2001, Schmitz et al., 2003, Wu et al., 2002, Benoit-Marand et al., 2011), therefore, inhibiting the pro-rewarding effects. Therefore, DAT is one of the major regulators of DA in the synapse. They are highly abundant in brain regions where kappa opioid receptors (KOPr) are expressed (Ciliax et al. 1995,1999) (Figure 1B). Following reuptake, DA is repackaged and recycled for future release or is degraded by monoamine oxidases. 
A) Normal Activated Synapse

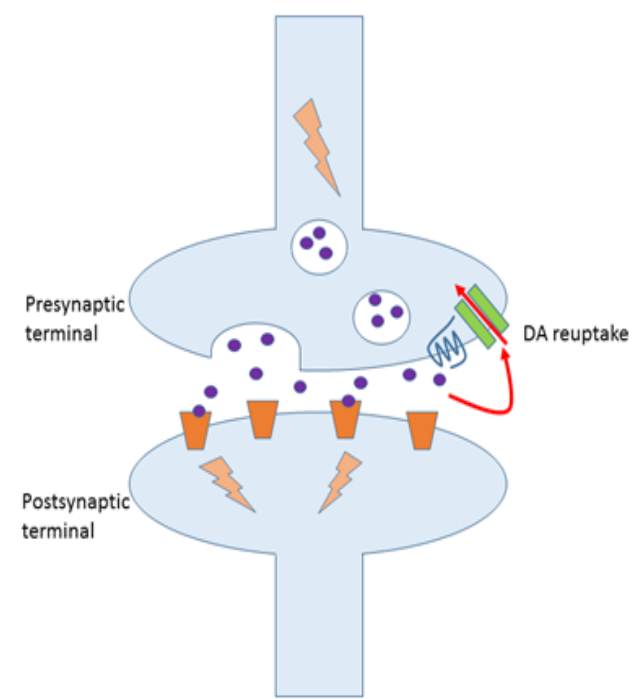

B) Effect of Cocaine on the Synapse

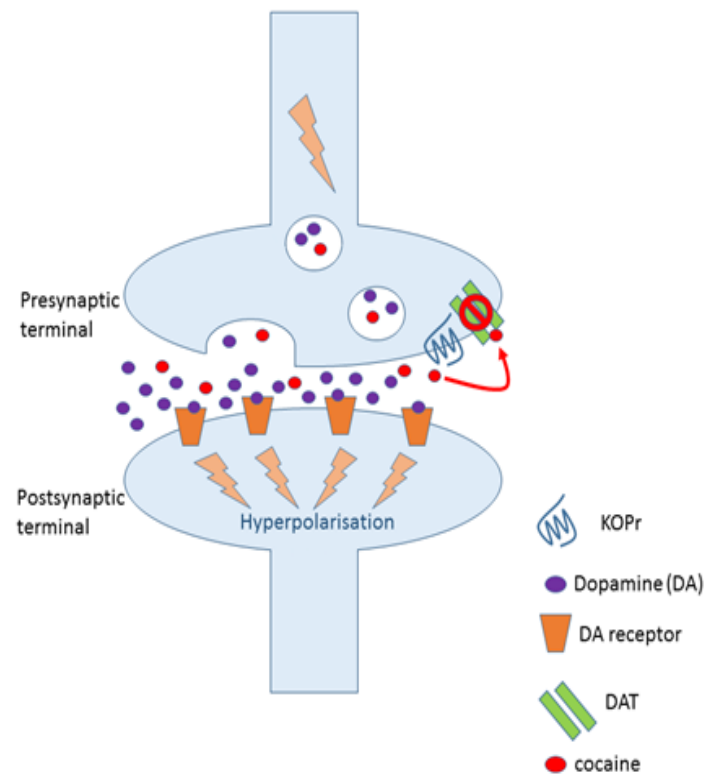

Figure 2: Comparison of a normal synapse and a synapse in the presence of cocaine

A) An activated synapse - A stimulated neuron releases dopamine (DA) from the presynaptic terminal into the synapse. DA binds to its receptor and activates the postsynaptic neuron to transmit the action potential. When activated, the kappa opioid receptor (KOPr) acts on the dopamine transporter (DAT) so that it takes up excess DA in the synapse. There are 5 types of DA receptor types (D1-D5), those that belong to D1-like receptor subfamily (D1 \& D5) stimulate neuronal signalling. Those that belong to the D2-like subfamily (D2-4) exert inhibitory effects on reward by increasing the expression of DAT. DA is transported back into the presynaptic terminal by DAT where it is packaged into vesicles for reuse or is degraded by monoamine oxidases (MAO).

B) The effect of cocaine on the synapse - when an individual takes cocaine, their dopaminergic neurons are highly stimulated resulting in the release of DA as seen in (A). However, cocaine molecules also enter the synapse and blocks the functioning of DAT. With DAT being physically blocked, the reuptake of DA is hindered and leads to excessive DA in the synapse, this results in the hyperpolarization of postsynaptic neurons and an intense experience of euphoria. 


\subsection{Changes in the reward pathway following drug abuse}

Drugs of abuse are characterised by their ability to hyperactivate the reward pathway resulting in an increase in extracellular DA (Di Chiara \& Imperato, 1988). Depending on what type of drug is being used, the mechanisms by which they exert their effects are varied and numerous. Cocaine is the best-characterised drug of abuse. It operates in a two-step process, functioning first to increase DA release in the synapse, whilst simultaneously inhibiting DAT (Figure 2B). The net result is a prolonged and extended period of dopaminergic stimulation, where the DA is not cleared from the synapse efficiently (Cass et al., 1992; Ritz et al., 1987). This extended period of stimulation is felt by the user as a potent euphoric experience (Volkow et al., 1997).

Addiction operates as an ongoing cycle of repeated patterns of behaviour (Figure 3; Table 1). The longer an individual uses and abuses a drug the more likely they are to become dependent or addicted to that drug. It is a self-fulfilling negative cycle (Figure 3 ) where a user has a period of drug use (also known as intoxication) providing them with a euphoric experience followed by the negative effects of withdrawal which leads to a drug preoccupation or anticipation phase where they are craving and seeking euphoric effects, thus, leading back once more to intoxication (Koob \& Bloom, 1988; Koob \& Moal, 1997). DA plays an essential role in the development and facilitation of drug addiction throughout the cycle. The 'dopamine-depletion' hypothesis aimed to explain the centralised role of dopamine and postulates that chronic hyperstimulation of the reward pathway results in the depletion of DA stores thus the individual experiences increased craving for the drug (Dackis \& Gold, 1985). Alternatively, the 'incentive-sensitization' theory states that chronic abusers develop neurophysiological adaptations that result in dopaminergic systems that are highly sensitized to their drug of choice (Robinson \& Berridge, 1993). The underlying consequence of both rationales is that drug addiction is a result of attempts to try and mitigate the negative symptoms of withdrawal. Tolerance occurs when there is a decrease in the effectiveness of a drug despite repeated administration, thus it requires them to administer greater concentrations of a drug to maintain a baseline (Stewart \& Badiani, 1993).

Long-term neurophysiological changes occur following drug use. For example, when cocaine is used chronically, D1 receptors are activated in favour of D2 receptors (Navarro et al., 2013; 
Park et al., 2013). Furthermore, as a result of chronic cocaine use, it was found that there was a reduction in vesicular monoamine transporter- 2 which functions to regulate DA storage. The downstream effects of this lead to reduced mesolimbic DA (Little et al., 2003; Narendran et al., 2012; Taylor \& Ho, 1977). An updated systematic review by Volkow \& Morales. (2015) investigated dopaminergic activity in those addicted to methamphetamine and cocaine, using positron emission tomography (PET) imaging and a specific D2 receptor radioligand. The authors found that following cocaine, heroin, alcohol, or methamphetamine use, drug users exhibited a significant loss of dopaminergic activity in the striatum in comparison to non-drug users. 


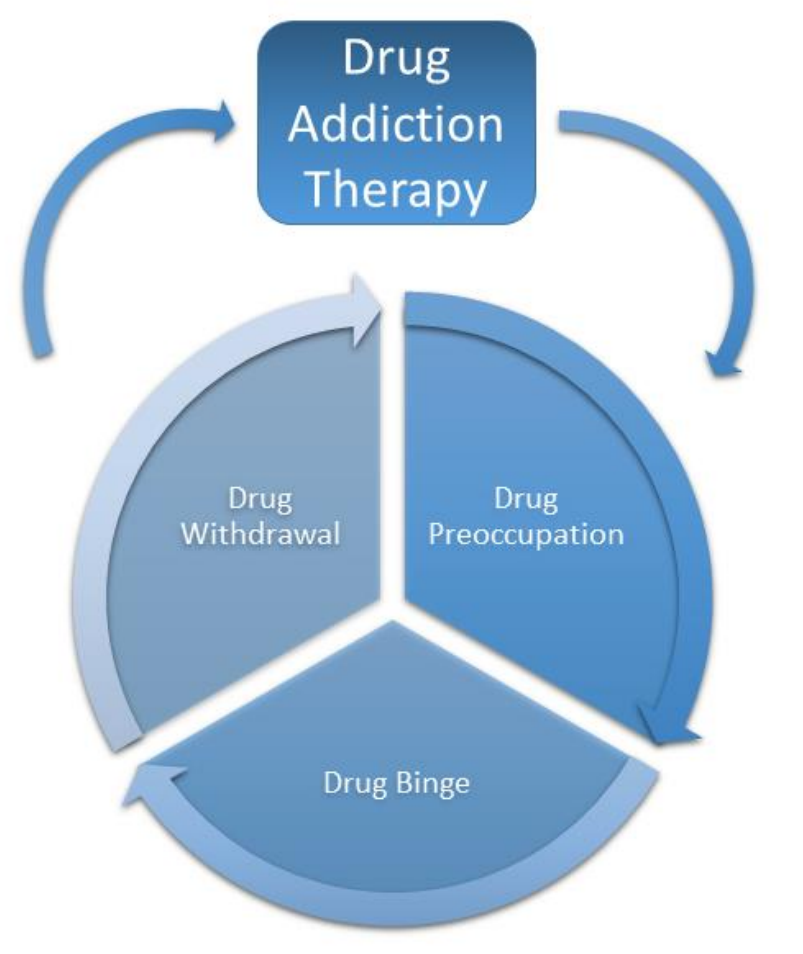

\section{Figure 3: The three stages of addiction}

There are three primary stages of addiction. The preoccupation for the drug (anticipation) leads to drug use (binge/intoxication) after which users will feel the negative effects associated with withdrawal (anhedonia) thus perpetuating the cycle again with preoccupation for the drug. The aim of traditional drug addiction therapies is to target individuals at the withdrawal stage to break the cycle of addiction. However, if the therapy is ineffective or fails then the individual will likely relapse back into the cycle. KOPr pharmacotherapies have the potential to target addiction at various stages of cycle, with this thesis looking into of 16-Ethynyl Salvinorin A and its potential to mitigate drug taking during the drug binge phase. Modified from Koob and Moal (1997). 


\begin{tabular}{|c|c|c|}
\hline Stage of addiction cycle & Type of reinforcement & Animal model \\
\hline Preoccupation/anticipation & $\begin{array}{l}\text { Conditioned positive } \\
\text { reinforcement }\end{array}$ & $\begin{array}{l}\text { Drug/cue/stress-induced } \\
\text { reinforcement }\end{array}$ \\
\hline Binge/intoxication & Positive & $\begin{array}{l}\text { Conditioned place } \\
\text { preference, self- } \\
\text { administration }\end{array}$ \\
\hline Withdrawal & Negative & Conditioned place aversion \\
\hline
\end{tabular}

Table 1: Behavioural models for the three stages of addiction

The stages of addiction described by Koob and Moal (1997) explore three distinct patterns of behaviour. The preoccupation/anticipation stage describes the craving phase of an addict for a drug, animal models can mimic this behaviour of craving through conditioned positive reinforcement. The binge/intoxication phase is where an individual pursues drug-taking behaviour, the positive reinforcement of self-administration is the most common method of mimicking this in a laboratory setting. Finally, when a drug is no longer available to a user, they experience withdrawal. This is a negative experience and the aversive effects of compounds can be tested using the conditioned place aversion paradigm. 


\subsection{The kappa opioid system}

\subsubsection{Kappa opioid receptor physiology}

The kappa opioid system is an essential component regulating mood within the central nervous system. The kappa opioid receptor (KOPr) is a seven transmembrane inhibitory GPCR. KOPrs are a part of a family of opioid receptors that include mu (MOPr), delta (DOPr) and the nociception receptor (Feng et al., 2012). The opioid receptors are found widely distributed throughout the brain, as well as the spinal cord, digestive tract and pain neurons (Knoll \& Carlezon, 2010). Activation of the different opioid receptor subfamilies has demonstrated different physiological effects; for example, DOPr activation has been shown to promote neural differentiation (Narita et al., 2006) and has an endogenous neuroprotective mechanism that functions prior to ischemia or severe hypoxia to protect spinal motor, cortical, cerebellar and hippocampal networks (Johnson \& Freiberg., 2010). Activation of MOPr induced potent analgesic effects. Morphine, a MOPr agonist, is perhaps the most wellknown and widely prescribed pain medication available for the treatment of severe acute and chronic pain (Jordan, Cvejic \& Devi., 2000).

\subsubsection{Dynorphin}

Dynorphin is the primary endogenous ligand that binds the KOPr. Dynorphin acts as a natural suppressor of the reward pathway in the brain by reducing dopamine release in the NAc and prefrontal cortex, as well as increasing the dopamine reuptake via DAT (Maisonneuve et al., 1994; Margolis et al., 2006; Shippenberg et al., 2007; Thompson et al., 2000). Dynorphin is distributed throughout the central nervous system but is found at the highest concentration within the hypothalamus, substantia nigra, pallidum and the dorsal striatum. Dynorphin has antinociceptive effects and operates as a natural suppressor of the reward pathway (Knoll \& Carlezon., 2010). However, when dynorphin is chronically released, it is thought that it contributes the negative side effects of anhedonia, withdrawal, depression and dysphoria, by inhibiting DA release and increasing DAT function (Chartoff et al., 2012). Dynorphin mRNA expression is upregulated in the striatum of humans following cocaine use (Hurd \& Herkenham, 1993). This was also observed in animal models following cocaine exposure (Carlezon et al., 1998) which suggests that long-term drug abuse can lead to the up-regulation 
of the kappa opioid system. The implication, therefore, in respects to addiction, is that increased dynorphin could potentially relate to the motivational aspects of psychostimulant withdrawal, where the user experiences intense dysphoria, anhedonia and ultimately drug craving (Cole et al., 1995). 


\begin{tabular}{|c|c|c|c|c|c|c|c|}
\hline & & \multicolumn{4}{|c|}{ KOPr agonist } & \multirow{2}{*}{$\begin{array}{l}\text { KOPr antagonist } \\
\text { nor-BNI }\end{array}$} & \multirow[b]{2}{*}{ Reference } \\
\hline Side effect & $\begin{array}{l}\text { Behavioural } \\
\text { paradigm }\end{array}$ & U50, 488H & U69, 593 & Sal A & 16-Ethy & & \\
\hline $\begin{array}{c}\text { Drug } \\
\text { seeking }\end{array}$ & $\begin{array}{l}\text { Drug prime } \\
\text { reinstatement }\end{array}$ & $\begin{array}{c}\downarrow \\
30, \text { i. } p^{2}\end{array}$ & $\begin{array}{c}\downarrow \\
0.32, \mathrm{~s} . \mathrm{c}^{1,2}\end{array}$ & $\begin{array}{c}\downarrow \\
0.3,1.0, \text { i. } p^{2}\end{array}$ & $\begin{array}{c}\downarrow \\
0.1,0.3 \\
\text { i. } p^{20}\end{array}$ & $\begin{array}{c}\downarrow \\
10, \text { i. } p^{22}\end{array}$ & $\begin{array}{l}1 \text { Schenk et al., (1999) } \\
2 \text { Morani et al., (2009) } \\
3 \text { Tejeda et al., (2013) } \\
4 \text { Chefer et al., (2013) }\end{array}$ \\
\hline Aversion & CPA & $\begin{array}{c}\uparrow \\
1.0,2.0 \text { s.c }{ }^{7} \\
10, \text { i. } p^{8}\end{array}$ & $\begin{array}{c}\uparrow \\
0.32 \text {, s.c (rats } \\
\text { and mice) })^{3,4}\end{array}$ & $\begin{array}{c}\uparrow \\
0.3,1.0, \text { i. } p^{11} \\
160 \mathrm{ug} / \mathrm{kg}, \text { i. } p^{12} \\
\uparrow \\
1.0,3.2, \text { i. } p^{13} \\
\downarrow \\
0.1-40 \mathrm{ug} / \mathrm{kg}, \text { i. } p^{12}\end{array}$ & & $\begin{array}{c}\downarrow \\
20, \text { i.p }{ }^{17}\end{array}$ & $\begin{array}{c}5 \text { Mague et al., (2003) } \\
6 \text { Privette \& Terrian, (1995) } \\
7 \text { Mucha \& Herz, (1985) } \\
8 \text { Suzuki et al., (1992) } \\
\text { 9 Valdez \& Harshberger, (2012) } \\
10 \text { Paris et al., (2011) } \\
11 \text { Sufka et al., (2014) } \\
12 \text { Braida et al., (2008) } \\
13 \text { Zhang et al., (2005) } \\
14 \text { Morani et al., (2012) } \\
15 \text { Carlezon et al., (2006) } \\
16 \text { Braida et al., (2009) }\end{array}$ \\
\hline Depression & FST & - & $\begin{array}{c}\uparrow \\
0.3-10, \text { i. } p^{5}\end{array}$ & $\begin{array}{c}\uparrow \\
0.25-2.0, \text { i. } p^{14,15} \\
\downarrow \\
10-1000 \mathrm{ug} / \mathrm{kg} \\
\text { s.c }{ }^{16}\end{array}$ & $\begin{array}{l}\text { n.e } \\
0.3, \\
\text { i.p.p }\end{array}$ & $\begin{array}{c}\downarrow \\
1.25-20 \mathrm{ug} / \mathrm{kg}^{19}\end{array}$ & $\begin{array}{l}17 \text { Kelsey et al., (2015) } \\
18 \text { Kivell lab, unpublished data } \\
19 \text { Mague et al., (2003) } \\
20 \text { Riley et al., (2014) } \\
21 \text { Knoll et al., (2007) } \\
\text { 22Polter et al., (2014) }\end{array}$ \\
\hline
\end{tabular}




\begin{tabular}{|c|c|c|c|c|c|c|}
\hline Anxiety & EPM & $\begin{array}{c}\downarrow \\
10,100 \mathrm{ug} / \mathrm{kg}, \\
\text { i. } p^{6} \\
\uparrow \\
10, \text { i. } p^{9}\end{array}$ & $\begin{array}{c}\downarrow \\
100 \mathrm{ug} / \mathrm{kg}, \text { i. } p^{6}\end{array}$ & $\begin{array}{c}\downarrow \\
0.1-160 \mathrm{ug} / \mathrm{kg}, \\
\text { s.c }\end{array}$ & & $\begin{array}{c}\downarrow \\
3.0-30, \text { i. } p^{21}\end{array}$ \\
\hline Sedation & Locomotor activity & $\begin{array}{c}\uparrow \\
0.3-10, \text { i.p } \\
{(\text { mice })^{10}}^{10}\end{array}$ & $\begin{array}{c}\uparrow \\
10, \text { i. } p^{5}\end{array}$ & $\begin{array}{c}\uparrow \\
1.0,3.2, \text { i.p } \\
(\text { mice })^{13} \\
\text { n.e } \\
0.125-2.0 \text {, i.p }{ }^{14,15} \\
\text { n.e } \\
0.001-1.0 \mathrm{ug} / \mathrm{kg}, \\
\text { s.c (mice) }{ }^{16}\end{array}$ & $\begin{array}{l}\text { n.e } \\
0.3, \\
\text { i.p }\end{array}$ & \\
\hline
\end{tabular}

\section{Table 2: Behavioural effects of acute KOPr agonist and antagonist treatment}

Effects: $\uparrow=$ side effect present, $\downarrow=$ attenuation of side effect, $\mathrm{n} . \mathrm{e}=$ no effect $/$ change. Doses provided under effects are given in $\mathrm{mg} / \mathrm{kg}$ and unless stated otherwise all behavioural tests were conducted on rats. 


\subsubsection{Kappa opioid receptor signalling}

When the KOPr system is activated through agonist treatment, it stimulates the receptor to interact and exert their effects on various intracellular effectors and pathways (Figure 4). Since the KOPr is a GPCR, the activation of the receptor exerts its effects through the dissociation of its associated G-protein (Dogra \& Yadav., 2015). When an agonist binds to the receptor, the receptor changes shape leading to the dissociation of the $G_{\beta \gamma}$ subunit from the $\mathrm{G}_{\alpha i}$ subunit. The active $\mathrm{G}_{\beta \gamma}$ subunit causes an increase in membrane potential and modulates voltage-gated potassium $\left(\mathrm{K}^{+}\right)$and calcium $\left(\mathrm{Ca}^{2+}\right)$ channels, inhibiting $\mathrm{Ca}^{2+}$ influx and stimulating $\mathrm{K}^{+}$efflux (Rusin et al., 1997). The $\mathrm{G}_{\alpha i}$ subunit inhibits adenylyl cyclase which in turn leads to an inhibition of cyclic adenosine monophosphate (cAMP) being produced by adenylyl cyclase (Taussig et al., 1993). The $G_{\alpha i}$ subunit leads to phosphorylation of the second messenger extracellular signal-regulated kinase 1 and 2 (ERK1/2) (McLennan et al., 2008). The phosphorylation of ERK1/2 is thought to occur in two time phases, early phase ERK1/2 activation is thought to take place between 5-15 min after agonist treatment (Belcheva et al., 2005). This early phase ERK activation is facilitated through phosphoinositide 3 kinase and protein kinase $\mathrm{C}$ zeta, which in turn mobilises $\mathrm{Ca}^{2+}$ for signalling (Belcheva et al., 2005). The early phase signalling pathway is known as the G-protein coupled cascade and has been found to be correlated with the anti-cocaine effects following treatment with KOPr agonists (Simonson et al., 2015). This occurs by increasing the number of dopamine transporters, thus increasing the level of dopamine reuptake (Moron et al., 2003). See Bruchas \& Chavkin (2010) for a full review of KOPr signalling pathways.

When an agonist binds to the KOPr, the intracellular domain is phosphorylated by G-coupled protein kinase 3 (GRK3) and this in turn recruits $\beta$-arrestin (Dogra \& Yadav., 2015; Liu-Chen., 2004), leading to the internalisation and degradation of the KOPr (Liu-Chen., 2004). Downstream, p38 mitogen-activated protein kinase (p38 MAPK) and ERK1/2 are phosphorylated. This phosphorylation of ERK1/2 occurs after early phase activation and is therefore known as late-phase phosphorylation, which can take up to 2 hours after agonist treatment (McLennan et al., 2008). This results in the phosphorylation of cAMP response element binding protein (CREB) (Dogra \& Yadav., 2015), which signals the activation of various transcription factors for the transcription of target genes (Bruchas \& Chavkin., 2010). 
As a result, in the late phase pathway, ERK1/2, as well as p38 MAPK are activated. The phosphorylation of these two effectors, however, corresponds to the negative side effect profile of KOPr agonists expressed through the activation of this pathway. For example, in animal models, aversive and other negative stress-induced behaviours have been shown to correspond with the activation of p38 MAPK (Bruchas et al., 2011). Through the internalization of the receptor, the $\beta$-arrestin pathway induces human KOPr desensitization (Li et al., 1999). It is therefore important to evaluate novel KOPr compounds for their ability to modulate $\beta$-arrestin recruitment and correlate this to behavioural side-effects.

KOPr is also known to regulate DAT function via the ERK1/2-dependent signalling pathways (Kivell et al., 2014). In vitro experiments have shown that cells that express KOPr had increased DA uptake when Salvinorin A, a KOPr agonist was applied (Kivell et al., 2014). This finding is important, as the role of DAT is a vital mechanism by which we can combat the addiction. Not only would modulating DAT prove beneficial for addiction, but it would have far-reaching implications for the medical field as its activity has been associated with several different disorders including clinical depression, Parkinson's disease, Angelman syndrome, Attention Deficit Hyperactivity Disorder (ADHD) and bipolar disorders (Roxanne \& James., 2014; Wiers et al., 2015). It was found that both DAT and KOPr were co-expressed within dopaminergic cells found in a rats NAc (Svingos et al., 2001). Furthermore, the co-expression of KOPr and DAT has been seen in different areas of the rat and human brain (Ciliax et al., 1999; Ciliax et al., 1995; Mansour et al., 1987; Tempel \& Zukin., 1987). Evidence indicates that there may be direct regulation of DAT through physical interactions with KOPr as seen in cells that were co-transfected with KOPr and DAT where the formation of KOPr-DAT was expressed (Kivell et al., 2014). Thus the regulatory interaction of the KOPr on DAT could be vital in understanding the negative regulation of the reward pathway and other KOPr-mediated behavioural effects.

KOPr is highly expressed in the NAc, the effects, however, are different based on its location and how it operates in subregions of the NAc. Al-Hasani R et al. (2015) found using optogenetic techniques, that specific brain regions could be stimulated to release dynorphin through photo-stimulation. They generated a dynorphin-tdTomato-reporter mouse which allowed them to visualise, track and determine the key regions of the brain influenced by dynorphin. The authors found that dynorphogenic neurons in the ventral subregion of the 
NAc caused KOPr mediated aversive behaviour whilst those in the dorsal subregion of the NAC when stimulated caused the animal to display preference. This study highlighted the complexity of KOPr activation and how they can drive opposite behavioural responses depending on where it was located. Their research had unveiled that the kappa opioid system played a more intricate role than its conventionally designated role as the mediator of aversive and dysphoric emotional states.

Early Phase

Late Phase

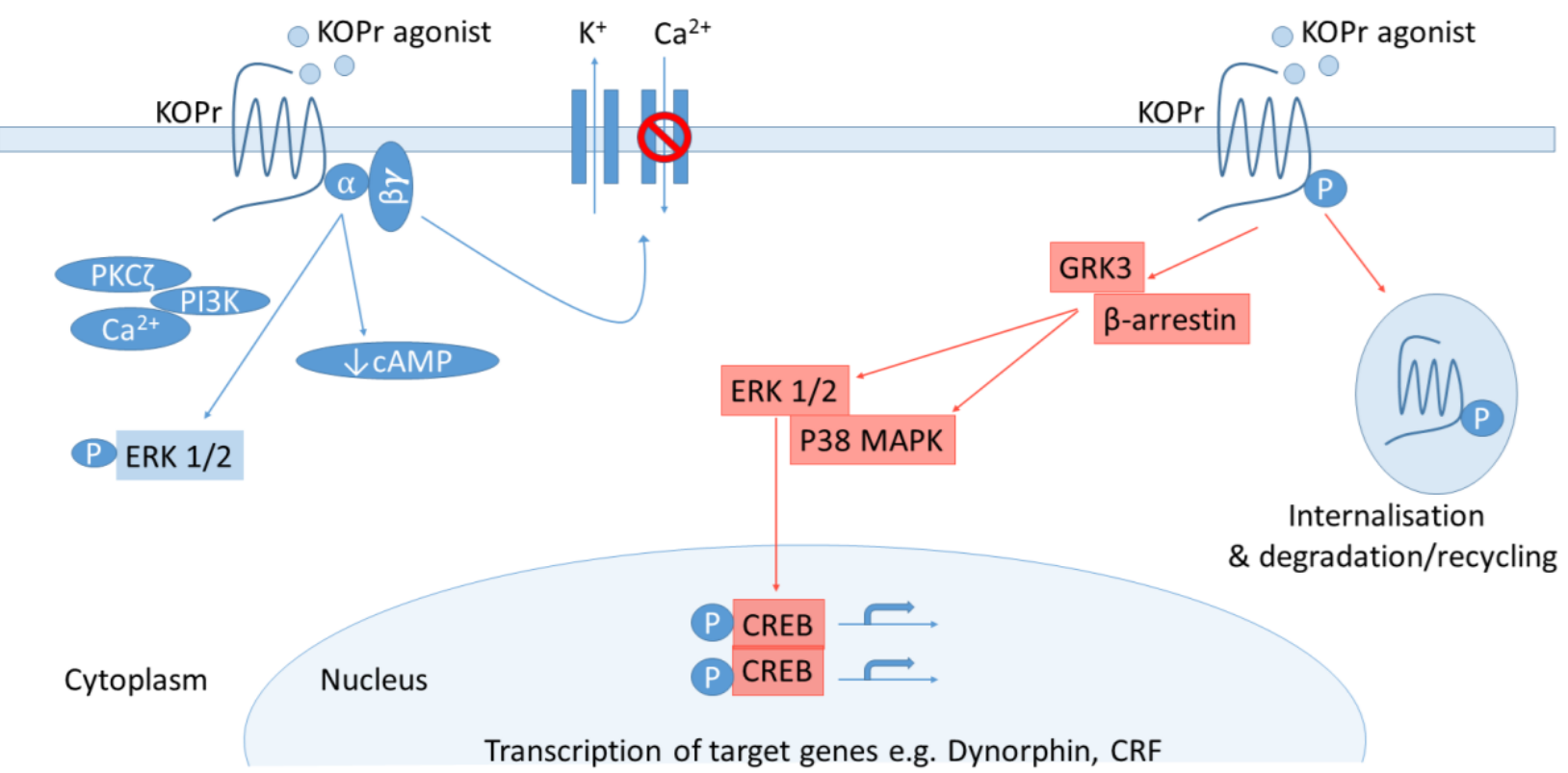

Figure 4: Kappa opioid receptor signalling pathways

When an agonist binds to the KOPr it can lead to the activation of multiple second messenger cascades including the G-protein coupled (left) or the $\beta$-arrestin pathway (right). With this knowledge, it is possible that drugs can be produced that have functional selectivity to be able to recruit the desired pathways (G-coupled pathway) and avoid ones that could potentiate undesirable side effects ( $\beta$-arrestin pathway). $c A M P=$ cyclic adenosine monophosphate, $C R E B$ $=$ cAMP response element binding protein, $C R F=$ corticotrophin-releasing factor, ERK $1 / 2=$ extracellular signal-regulated kinases 1 and 2, GRK3 = G-protein coupled receptor kinase 3, $\mathrm{KOPr}=\mathrm{Kappa}$ opioid receptor, $\mathrm{p} 38 \mathrm{MAPK}=$ p38 mitogen-activated protein kinase, $\mathrm{PI} 3 \mathrm{~K}=$ phosphoinositide 3-kinase, $\mathrm{PKC} \zeta=$ protein kinase $\mathrm{C}$ zeta. 


\subsection{Kappa opioid receptor agonists in addiction research}

Preclinical trials are currently investigating the use of KOPr agonists as possible therapeutics in combating addiction as compounds that target the KOPr have been identified to be able to decrease the rewarding effects exerted from drugs of abuse. However, their behaviour in modulating addiction is complex.

\subsubsection{Acute administration of kappa opioid receptor agonists}

A single dose of the selective KOPr agonist trans-( \pm )-3,4-Dichloro-N-methyl-N-[2-(1pyrrolidinyl)cyclohexyl]benzeneacetamide $(\mathrm{U} 50,488 \mathrm{H}$; for structure see Figure 5$)$ at a dose of $5 \mathrm{mg} / \mathrm{kg}$, i.p was found to elicit a long-term reduction in cocaine relapse (Heinsbroek et al., 2018). U50,488H has previously been found to block conditioned place preference (CPP) for cocaine at $5 \mathrm{mg} / \mathrm{kg}$, as well as attenuate cocaine-induced hyperactivity in rats (Crawford et al., 1995) and has shown itself to be able to attenuate cocaine self-administration in rhesus monkeys (Negus et al., 1997).

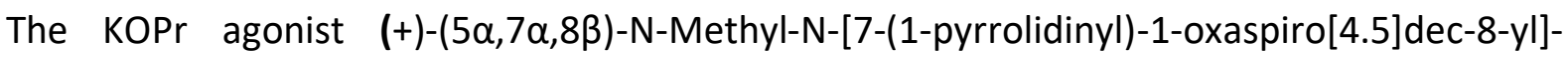
benzeneacetamide $(U 69,593)$, reduced cocaine reinstatement of drug-seeking behaviour but not with amphetamines at pretreatment doses of 0.16 and $0.32 \mathrm{mg} / \mathrm{kg}$ (Schenk et al., 1999). This was an important finding as it showed that the interactions and effects of the KOPr agonists were specific to cocaine since amphetamine-induced cocaine seeking was not altered following the administration of U69,593 (Schenk et al., 1999). Additionally, it highlighted that there were differences in effective dosing regimens as they generated a doseresponse curve and found the KOPr agonist to be effective at low cocaine doses but there was no change to rats that were responding to higher concentrations of cocaine (Schenk et al., 1999). Furthermore, the use of KOPr agonists has been shown to be able to attenuate cocaine prime-induced reinstatement of drug-seeking behaviour in a dose-dependent manner in rats that are subjected to cocaine self-administration (Morani et al., 2009). In rats, acute administration of KOPr agonists attenuated alcohol self-administration and reduced alcoholinduced CPP (Zhou \& Leri, 2016).

In contrast to these positive effects, KOPr agonists are putative pharmacological stressors and have been shown to induce stress-like states in humans and animals (Bruchas et al., 
2010; Van't Veer and Carlezon., 2013). Activation of the KOPr system through either foot shock stress, forced swim stress or an acute administration of $\mathrm{U} 50,488 \mathrm{H}$ resulted in stressinduced reinstatement of cocaine drug-seeking behaviour in mice (Redila \& Chavkin, 2008; Valdez et al., 2007). Cocaine-seeking behaviour was also reinstated in monkeys that received systemic administration of the KOPr agonists, spiradoline and enadoline. Systemic administration of $\mathrm{U} 50,488 \mathrm{H}$ resulted in the reinstatement of nicotine and alcohol seeking in rats (Funk et al., 2014; Grella et al., 2014). Moreover, reinstatement of drug-seeking was blocked using KOPr antagonists (Beardsley et al., 2005).

Freeman et al. (2014) identified KOPr agonists having the ability to act as 'punishers' of drug seeking. They observed that Rhesus monkeys that were self-administering either cocaine or the MOPr agonist, remifentanil, had reduced self-administration of both drugs following the administration of the KOPr agonist Salvinorin A (Sal A). 


\subsubsection{Chronic administration of kappa opioid receptor agonists}

Through chronic administration of KOPr agonists, it was uncovered that $\mathrm{U} 50,488 \mathrm{H}$ and U69,593 could block rats from developing behavioural sensitization to cocaine (Heidbreder et al., 1995). Paradoxically, research has shown that chronic KOPr agonist treatments can increase drug-induced self-administration (Negus., 2004; Potter et al., 2011). Despite some of the positive attributes of KOPr agonists, the opponent process theory of drug abuse proposed that that brain mitigates the initial hyperactivity of the reward pathway following drug use by inducing a reciprocal aversive or dysphoric state (Solomon \& Corbit., 1974; Vargas-Perez et al., 2007). The increase in drug-induced self-administration with chronic KOPr agonist treatment might be explained under the theory. If the aversive effects of KOPr signalling outweigh the rewarding effects of cocaine then the discrepancy would enhance withdrawal symptoms, and through negative reinforcement of drug taking, intensify the dependency upon the drug of abuse (Wee \& Koob., 2010; Walker et al., 2012).

Research has supported this theory, for example, alcohol-dependent rats have reduced levels of alcohol consumption following administration of the KOPr antagonist nor-binaltorphimine (nor-BNI; 15 and $20 \mathrm{mg} / \mathrm{kg}$ ). This suggests that the blockade of the KOPr system can reduce drug-taking, (Walker et al., 2007, 2011, 2012). In cocaine and methamphetamine selfadministration models of, nor-BNI (15 and $30 \mathrm{mg} / \mathrm{kg}$ ), reduced the escalation of drug-taking (Wee et al., 2009; Whitfield et al., 2015).

Therefore, KOPr agonists are being investigated as potential therapies to combat the rewarding effects of drugs of abuse following acute administration, whereas KOPr antagonists are to attenuate stress-induced relapse. Unfortunately, there is an array of undesirable side effects that are associated with the traditional KOPr agonists such as dysphoria, sedation, depression and nausea, preventing the viability of the clinical applications of these compounds. Therefore, the side effect profile of novel KOPr agonists needs investigating. 


\subsubsection{KOPr agonists clinical potential}

Nalfurafine is the only clinically available KOPr agonist, approved in Japan for the treatment of Uremic pruritis (chronic kidney disease) that can arise in haemodialysis patients and is often characterised by bouts of itching. In 2009, nalfurafine was tested as an anti-pruritic agent for itch in Japan (Nagase et al., 2010). The compound was developed from a KOPr antagonist, naltrexone (Nakao \& Mochizuki., 2009). Pre-clinical trials indicated that nalfurafine induced no aversion or preference behaviour in rats using the conditioned place preference test, or dependence in monkeys who were subject to the self-administration paradigm (Nagase et al., 2010). Clinical trials demonstrated the compound's efficacy and ability to be safely used on haemodialysis patients and was used as a therapeutic agent thereafter (Nakao \& Mochizuki., 2009; Nagase et al., 2010). Follow up trials were undertaken and found nalfurafine to cause no difference in dependence liability compared to those patients given vehicle treatment, or cause any adverse effects on body temperature, blood pressure, pupil diameter or respiratory rates (Ueno, Mori, \& Yanagita., 2013). Most recently, a prospective trial showed high recurrence rates of pruritus in patients who stopped using nalfurafine (Akuta et al., 2018). Nalfurafine was the first and currently the only selective KOPr agonist approved for clinical use but it demonstrated the powerful potential of KOPr agonists as clinical therapeutics. 


\subsection{Salvinorin A and analogues}

Sal $A$ is a highly potent and selective KOPr agonist (Roth et al., 2002). It is the active component found in Salvia divinorum, a hallucinogenic plant that was used by the Mazatec Indians of Oaxaca, Mexico as part of their traditional religious practices (Valdes., 1983). More recently, Sal A has gained rapid popularity as a recreational drug. Unlike other hallucinogens such as lysergic acid diethylamide (LSD), Sal A can selectively activate KOPr without interacting with 5-HT receptors (Butelman et al., 2007; Roth et al., 2002). The point of difference from Sal A and traditional KOPr agonists is that within its structure, there is no charged nitrogen group which was one of the hallmarks of a traditional opioid agonist (Bera \& Ghoshal., 2014) (for chemical structure see Figure 5). As with other KOPr agonists, the anti-addictive mechanism by which Sal A operates is through increasing DAT activity (Kivell., 2014) as well as by attenuating DA release in the NAc (Ebner et al., 2010). Acute administration of Sal A at $0.3 \mathrm{mg} / \mathrm{kg}$ attenuated cocaine prime-induced drug-seeking behaviour in rats (Morani et al., 2009). Moreover, in contrast to traditional KOPr agonists such as $U 50,488 \mathrm{H}$, it does not exert sedative effects in the spontaneous locomotor activity paradigm or elicit any taste aversion (Morani et al., 2012). With this knowledge, Sal A is being looked at as a primary compound for novel anti-addictive (Prisinzano et al., 2008) and antinociceptive (McCurdy et al., 2006) drug therapies. One of the issues with Sal A, however, is that it is rapidly metabolised and has a short half-life in vivo ( 50 min) (Butelman et al., 2009; Hooker et al., 2008; Schmidt et al., 2005; Teskin et al., 2009). This is likely due to clearance from the central nervous system by P-glycoprotein (Butelman et al., 2012) and metabolism occurring at the C-2 position which coverts it to an inactive metabolite, Salvinorin B (Beguin et al., 2005; Chavkin et al., 2004). Sal $A^{\prime}$ 's short duration of action is not ideal for therapeutic use (Hooker et al., 2008), therefore, longer acting structural analogues are being investigated in developing more effective treatments. 
<smiles>CN(C(=O)Cc1ccc(Cl)c(Cl)c1)[C@@H]1CCCC[C@H]1N1CCCC1</smiles>

$\mathrm{U} 50,488 \mathrm{H}$<smiles>COC(=O)[C@H]1C[C@@H](OC(C)=O)C(=O)[C@]2(C)[C@]3(C)C[C@@H](c4ccoc4)OC(=O)[C@]3(C)CC[C@]12C</smiles>

Salvinorin A<smiles>C#Cc1occc1[C@H]1C[C@H](C)[C@@]2(C)[C@H](C(=O)[C@H](OC(C)=O)C[C@H]2C(=O)OC)[C@]2(C)CC[C@]1(C)C(=O)O2</smiles>

16-Ethy Salvinorin A

\section{Figure 5: Molecular Structures of KOPr Compounds}

Molecular structures of the synthetic KOPr agonist analogues. Of interest are the structures of Salvinorin A (Sal A) and 16-Ethynyl Sal A (16-Ethy) in relation to traditional kappa opioid receptor compounds such as $U 50,488 \mathrm{H}$. Sal $A$ has no nitrogenous group in its structure and its derivative, 16-Ethy, has a C16 ethynyl addition. 
Sal A exhibited some differences in KOPr internalization when it caused approximately a 40fold decrease in KOPr internalization through the $\beta$-arrestin pathway as compared to the traditional KOPr agonist U50,488 (Wang et al., 2008). In tests of depression such as the forced swim test (FST), rats administered with Sal A at $0.03 \mathrm{mg} / \mathrm{kg}$ have been shown to cause depressive-like effects (Carlezon et al., 2006; Morani et al., 2012). However, administered at very low doses $(0.001-1000 \mu \mathrm{g} / \mathrm{kg})$, Sal A appears to induce anti-addictive effects both in mice and rats (Braida et al., 2009) as well as generating rewarding effects at 5 and $10 \mu \mathrm{g} / \mathrm{kg}$ when administered in zebrafish (Braida et al., 2007).

Sal A has beneficial anti-addictive characteristics but due to adverse side effects such as sedation and depression, its use may be limited for clinical development. However, the laboratory of Professor Thomas Prisinzano (University of Kansas) has synthesized novel KOPr agonists, analogues of Sal A with the intention of producing a compound that will be able to retain the functional capability of Sal $A$ to regulate/inhibit the mechanisms underlying addiction (Harding et al., 2006). One such alteration that has been synthesised is that of 16Ethynyl Salvinorin A (16-Ethy). 16-Ethy is structurally similar to its parent compound Sal A, however, there has been an addition of an ethynyl functional group to the 16-carbon position on the furan ring of Sal A (Figure 5). Screen testing of the compound on KOPr has shown that 16-Ethy is a KOPr agonist and has no activity on the MOPr (Riley et al., 2014). 


\begin{tabular}{|c|c|c|c|}
\hline Compound & U50,488H & Salvinorin A & 16-Ethynyl Salvinorin A \\
\hline \multicolumn{4}{|l|}{ Structure } \\
\hline $\mathrm{EC}_{50} \pm \mathrm{SD}$ & $0.8 \pm 0.40 *[2]$ & $\begin{array}{c}40 \pm 10^{\circ}[1] \\
0.0300 .004^{*}[2]\end{array}$ & $0.019 \pm 0.004 *[2]$ \\
\hline $\mathrm{E}_{\max } \pm \mathrm{SD}$ & - & $120 \pm 2 \%[1]$ & - \\
\hline$K_{i} \pm S D$ & $0.42 \pm 0.22[5]$ & $1.9 \pm 0.2[3]$ & - \\
\hline $\begin{array}{c}\text { Minimum effective } \\
\text { dose } \\
\text { (cocaine reinstatement) }\end{array}$ & - & $0.3 \mathrm{mg} / \mathrm{kg}$ [4] & $0.1 \mathrm{mg} / \mathrm{kg}[2]$ \\
\hline
\end{tabular}

Table 3: Pharmacokinetic properties of U50,488H, Sal A and 16-Ethy

[1]: Harding et al. (2005),

[2]: Riley et al. (2014),

[3]: Simonson et al. (2015),

[4]: Morani et al. (2013),

[5]: Beguin et al. (2008)

$\mathrm{EC}_{50} \pm \mathrm{SD}=$ the effective concentration of agonist required to achieve $50 \%$ of the maximum possible response, this was measured using the ${ }^{\circ}\left[{ }_{35} \mathrm{~S}\right] \mathrm{GTP} \gamma \mathrm{S}$ assay or through *testing for inhibition of forskolin-induced cAMP accumulation in $\mathrm{CHO}$ cells that express human KOPr.

$E_{\max } \pm \mathrm{SD}=$ the percentage in which the agonist stimulates the KOPr in comparison to the classical KOPr agonist, U50,488 (500 nM).

$\mathrm{K}_{\mathrm{i}} \pm \mathrm{SD}=$ the binding affinity of KOPr agonists on the receptor using $\left[{ }^{125} \mathrm{I}\right] \mathrm{IOXY}$ as a radioligand.

Minimum effective dose $=$ The minimum effective dose is that which has a significant effect on cocaine reinstatement paradigm. 
Previous research in our laboratory has demonstrated that a single treatment of 16-Ethy is more potent at attenuating drug-seeking behaviours seen through cocaine selfadministration tests as compared to Sal A. 16-Ethy ( 0.1 and $0.3 \mathrm{mg} / \mathrm{kg})$ effectively attenuated cocaine-primed reinstatement, a test of drug-seeking behaviour, compared to Sal A which also attenuated the behaviour at $0.3 \mathrm{mg} / \mathrm{kg}$ (Riley et al., 2014). It was also found that 16 -Ethy was the only Sal A derivative to be able to effectively attenuate the behavioural motivation to continue drug seeking as seen in the progressive ratio self-administration model at $2 \mathrm{mg} / \mathrm{kg}$ which was not seen in Sal A at the same dose (Young., 2015). 16-Ethy also proved to hold a lot of promise as a therapeutic as it did not show many of the classical adverse side effects as traditional KOPr agonists. Unlike Sal A, 16-Ethy at $0.3 \mathrm{mg} / \mathrm{kg}$ did not show any sedative, anxiogenic, pro-depressive or aversive effects and did not display long-term memory impairment (Young., 2015; Culverhouse., 2016; Welsh., 2017). However, the side effect profile of 16-Ethy had not been explored at the higher dose $(2 \mathrm{mg} / \mathrm{kg})$ which attenuated progressive ratio. Therefore, this thesis aimed to explore the side effect profile of 16-Ethy at the higher $2 \mathrm{mg} / \mathrm{kg}$ dose. 


\subsection{Animal models of kappa opioid receptor-mediated side effects}

\subsubsection{Depression}

The Forced Swim Test (FST) is one of the most widely tested models of depression. The test was originally devised as a screening assay to test the antidepressant effects of novel compounds (Porsolt., 1977) but has been modified more recently to investigate prodepressive effects (Porsolt., 1977; Carlezon et al., 2006). The basis of the test is to expose a naive rat or mouse to water and observe their activity. This stressor causes the rodent to exhibit a powerful initial reaction indicating an escape-directed behaviour, as time continues the behaviours are observed, with a decrease in intensity of swimming and finally to immobility. Immobility is considered as a depressive-like behaviour as the immobility is believed to display the failure of the rat to continue persisting in trying to escape. The aim of this experiment is to test for any depressive side effects of drug treatments, in this case, Sal A and 16-Ethy.

\subsubsection{Sedation}

The basis of the locomotor test is simple in that a treatment is tested to see if it has any sedative effects. After administration, if the animal is found to have a high ambulatory count then this is indicative of increased exploration of the animal in the testing space thus little sedation is observed. Conversely, if the ambulatory count is low then this is indicative of sedative-like effects. The purpose of this experiment is to screen for any sedative side effects of 16-Ethy and Sal A. 


\subsubsection{Anxiety}

It is largely acknowledged that the activation of KOPr system produces anxiety and stressassociated behaviours (Van't Veer \& Carlezon Jr., 2013). The elevator plus maze (EPM) is commonly used to test for anxiety. EPM investigates the conflict of a rodent's intrinsic exploratory behaviour compared to its instinct for safety by avoiding elevated and brightly lit open platform arms. KOPr agonists are anxiogenic compounds, therefore they result in the animal spending more time in the closed arm compared to animals that are treated with an anxiolytic compound which would promote exploratory behaviour (Pellow et al., 1985).

\subsubsection{Aversion}

One of the most prominent paradigms to examine the aversive effects of compounds (drugs or otherwise) is through the conditioned place aversion test (CPA). This test aims to establish an association between an unconditioned stimulus (the characteristics of a drug) with a neutral environmental stimulus such as the colour, texture or pattern within the discrete test chamber. Through conditioning, the response of the animal to the stimuli demonstrates if a drug has preferential or aversive effects. This paradigm is useful then, to determine within the same system, diametrically opposed side effects, reward or aversion (Bals-Kubik et al., 1993). The benefits of this test are that it is cost-effective, fast and unlike self-administration, no surgery is required (Prus, James, \& Rosecrans., 2009). 


\subsection{Self administration - a preclinical behavioural model of addiction}

Drug self-administration in animals is used to characterise possible abuse liability of novel compounds (Balster., 1991, Panlilio \& Goldberg., 2007). Self-administration was first proposed by Weeks (1962), and the test operated by conditioning an animal to associate a lever press with an administration of a rewarding stimulus such as a drug. The premise of the experiment is that the more lever press responses an animal triggers, are indicative of drugseeking behaviour as they have associated they will be rewarded for that behaviour (Panlilio \& Goldberg., 2007).

The most widely used method of self-administration is conducted on rats, which are administered with a drug via a catheter that runs into their jugular vein, thus upon a lever press of the operant box the rat is in, the drug is administered intravenously using a delivery system (de Wit \& Stewart., 1981; Weeks, 1962). The administration of the drug, in our case cocaine, as a result of pressing the lever acts as such a powerful positive reinforcer that even when rats are required to press the lever multiple times to receive a single infusion, as in reinforcement models such as progressive ratio, they will still self-administer continuously (Griffiths et al., 1975), thus providing a robust model demonstrating the power of drug-taking behaviour in addicted individuals. This model is also versatile in demonstrating other phases of the addiction cycle. For example, the drug-primed reinstatement model (de Wit \& Stewart, 1981 ) is used as a behavioural representative of relapse in affected humans (Bossert et al., 2013; Shaham \& Miczek., 2003). In this model, a rat will display restored drug-seeking behaviours when it is exposed to a drug, or even an environmental cue that is associated with that drug, after a period of abstinence (de Wit., 1996). 


\section{Aims and Hypotheses}

Of all of the Sal A derivatives that have been researched in the Kivell laboratory thus far, 16Ethy was found not only to be the most potent, but also the only one to effectively attenuate the progressive ratio paradigm at $2 \mathrm{mg} / \mathrm{kg}$. Previous research into 16 -Ethy at $0.3 \mathrm{mg} / \mathrm{kg}$ has shown a favourable side effect profile, however, little work has been conducted to determine what the side effect profile of 16 -Ethy at the higher dose of $2 \mathrm{mg} / \mathrm{kg}$. This thesis aimed to evaluate the side effects at the $2 \mathrm{mg} / \mathrm{kg}$ dose to determine the potential of 16-Ethy as a pharmacotherapy to attenuate the rewarding effects of cocaine.

The side effect profile included tests for anxiety (elevated plus maze), depression (forced swim test) sedation (habituated and non-habituated locomotor activity), as well as aversion (conditioned place aversion). An evaluation was also conducted to expand on the known anticocaine effects through self-administration, dose-response and drug-behavioural sensitisation tests. Sal A has been shown to shown to have the ability to reduce the rewarding effects of drugs. We hypothesised that at $2 \mathrm{mg} / \mathrm{kg}, 16-$ Ethy would show similar or more potent anti-cocaine effects and have reduced side effects as compared to Salvinorin A. 


\section{Methods}

\subsection{Animals and housing}

All behavioural tests were conducted on male Sprague-Dawley rats. Rats were bred and housed within a secure facility in the School of Biological Sciences at Victoria University of Wellington. The facility operated within a 12-hour light/dark cycle (light on at 0700 hours). Rats were housed in white plastic cages in a shelved Scantainer Ventilated Cabinet (Scanbur Technology, Karlslunde, Denmark) with controlled humidity levels (55\%) and set temperature $\left(19-20^{\circ} \mathrm{C}\right)$. All rats were housed in groups of 3-4 rats per cage except those used in cocaine self-administration which were housed individually. Rats were provided food (Diet 86, Sharpes Stock Feed) and water ad libitum. In 2018, animal housing was updated to a new caging system (Optirat Gen II, Animal Care Systems) with one-pass, low-velocity airflow (82 cubic feet per min).

All behavioural experiments were conducted in the presence of white noise (67 decibels) and/or within sound-attenuating boxes. Rats used for self-administration and behavioural sensitization were cocaine naïve prior to surgery. All KOPr agonist and vehicle treatments were administered via intraperitoneal (i.p.) injections, self-administration animals received cocaine intravenously (i.v.). For behavioural assays in the absence of cocaine, rats were reused over multiple experiments after a minimum rest period of one week, using a Latin Square design (see appendix 6) in accordance to the recommendation by the National Centre for the Replacement, Refinement and Reduction of Animals in Research (UK) (Russell \& Burch, 1959). The Latin square was designed so that each rat received different treatments, the weeks rest period was employed to minimise carry-over effects between treatments.

All experiments were approved by the Victoria University of Wellington Animal Ethics Committee (Ethics Approval AEC- 2015- 22334). 


\subsection{Drug and chemical solution preparation}

\subsubsection{Kappa opioid receptor agonists}

Sal A and the 16-Ethy were provided by Prof. Thomas Prisinzano (University of Kansas). The powdered compounds were stored at $4^{\circ} \mathrm{C}$, protected from light and moisture. All compounds were determined to be $>95 \%$ pure using analytical High-Performance Liquid Chromatography (HPLC) (Riley et al., 2014). The KOPr agonists were dissolved in a 2:1:7 ratio of vehicle composed of dimethyl sulfoxide (DMSO), polysorbate 80 (Tween 80 ) and sterile $0.9 \%$ saline solution respectively. The compounds were weighed and dissolved in DMSO prior to adding Tween 80, then mixed by vortexing after saline was added, and inverting the Eppendorf tube. This process prevented the KOPr agonist precipitating out of solution.

\subsection{Behavioural assays}

\subsubsection{Spontaneous locomotor activity}

Male Sprague Dawley rats (300-400 g) were placed in an open top activity chamber (Med Associates, ENV-520) to habituate for $30 \mathrm{~min}$. The chambers were housed within cubicles that were both light and sound attenuating. Following habituation, rats were taken out of the box and administered Sal A (2 mg/kg), 16-Ethy ( $2 \mathrm{mg} / \mathrm{kg}$ ) or vehicle via intraperitoneal (i.p.) injection. The rats were then placed back in the chambers and allowed to explore the open space for a further $60 \mathrm{~min}$. Spontaneous locomotor activity was detected by horizontal infrared photobeams generated by transmitters and receivers positioned on all four sides of the box and recorded by Med Associates Activity Monitor Software (SOF-81). Stereotypic and ambulatory counts were recorded during habituation and test days. An ambulatory count was recognised by the software as three consecutive horizontal beam breaks made by the rat, a stereotypic count was determined as any horizontal movement detected below this threshold.

\subsubsection{Locomotor activity without habituation}

Rats (300-400g) were injected (i.p) with the KOPr agonist Sal A (2 mg/kg), 16-Ethy (2 mg/kg) or vehicle, $10 \mathrm{~min}$ prior to behavioural evaluation. Following drug pre-treatment, the rat was placed in the open top activity chamber (Med Associates, ENV-520) and allowed to explore 
the open space for $60 \mathrm{~min}$. Locomotor activity (stereotypic and ambulatory counts) were recorded as described above (see 3.3.1).

\subsubsection{Forced swim test}

Habituation to FST was carried out $24 \mathrm{hr}$ prior to testing. During habituation, rats (300-400 g) were placed into a water-filled (water temperature: $23-25^{\circ} \mathrm{C}$ ) cylinder $(40 \mathrm{~cm} \times 19 \mathrm{~cm}$ ), the water was filled up to $30 \mathrm{~cm}$ from the bottom of the cylinder. To habituate, rats were put in the cylinder for $15 \mathrm{~min}$, removed then towel and blow dried. On testing day, rats were pretreated with either vehicle, 16-Ethy ( $2 \mathrm{mg} / \mathrm{kg}$,) and Sal A ( $2 \mathrm{mg} / \mathrm{kg})$, pre-treatment times were $10 \mathrm{~min}$ for vehicle and 16-Ethy and $5 \mathrm{~min}$ prior for Sal A. The rat was then placed in the cylinder for the testing time of $5 \mathrm{~min}$. and filmed using a video camera. Following the swim test, the rats were taken out and dried. Any rats that climbed out of the cylinder either during the habituation or testing period were excluded from results. Video recordings were then analysed using SMART software (Panlab, Harvard Apparatus, USA) which detected immobility, swimming and climbing behaviour. See (Appendix 1: Setup and use of SMART software for FST video analysis) for details of SMART software configurations for FST video analysis.

\subsubsection{Elevated plus maze}

EPM was performed according to the procedure described by Walf and Frye (2007). The maze was constructed from black plastic with four arms (50 cm x $10 \mathrm{~cm}$ each) which are elevated $55 \mathrm{~cm}$ off the ground. The two open arms of the maze had $3 \mathrm{~cm}$ ledges made from clear plastic whilst the closed arms have $40 \mathrm{~cm}$ high black plastic walls. All the lighting was provided from the overhead ceiling lamps of the room. Rats were administered Sal A ( $2 \mathrm{mg} / \mathrm{kg}), 16$ Ethy $(2 \mathrm{mg} / \mathrm{kg}$ ) or vehicle. Pre-treatment times were $10 \mathrm{~min}$ for vehicle and 16-Ethy and $5 \mathrm{~min}$ prior for Sal A. The rats are placed in the middle of the maze facing an open arm and were filmed for 5 min (Panasonic HC-V160 High Definition Video Camera). An arm entry was characterized as having all four paws on the arm (Walf and Frye., 2007). The video recording was used to determine the number of entries and time spent on each arm. Any rats that fell off the maze were excluded from analysis. 


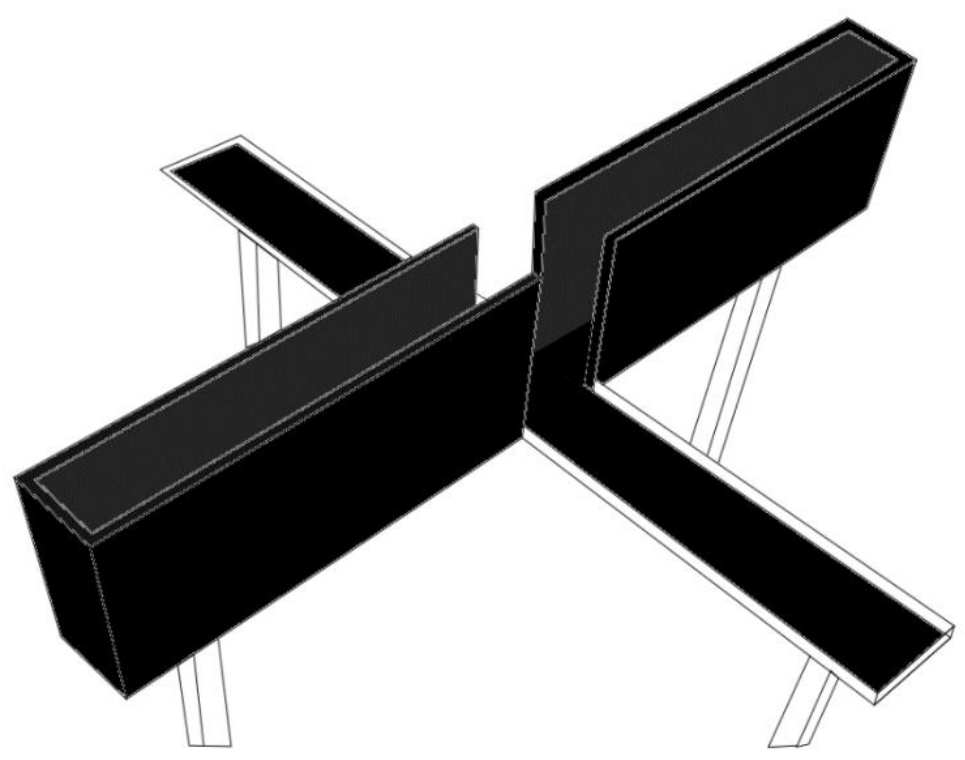

Figure 6: Schematic of elevated plus maze

Rats were injected with KOPr agonist and placed in the middle of the apparatus facing an open arm. A video camera was used to record the animal's activity on the maze for 5 min. Anxiolytic behaviours were measured using total time spent on the open arm, whilst total time spent in the closed arm represents more anxiogenic-like properties. 


\subsubsection{Conditioned place aversion}

The CPA paradigm was conducted according to the procedure described by Tejeda et al. (2013). The CPA apparatus was made up of two large chambers $(30 \times 30 \times 34 \mathrm{~cm})$ connected by a corridor $(8 \times 10 \times 34 \mathrm{~cm})$ with sliding doors, allowing the animal to be restricted to either chamber as needed (PanLab, Harvard Apparatus, USA). One chamber had white walls with a black polka dot pattern and black textured flooring whilst the other chamber had white smooth flooring and black and white striped walls. The corridor had grey walls and smooth grey flooring. Cameras were mounted directly above the chambers and the animal's movements were tracked and analysed using SMART 3.0 software. During the experiments, the main overhead lights of the room were turned off. Two free-standing LED lamps provided light with one facing the ceiling to provide enough ambient light for filming and another that was positioned over the corridor to deter the animal from lingering there. Each chamber was illuminated to approximately 20 lux, with the corridor at 60 lux.

Prior to the first experimental day, the rats were allowed to freely roam the apparatus for 15 $\min$ to habituate (day 0). On day one, they were allowed to freely roam for $15 \mathrm{~min}$. The total time the rat spent in each chamber was recorded. The preferred chamber was noted. Animals that exhibited a preference for one chamber over the other $(>80 \%)$ or preference for the corridor (>40\%) were excluded from the experiment.

On days two to seven, using a biased procedure, the rats were conditioned to the chambers so that the compound of interest was administered and placed within the preferred chamber. On days two, four and six, either vehicle or 16 -Ethy $(2 \mathrm{mg} / \mathrm{kg})$ was paired with placement into the preferred chamber for $45 \mathrm{~min}$. On the alternate days $(3,5,7)$ the rats were injected with vehicle and were placed in the opposite chamber (the non-preferred chamber). To minimise any experimental differences, the conditioning days were counterbalanced. On test day, the animal was placed in the corridor and allowed to freely roam through the apparatus for 15 min, with the time spent in each chamber recorded. 


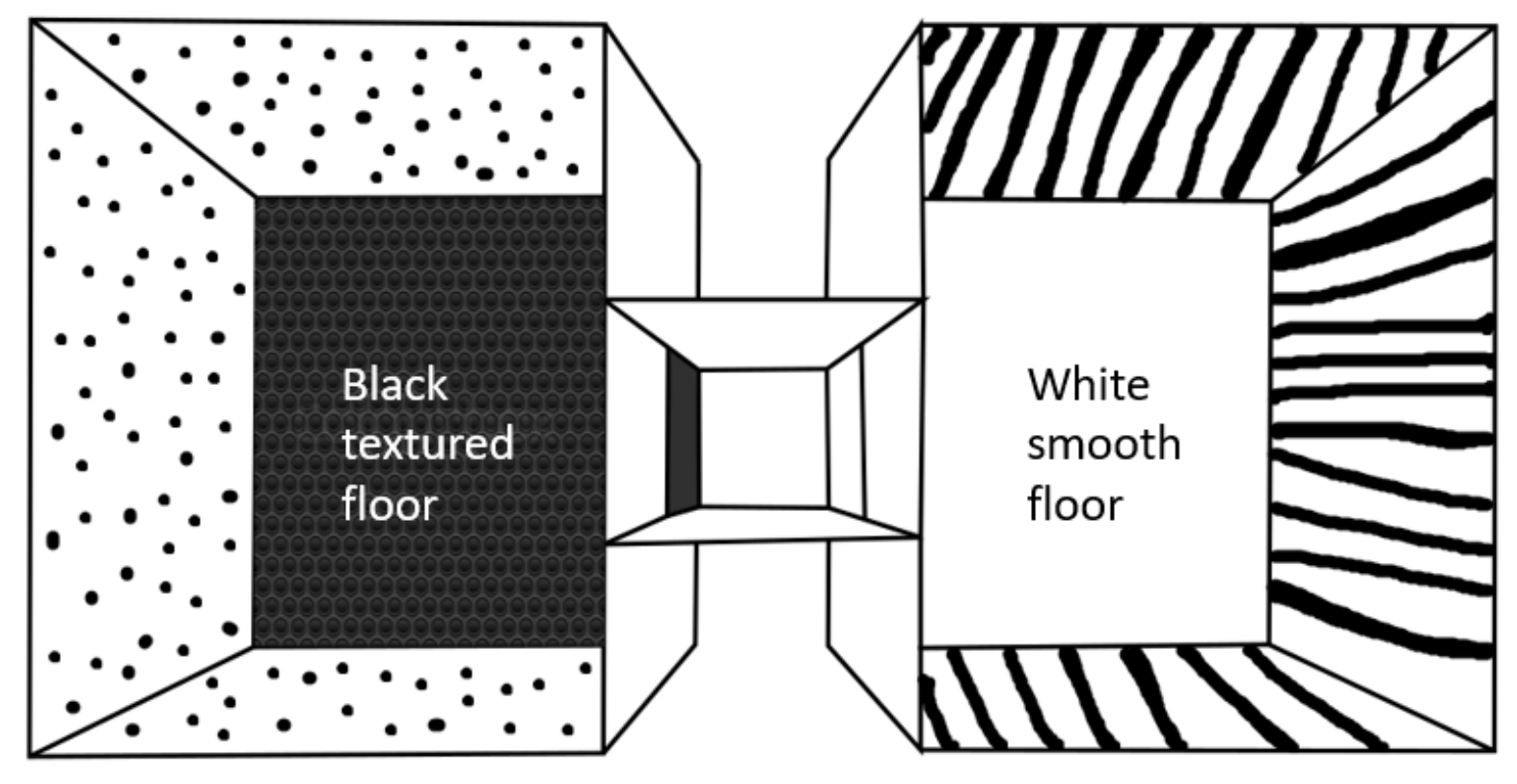

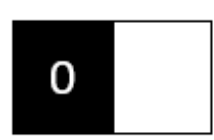

Habituation

(15 $\mathrm{min})$

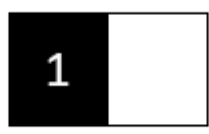

Pre-test (15 $\mathrm{min})$

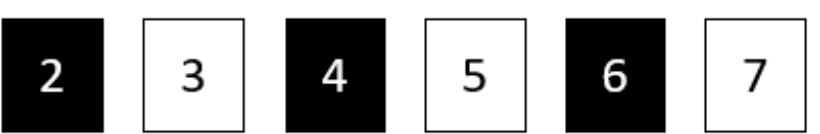

KOPr agonist or vehicle conditioning phase ( $45 \mathrm{~min}$ )

\section{8}

Post-test (15 $\mathrm{min})$

Figure 7: Conditioned place aversion apparatus and schedule

Schematic of the 3 chambered CPA apparatus. Rats were habituated to the entire apparatus for $15 \mathrm{~min}$ (day 0) prior to being electronically tracked for their chamber of preference, for 15 min (day 1). On days 2,4,6 rats were administered with KOPr agonist and placed in their preferred chamber for $45 \mathrm{~min}$. On days 3,5,7 rats were administered vehicle and placed in their least preferred chamber for $45 \mathrm{~min}$. On day 8 , rats were allowed to freely roam the entire apparatus for $15 \mathrm{~min}$, and their movements were electronically tracked. 


\subsection{Behavioural anti-cocaine effects of KOPr agonists}

\subsubsection{Cocaine Sensitization}

The cocaine sensitisation paradigm was used to determine if an acute 16-Ethy pre-treatment ( $2 \mathrm{mg} / \mathrm{kg}$ ) could suppress behavioural sensitization of locomotor effects on rats receiving daily cocaine injections $(20 \mathrm{mg} / \mathrm{kg}$, i.p). Drug naïve rats $(300-400 \mathrm{~g}, \mathrm{n}=8)$ were handled for a week before testing and were assigned to cocaine- or saline-treatment groups. On day 1, rats were habituated to the locomotor activity chamber (as in 3.3.1 Spontaneous Locomotor Activity) for 30 minutes and then injected with either cocaine $(20 \mathrm{mg} / \mathrm{kg})$ or saline-treatment groups (i.p), their locomotor activity was recorded using Med Associates Activity Monitor Software for 60 minutes. On days $2-5$, rats were injected with their assigned treatments and placed back in their home cage. On days 6-9, no treatments were administered. On day 10 , rats were again habituated to the locomotor activity chamber for $30 \mathrm{~min}$ before being pre-treated with either saline or 16-Ethy ( $2 \mathrm{mg} / \mathrm{kg}) .10$ minutes following pre-treatment, all rats were injected with cocaine $(20 \mathrm{mg} / \mathrm{kg})$ and placed back into the locomotor activity chamber for 60 minutes and their locomotor activity was recorded using the aforementioned software. 


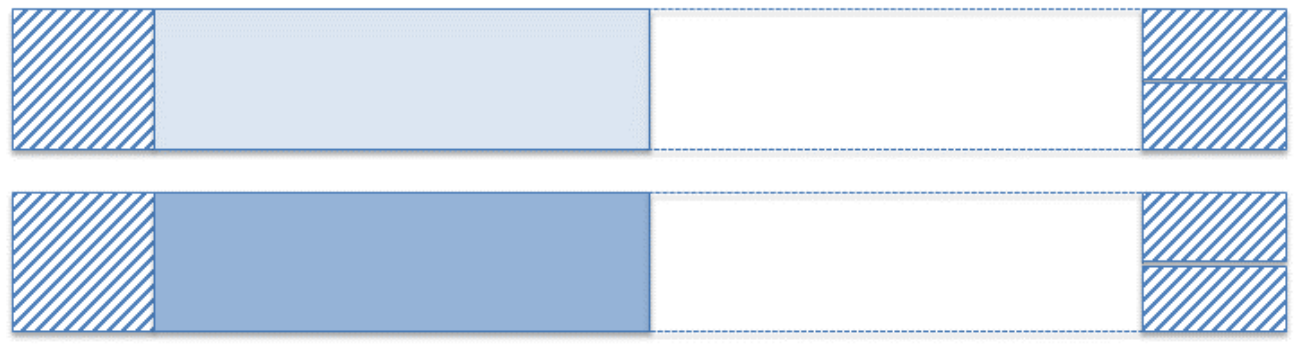

+ vehicle

+ 16-Ethy

$(2 \mathrm{mg} / \mathrm{kg})$

+ vehicle

+ 16-Ethy

$(2 \mathrm{mg} / \mathrm{kg})$

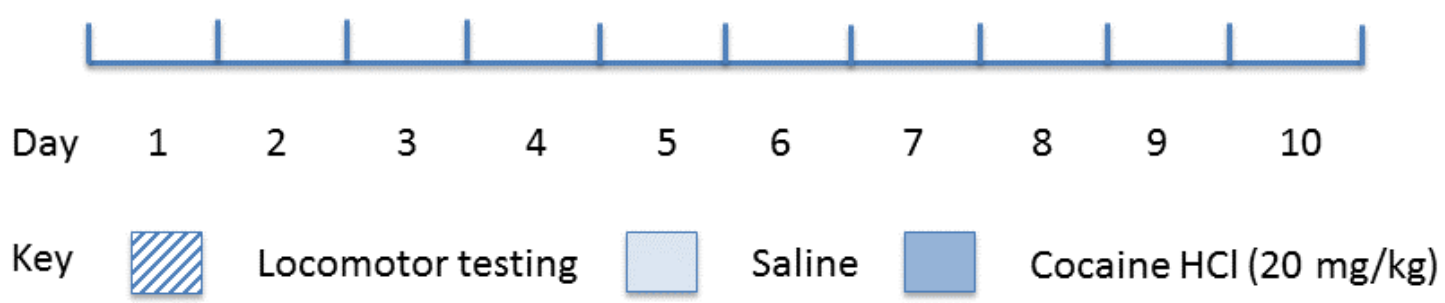

Figure 8: Treatment schedule for cocaine sensitization

Rats were assigned into two treatment groups: cocaine- $(20 \mathrm{mg} / \mathrm{kg}$ ) or saline (Days 1-5) and then further split for testing on day 10 receiving either vehicle or 16-Ethy, no treatments were administered on Days 5-9. The rat's locomotor activity was recorded on Days 1 and 10. 


\subsubsection{Self-administration intra-jugular surgery}

For self-administration, two different systems of intravenous (i.v.) drug delivery were employed. The details of catheter preparations and a more in-depth procedure of both surgery methodologies and post-operative care are detailed in the supplementary information (Appendix 2-5; pages 82-88). Succinctly, Sprague-Dawley rats weighing between 300-350 g were anaesthetised using a ketamine-xylazine mixture $(90 \mathrm{mg} / \mathrm{kg}$ Ketamine, 9 $\mathrm{mg} / \mathrm{kg}$ xylazine, i.p.) and surgery performed to insert a catheter into their right jugular vein. All surgeries were kindly performed by Diana Atigari.

The first method of drug delivery was through the headpiece system, where the metal piece of the catheter was fixed onto the crown of the rat's skull using jewellers screws and dental acrylic. The open end of the metal piece was capped off using a piece of sealed Tygon tube. The rats were given a week to recover with their overall health and weight monitored daily prior to self-administration training. To inhibit blood clotting within the catheter, $0.2 \mathrm{~mL}$ of penicillin/heparin solution was flushed through daily. Once a week, the patency of the catheter was tested by drawing back blood, if no bloodline was observed then $0.15 \mathrm{~mL}$ of 50 $\mathrm{mg} / \mathrm{kg}$ pentobarbital was flushed through the catheter. If the animal did not immediately experience sedation, then it indicated the presence of a leak. If this was the case, then the rat underwent additional surgery to insert a new catheter into its left jugular vein. If the second catheter also failed, then the animal was euthanized. A blocked headpiece was fixed by simply replacing the metal piece.

The second method of delivery was through the backpack system, where the catheter was subcutaneously routed to the rats back and attached to a Vascular Access Button (VAB95BS, Instech). This is a closed looped system, so like in the headpiece system, $0.2 \mathrm{~mL}$ of penicillin/heparin solution was flushed through it daily. To test patency, $0.15 \mathrm{~mL}$ of $50 \mathrm{mg} / \mathrm{kg}$ pentobarbital was flushed through to visualise sedation, however no blood was drawn. If the catheter failed, then the animal underwent another surgery to insert a catheter into its left jugular vein. Failure of the second catheter resulted in the animal being euthanized. 


\subsubsection{Cocaine self-administration training}

Cocaine self-administration training was executed as described by Bosch (2013). Selfadministration testing is conducted in operant chambers (ENV-001, Med Associates, St. Albans, Vermont) encased within light and sound-attenuating boxes. Each chamber has an active (right hand) and inactive (left hand) levers, paired with a light stimulus located above the lever. Upon pressing the active lever, a dose of cocaine is administered to the rat through their jugular cannula. The headpiece is connected to a $20 \mathrm{~mL}$ syringe of cocaine solution (1.65 $\mathrm{g} / \mathrm{L}$ ), the administration of which is conducted using a mechanical pump (PHM-100VS, Med Associates) through Tygon tubing (Cole-Parmer C-P06418-02, Thermo-Fisher Scientific Inc., Melbourne, Australia). With the backpack system, the $20 \mathrm{~mL}$ syringe was connected to the backpack tether which screwed onto the vascular access button (VAB95BS, Instech).

Prior to, and after every self-administration session, the rats were flushed with $0.2 \mathrm{~mL}$ of saline containing heparin $(30 \mathrm{U} / \mathrm{mL})$ and penicillin $\mathrm{G}$ potassium $(250,000 \mathrm{U} / \mathrm{mL})$ to prevent blood clot formation. The timetable for testing consisted of five consecutive days of selfadministration with two rest days where the patency of the catheters were tested with heparinised saline $(3 \mathrm{U} / \mathrm{mL})$ and flushed with the heparin-penicillin solution. Rats were initially trained using a Fixed-Ratio-1 ratio schedule (FR-1), whereby a single press of the active lever administered an infusion of heparinized cocaine $(0.1 \mathrm{~mL}$ of $0.5 \mathrm{mg} / \mathrm{kg} /$ infusion for $12 \mathrm{~s})$ and illumination of the paired light stimulus. When a rat consistently received 20 infusions/per day for 3 consecutive days over the 2-hour test period, with at least a 2:1 ratio of active: inactive lever presses, they were considered to have acquired drug-seeking behaviour. Upon achievement of this criteria, FR-1 rats progressed to an FR-2 schedule or reinforcement, whereby two active lever presses were required to receive an infusion. When the same criteria were met on FR-2 (20 infusions/session for 3 days) each rat moved to an FR5 schedule of reinforcement (five lever presses per infusion), for a minimum of 10 days. To determine the baseline level of active cocaine response for each rat, a mean was calculated from the number infusions over three consecutive FR-5 sessions, the variability between means had to be less than $20 \%$. All the lever presses and infusions were recorded using Med Associates software (MED-PC IV, version 4.2). 

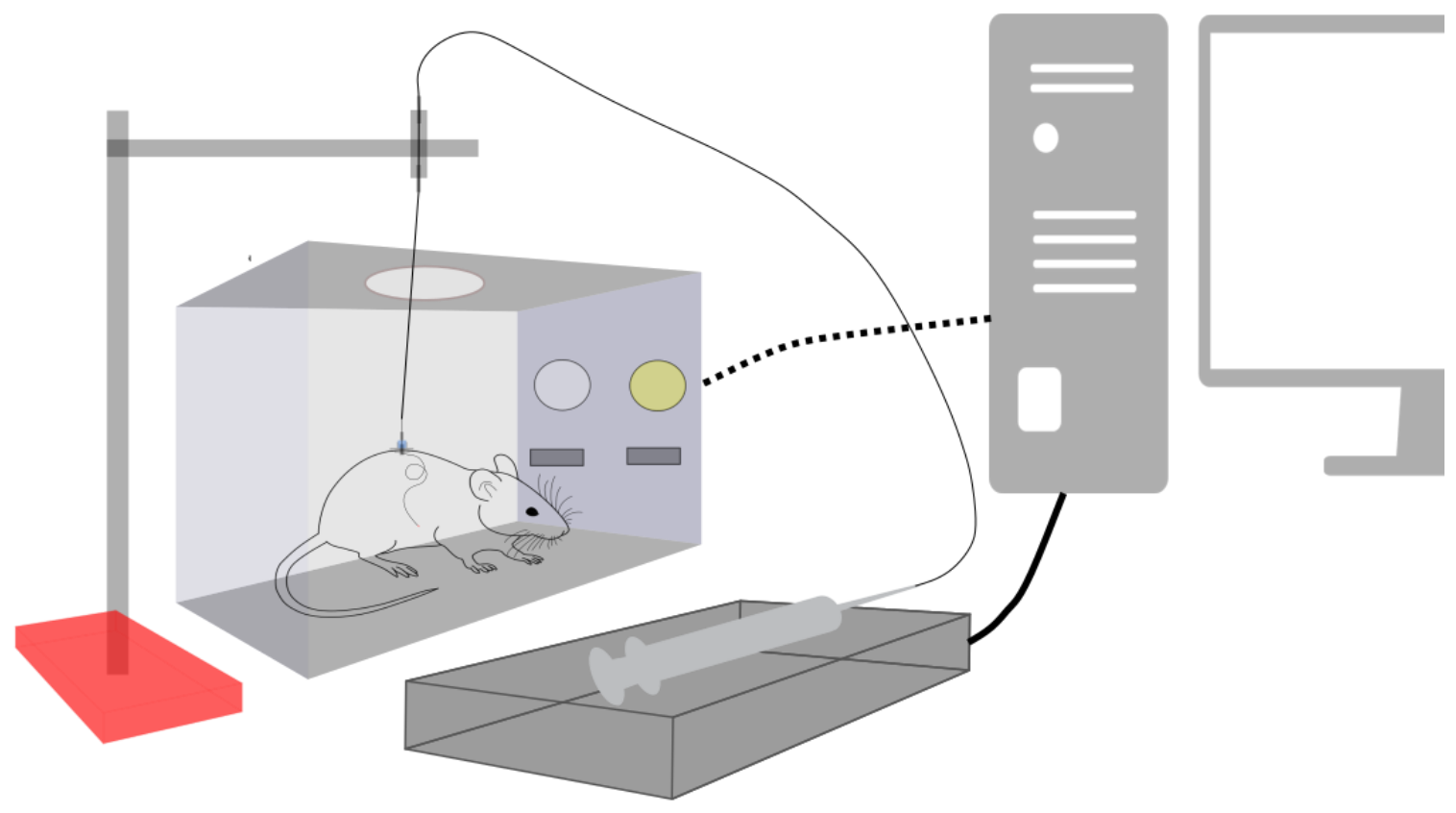

Figure 9: Self-administration schematic

Rats were placed in self-administration chambers that has two levers. Upon pressing the right lever, a corresponding light turned on and the animal received an infusion (i.v) of cocaine solution $(0.5 \mathrm{mg} / \mathrm{kg}, 0.1 \mathrm{ml}$ for $12 \mathrm{~s})$ through its jugular cannula. The left lever was inactive and the animals did not receive any drug infusions. All the lever presses and infusions were recorded using Med Associates software. 


\subsubsection{Cocaine dose-response}

Cocaine dose-response begins as cocaine self-administration training where the rats were trained on FR-1 and FR-2 schedules, each lever press in the corresponding schedules administered $0.5 \mathrm{mg} / \mathrm{kg}$ cocaine solution. Once a stable baseline had been established in the FR-2 schedule with the parameters met as per the self-administration training method, the rat was ready for cocaine dose-response tests.

In the dose-response experiment a full range of cocaine doses $(0.0,0.03,0.15,0.5,1$ and 2 $\mathrm{mg} / \mathrm{kg}$ ) are administered in a single session. Each session consists of six sequential 20-minute testing periods (one dose per period), followed by a 20 min timeout period where the cocaine dose can be changed. Prior to each dosage self-administration session there is a 30 -minute extinction period ( 3 unit heparin/saline solution $=0 \mathrm{mg} / \mathrm{kg}$ cocaine). This testing continued until a stable cocaine-maintained response was achieved (at least $10 \mathrm{mg} / \mathrm{kg}$ cocaine infusions per session, with $<10 \%$ variation for 3 consecutive days or $20 \%$ variation for 2 days, additionally there must be at least a fivefold increase in maximal response rates when compared to those during extinction). Following stable responding, the treatment trial can be conducted. The rat was injected with the KOPr agonist (16-Ethy; $2 \mathrm{mg} / \mathrm{kg}$ ) and after the pretreatment time $(10 \mathrm{~min})$ was placed in the operant chamber and the dose-response test conducted as previously described to evaluate the effects of KOPr-agonist treatment on cocaine self-administration. If another treatment dose was needed to be tested, the rats underwent 5-7 days of cocaine self-administration until a baseline was re-established, after which the next KOPr dose was administered. 


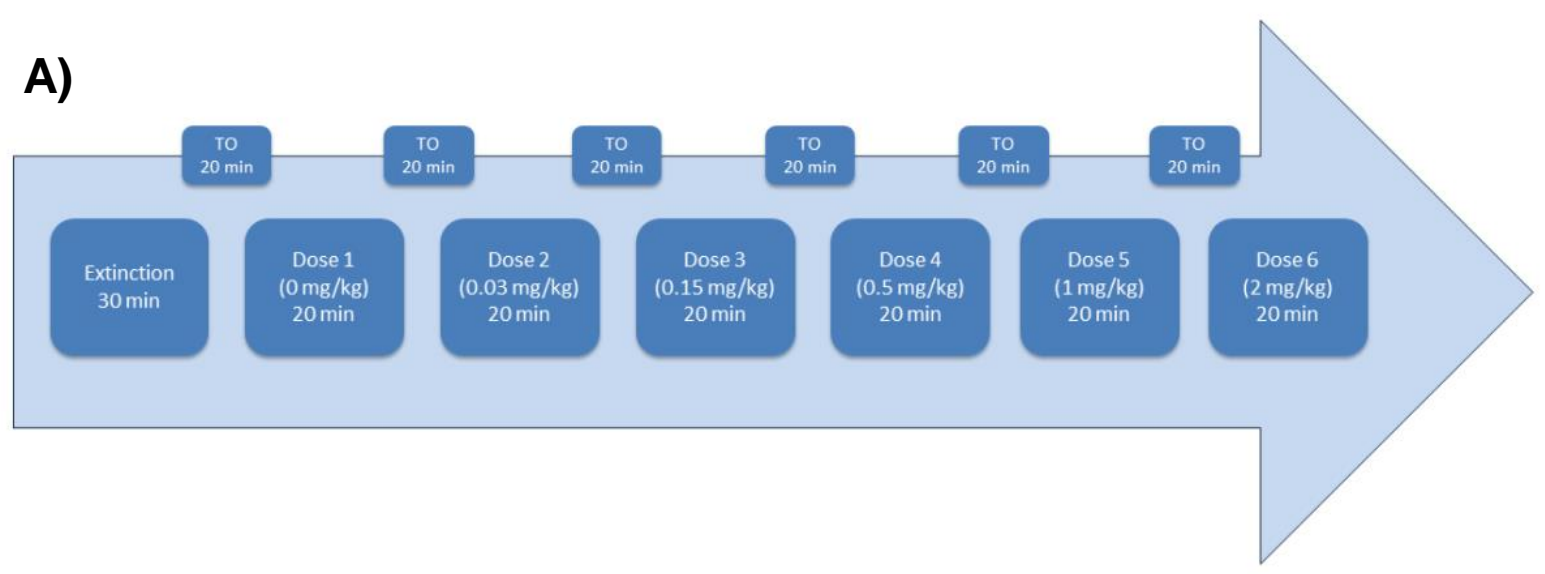

B)

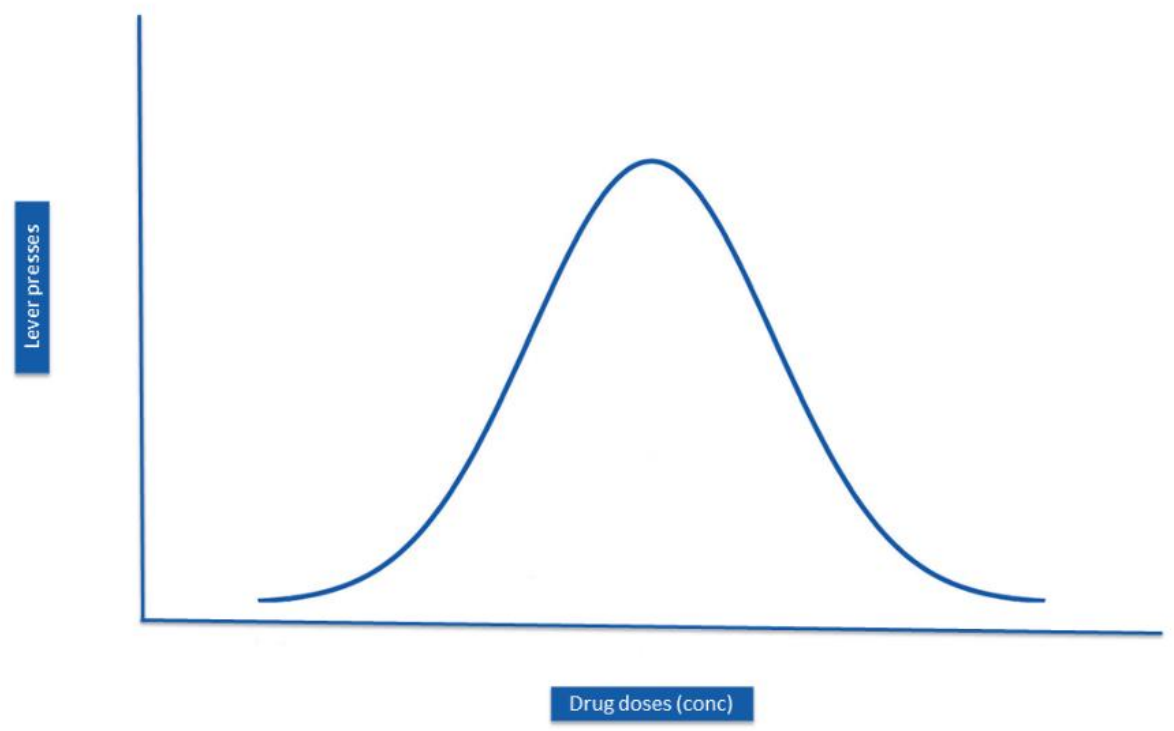

Figure 10: Cocaine Dose Response

A) The cocaine dose-response schedule with six consecutive and increasing cocaine doses, all administered in a single session. TO = time out, no infusions are given during this period.

B) Dose-response curve with escalating cocaine concentrations infusion in each time period. Lever presses increase as cocaine concentrations rise, however when the concentration is too high, it is no longer desirable to consume more, therefore lever presses decrease. 


\subsection{Statistical analysis}

All statistical analyses were performed using GraphPad Prism 6.0 software (GraphPad Software, La Jolla, CA, USA). One-way analysis of variance (ANOVA) tests was used to analyse the variances of three or more means. Two-way repeated measures ANOVA tests were used to examine time course effects of treatments for the locomotor activity experiments. Bonferroni post-tests were used in all analyses. Results were considered significant when $p<0.05$. In-text numerical results are reported as the mean \pm standard error of the mean (SEM). 


\section{Results}

\subsection{Habituated locomotor activity}

Locomotor activity is a test for sedation. A reduction in ambulatory counts, following drug administration indicates that a drug has sedative effects.

A one-way ANOVA showed a significant effect of treatment on total ambulatory counts $[F(2,31)=5.839, p=0.0070]$ (Figure 11). Rats treated with 16-Ethy $(2 \mathrm{mg} / \mathrm{kg})$ did not show any significant difference in ambulatory counts in comparison to vehicle treatment $(p=$ $0.3044)$ during the 1-hour test phase. Rats treated with Sal A (2 mg/kg), showed a significant increase in ambulatory counts during the test phase in comparison to vehicle treatment $(p=$ 0.0037) (Figure 11A), indicating that 16-Ethy did not have sedative effects. For the time course data, two-way repeated measures ANOVA showed there was no interaction of treatment and time $[F(34,544)=1.278, p=0.1384]$ (Figure 11B).

One-way ANOVA identified no significant effect of treatment on total stereotypic counts $[F(2,32)=0.5048, p=0.6083]$ (Figure 11C). Time course analyses of stereotypic counts (twoway repeated measures ANOVA, Bonferroni post-test), however, identified a significant effect of time upon stereotypic counts $[F(34,544)=1.511, p=0.0340]$, with Sal A-treated rats showing significantly lower ambulatory counts at the 15 min time point $(p=0.0229)$ and 16 Ethy significantly lower at the 35 min time point $(p=0.0269)$ compared to vehicle (Figure 11D). 
A

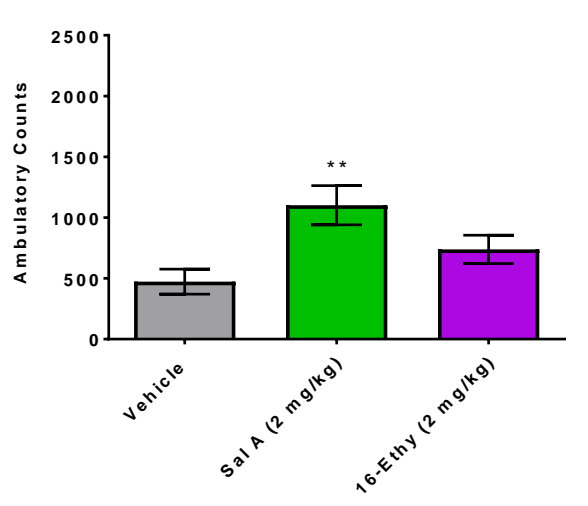

C

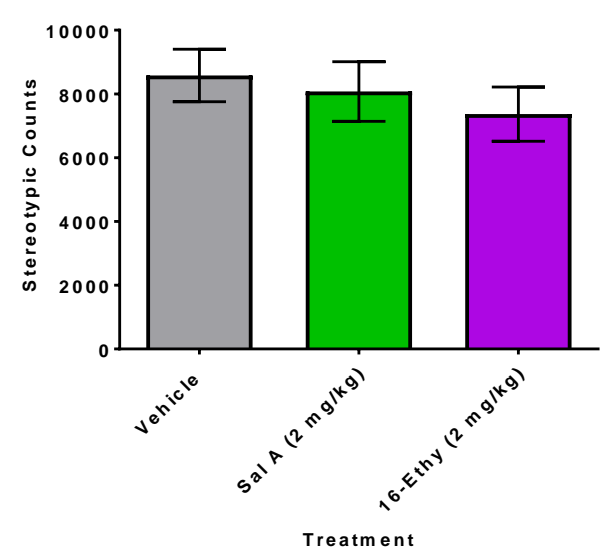

B

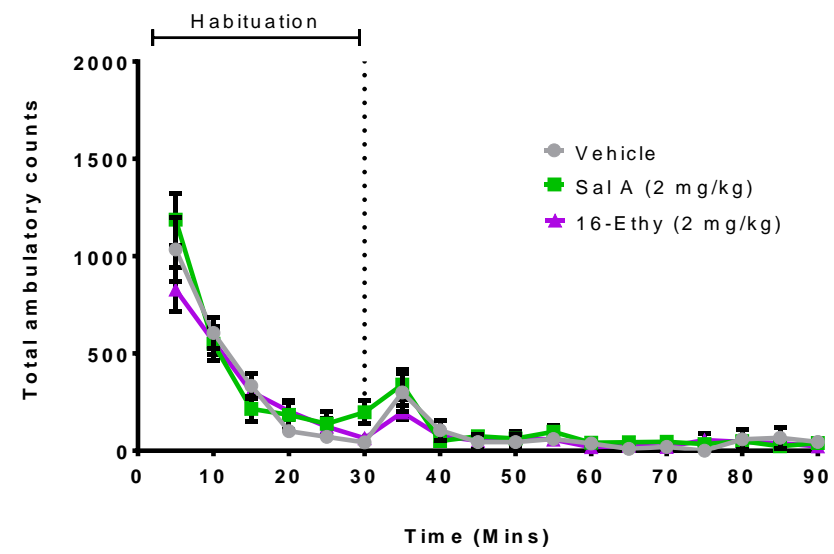

D

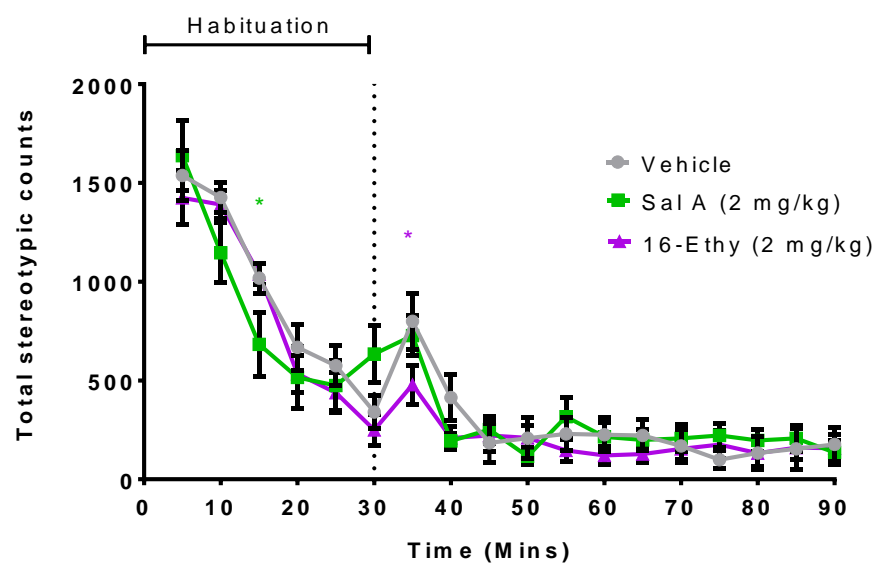

Figure 11: Effects of Sal A and 16-Ethy on habituated locomotor activity

Rats treated with Sal A ( $2 \mathrm{mg} / \mathrm{kg}$ ) after 30 min habituation to an open field activity chamber showed an increase in post-habituation ambulatory counts (A) but not stereotypic counts (C) compared to vehicle treatment $(p<0.05), 16$-Ethy did not show any significant difference in ambulatory or stereotypic counts. Time course analysis of ambulatory (B) and stereotypic (D) behaviours with Sal A and 16-Ethy post-habituation identified Sal A had no significant difference in ambulatory counts but did have a significant reduction in stereotypic counts at the 15 min mark (two-way ANOVA with Bonferroni post-test, $p<0.05$ ), 16-Ethy had significant reduction in ambulatory counts at the $35 \mathrm{~min}$ time point for stereotypic counts. $(n=11-12)$. 


\subsection{Non-habituated locomotor activity}

In the habituated locomotor activity test, the greatest period of activity occurred during the 30 min habituation period. After the administration of KOPr agonist, Sal A and 16-Ethy at 2 $\mathrm{mg} / \mathrm{kg}$, there was little to no locomotor activity observed. This raised the question of whether the reduction in ambulatory counts was due to sedative effects of the KOPr agonists or due to a floor effect. This test was used to determine if without habituation to the open field chamber, there would be a change in locomotor activity following KOPr treatment. A reduction in ambulatory counts would indicate sedative effects.

A one-way ANOVA analysis found a significant effect of treatment on total ambulatory counts $[F(2,18)=5.865, p=0.0109]$. Rats treated with 16-Ethy $(2 \mathrm{mg} / \mathrm{kg})$ showed a significant reduction in ambulatory counts in comparison to vehicle treatment $(p=0.0061)$, however Sal A $(2 \mathrm{mg} / \mathrm{kg}) \operatorname{did}$ not $(p=0.1241)$ (Figure 12A).

Two-way repeated measures ANOVA of the time course data for the ambulatory counts identified a significant interaction of treatment and time $[F(22,198)=3.041, p<0.0001]$. Bonferroni post-test analysis identified significant differences between the treatment groups, 16-Ethy had significantly lower ambulatory counts compared to vehicle at the 5 min time point $(p<0.0001)$. Sal A was also significantly lower than vehicle at the $5 \min (p<0.0001)$ and the 10 min time point $(p=0.0274)$ (Figure 12B).

One-way ANOVA analysis on the total stereotypic counts identified a significant difference between treatments $[F(2,18)=7.7997, p=0.0033]$. Rats treated with 16 -Ethy $(2 \mathrm{mg} / \mathrm{kg})$ showed significant reduction in stereotypic counts in comparison to vehicle treatment $(p=$ 0.0017) however Sal A did not ( $p=0.0886$ ) (Figure 12C). However, two-way repeated measures ANOVA of the time course data of stereotypic counts identified a significant interaction of treatment and time $[F(22,198)=1.902, p=0.0113]$, Bonferroni post-tests showed Sal A was significantly lower than vehicle at the $5(p=0.0136)$ and $10 \min (p=0.0239)$ time points, 16 Ethy was significantly lower than vehicle at the $5(p<0.0001), 10(p=0.0046)$ and 15 min time points ( $p=0.0077$ ) (Figure 12D). 

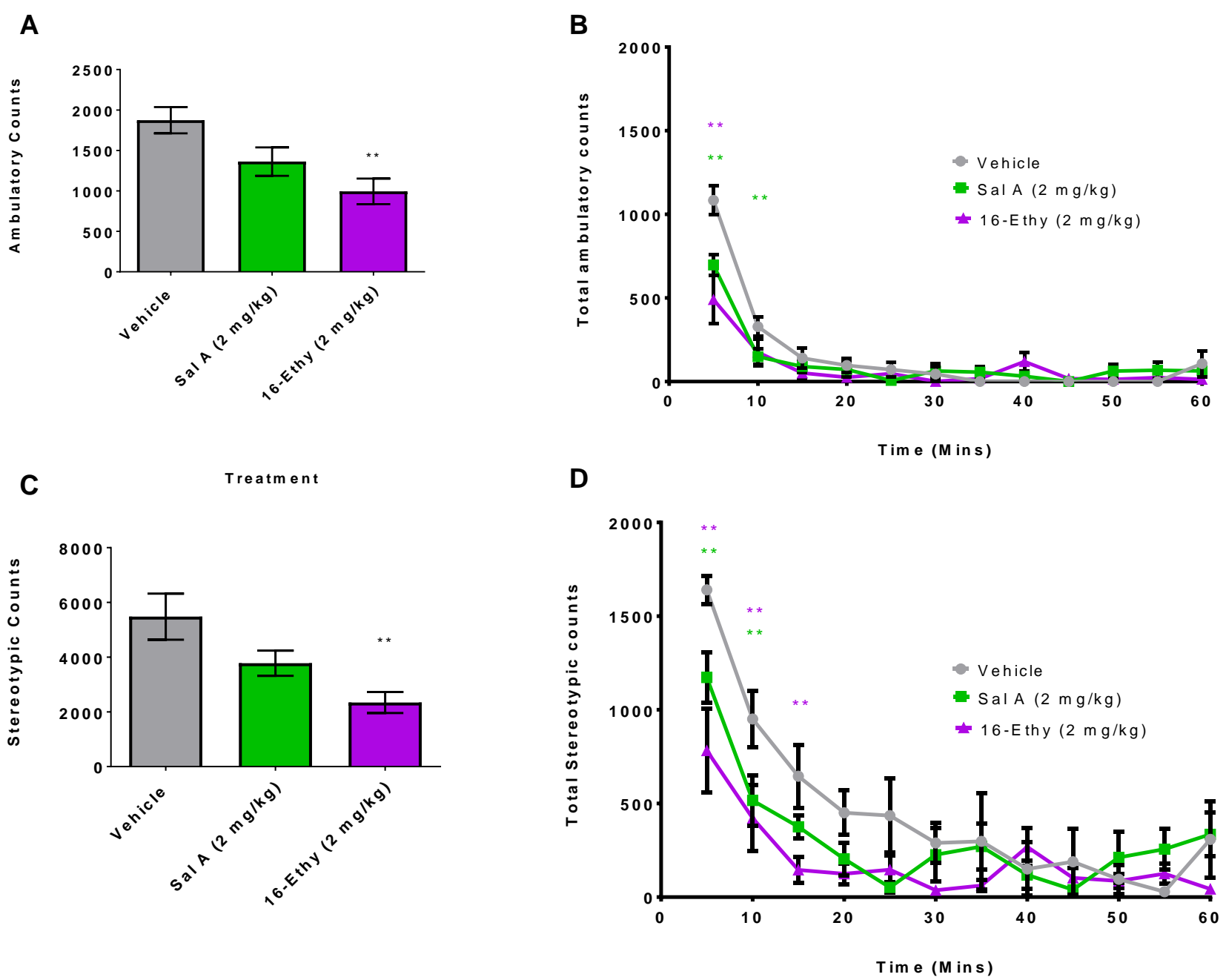

Treatment

Figure 12: Effects of Sal A and 16-Ethy on non-habituated locomotor activity

Rats treated with 16-Ethy $(2 \mathrm{mg} / \mathrm{kg}$ ) showed a significant reduction in total ambulatory (A) and stereotypic (C) counts compared to vehicle $(p<0.05)$, Sal A $(2 \mathrm{mg} / \mathrm{kg})$. Time-course analysis of ambulatory (B) and stereotypic (D) behaviours found a significant effect upon time for both treatment groups (two-way ANOVA, $p<0.0001$ ). For time course ambulatory counts, Sal $A(5$ and $10 \mathrm{~min}$ ) and 16-Ethy ( $5 \mathrm{~min}$ ) have decreased ambulatory counts (B) compared to vehicle-treated control rats. Sal A (5 and $10 \mathrm{~min}$ ) and 16-Ethy (5, 10 and $15 \mathrm{~min})$ showed reduced stereotypic counts (D) compared to vehicle. $(n=8)$. 


\subsection{Elevated plus maze}

The EPM measures anxiety, the longer a rat spends in the open arm the less anxiogenic a compound is thought to be. In the EPM paradigm there was no significant effect of treatment on time spent on the open $\operatorname{arm}[F(3,31)=1.503, p=0.2332]$ (Figure 13). Neither 16-Ethy nor Sal A ( $2 \mathrm{mg} / \mathrm{kg})$ treated rats showed any significant increase in time spent in the open arm, indicating no anxiogenic effects.

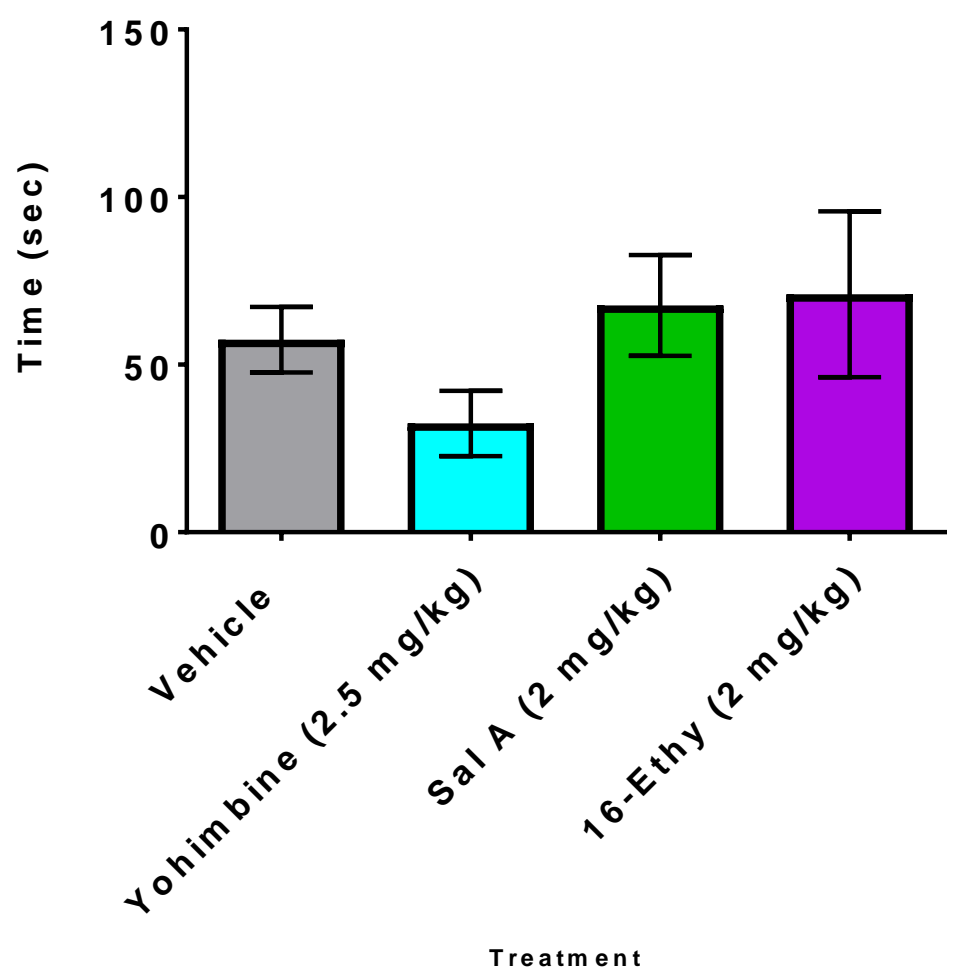

Figure 13: Neither Sal A nor 16-Ethy change time open arm time in the elevated plus maze

The anxiogenic effects of the KOPr agonists were measured using the elevated plus maze. Administration of 16-Ethy $(2 \mathrm{mg} / \mathrm{kg})$ did not result in significant differences in open arm time when compared to vehicle, yohimbine $(2.5 \mathrm{mg} / \mathrm{kg})$ or Sal A (2 mg/kg). One-way ANOVA with Bonferroni's multiple comparisons. $(n=7-10)$. 


\subsection{Forced swim test}

The FST is a preclinical measure of pro-depressive effects of compounds. Three different behaviours were observed in the FST; immobile, swimming and climbing times. If a rat spent more time in an immobile state then the drug is thought to have a pro-depressive effect, if it has more mobile behaviour (swimming and climbing) then the drug is thought to have less pro-depressive effects.

Comparison of the vehicle treatment group with 16-Ethy $(2 \mathrm{mg} / \mathrm{kg})$ treatment did not identify any significant differences in the total amount of time that a rat spent immobile $[t(8)=0.2600$, $p=0.8014]$, swimming [t(8) $=0.1841, p=0.8585]$ or climbing [t $(8)=1.2015, p=0.2627]$. Rats treated with Sal A $(2 \mathrm{mg} / \mathrm{kg})$ also did not show any significant differences in time spent immobile [t(9) $=0.3224, \mathrm{p}=0.7545]$, swimming $[\mathrm{t}(9)=0.3362, \mathrm{p}=0.7444]$ or climbing $[\mathrm{t}(9)=$ 1.636, $p=0.1362$ ] compared to vehicle-treated controls. Rats treated with yohimbine $(2.5$ $\mathrm{mg} / \mathrm{kg}$ ) did not show any significant differences in total time spent swimming $[\mathrm{t}(8)=0.7490$, $p=0.4753]$, however, compared to vehicle treated rats, they did show a significant reduction in total time spent immobile $[\mathrm{t}(8)=2.947, \mathrm{p}=0.0185]$ and a significant increase in total time spent climbing $[\mathrm{t}(8)=4.430, \mathrm{p}=0.0022$ (Figure 14) indicating that yohimbine does not show pro-depressive effects but anti-depressant effects. 16-Ethy and Sal A did not show prodepressive effects in this assay. 


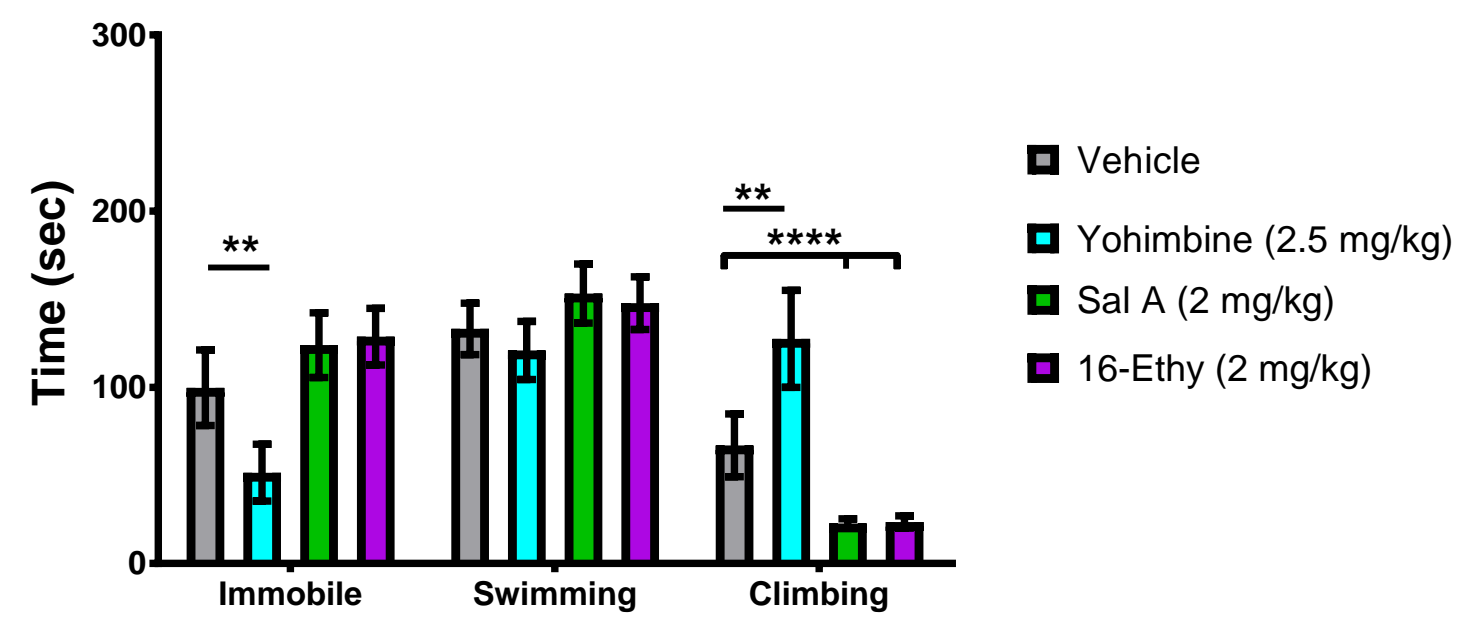

\section{Behaviour}

Figure 14: Forced swim test with acute KOPr agonist treatment

The forced swim test revealed no significant differences between immobile and active behaviours (swimming and climbing combined) between vehicle and Sal A ( $2 \mathrm{mg} / \mathrm{kg}$ ), and 16Ethy $(2 \mathrm{mg} / \mathrm{kg})$. Significant differences were found between vehicle and yohimbine $(2.5$ $\mathrm{mg} / \mathrm{kg}$ ), there was a significant reduction in immobility behaviour and subsequently a significant increase in climbing behaviour but not in swimming behaviour, indicating antidepressive effects (t-test, $p<0.05),(n=9-13)$. 


\subsection{Conditioned place aversion}

CPA measures aversion, less time spent in drug-paired chambers indicates the drug has aversive effects. In the CPA paradigm, 16-Ethy $(2 \mathrm{mg} / \mathrm{kg})$ did not cause significant a change in time spent in the drug-paired chamber $[\mathrm{t}(6)=1.011, \mathrm{p}=0.3511]$. Sal A $(0.3 \mathrm{mg} / \mathrm{kg})$ did produce a significant reduction in time spent in the drug-paired chamber $[t(8)=3.742, p=0.0057]$ (Figure 15). Unlike Sal A, 16-Ethy did not show conditioned place aversion. 
A

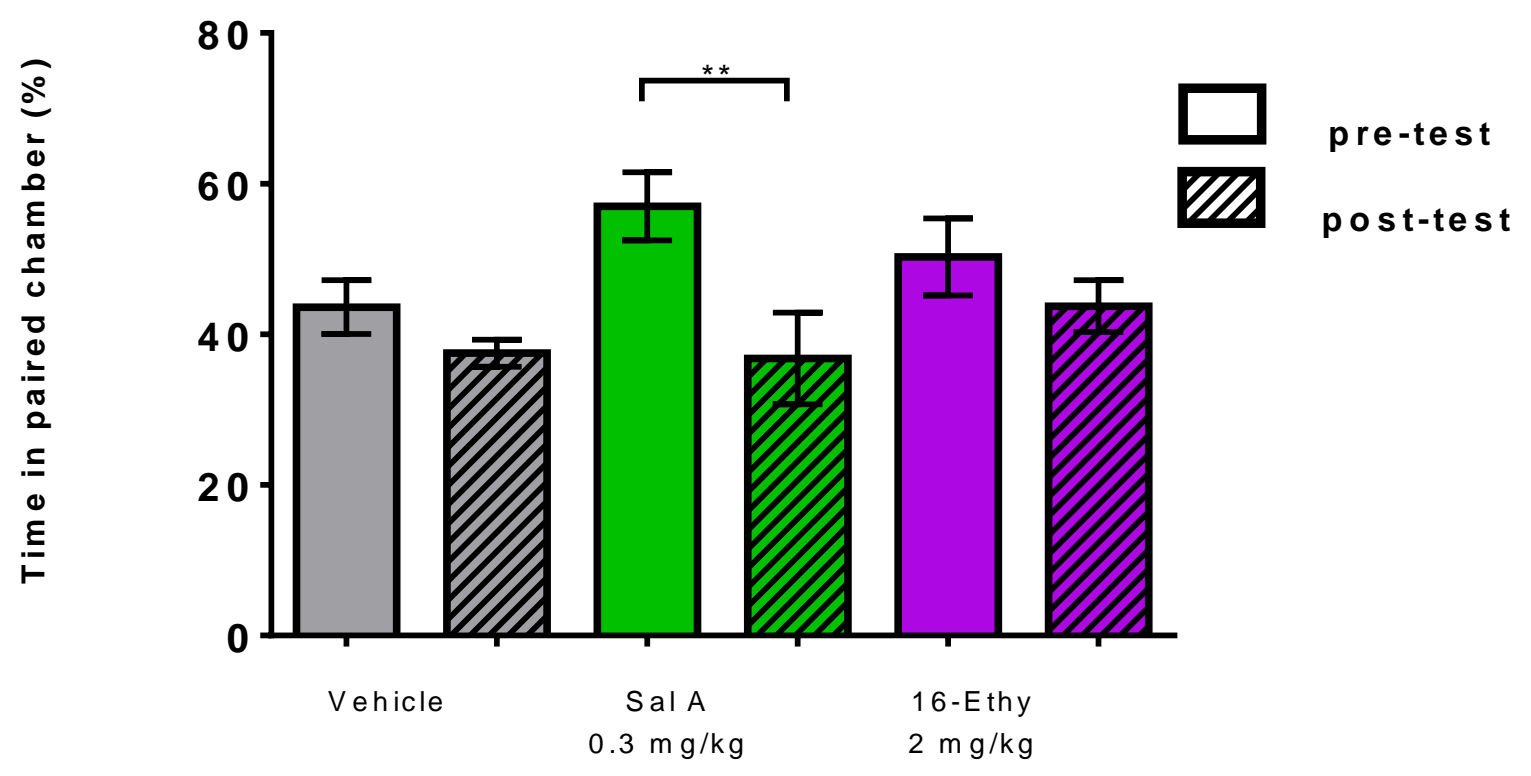

Treatment (dose)

B

Vehicle

Sal A

16-Ethy
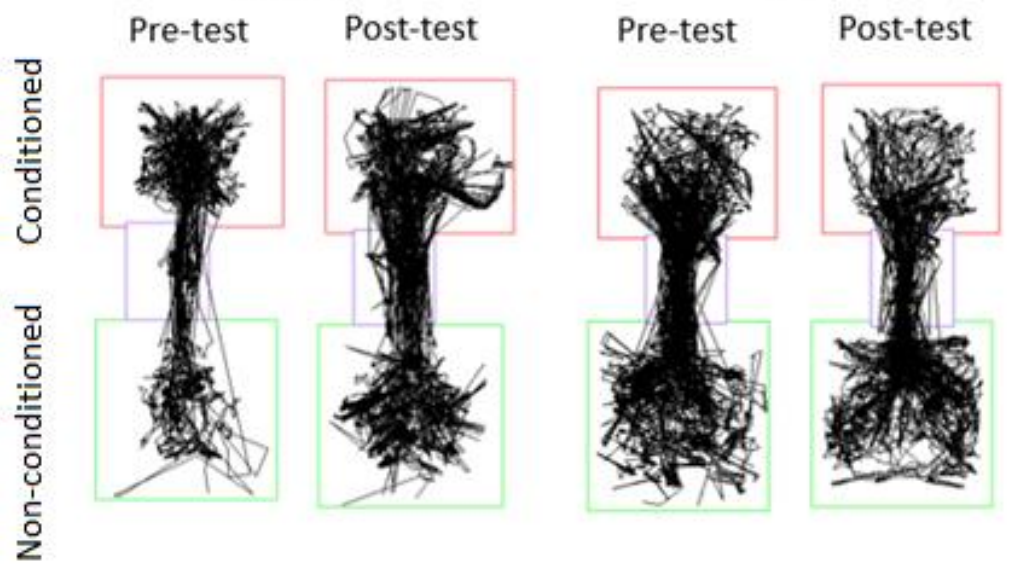

Pre-test

Post-test
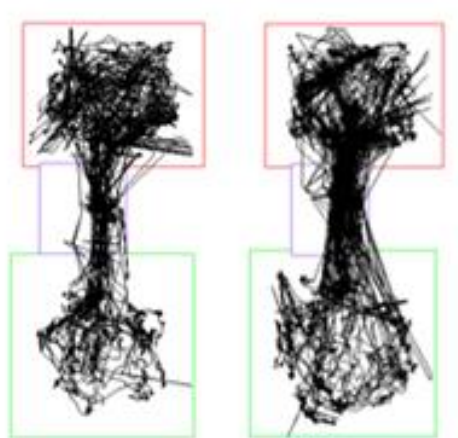

Figure 15: Comparison of time spent in the preferred chamber pre- and post-conditioning

A) Time spent in drug-paired chamber pre- and post-test- 16-Ethy $(2 \mathrm{mg} / \mathrm{kg})$ did not result in a significant reduction in time spent in the initially preferred chamber. Paired Student's t-test $(* * p<0.001),(n=7-11)$.

B) Representative traces of explorative behaviour seen during pre- and post-test. 


\subsection{Behavioural sensitisation to cocaine with acute KOPr treatment}

Repeated exposure to drugs of abuse such as cocaine enhances the motor-stimulant response to the drug. This experiment measured behavioural sensitisation to cocaine following KOPr agonist administration to determine whether KOPr agonists reduce cocaine sensitisation. Sensitisation would be seen if there is a significant increase in ambulatory counts on Day 10 compared to Day 1. This effect should be seen particularly in the cocaine-vehicle treatment group that received cocaine for the first five days, were not administered anything between Days 6 and 9 and then received vehicle pre-treatment prior to one final administration of cocaine on Day 10.

One-way ANOVA analysis of ambulatory counts between treatments, indicated a significant effect of treatments on Day $1[F(3,28)=3.894, p=0.0192]$, however post-test Bonferroni's multiple comparisons revealed no significance of treatments compared to cocaine-vehicle (Figure 16A). One-way ANOVA analysis of ambulatory counts between treatments (cocainevehicle and saline-vehicle or cocaine-16-Ethy and saline-16-Ethy) identified no significance between treatments on Day $10[F(3,28)=1.69 p=0.1918]$. One-way ANOVA analysis of stereotypic counts between treatments, indicated a significant effect of treatments on Day 1 $[\mathrm{F}(3,28)=10.68, \mathrm{p}<0.0001]$ (Figure 16B). Bonferroni post-test multiple comparisons identified a significant reduction in stereotypic counts of saline-vehicle $(p=0.0012)$ and saline-16-Ethy $(p=0.0057)$ treatment groups compared to cocaine-vehicle, but the cocaine16 -Ethy treatment group was not different to cocaine-vehicle ( $p>0.9999)$. One-way ANOVA analysis of stereotypic counts between treatments did not show a significant effect $[F(3,28)$ $=2.884, \mathrm{p}=0.0534]$.

Paired t-tests were used to analyse differences in ambulatory and stereotypic counts within treatment groups between Day 1 and Day 10. Analysis of ambulatory counts within treatments (Figure 16C) identified a significant increase in ambulatory counts in the chronic cocaine-vehicle group on Day 10 (9261 \pm 1170$)$ compared to Day $1(3633 \pm 499.7)[\mathrm{t}(7)=3.89$, $p<0.05]$. Saline-vehicle treated rats also showed significant increase in ambulatory counts on Day 10 (6649 \pm 1887$)$ compared to Day $1(1281 \pm 371.8)$ [t(7) 2.637, $p=0.0336)$. Saline-16Ethy treated rats also showed significant increase in ambulatory counts on Day 10 (3976 \pm 1079) compared to Day $1(1201 \pm 302.8)[t(7)=3.019, p=0.0194]$. Cocaine-16-Ethy did not 
have significant differences between Day 10 (5282 \pm 2449$)$ and Day 1 (4130 \pm 1397$)$, ( $p=$ 0.4001).

Analysis of stereotypic counts between Day 1 vs Day 10 also found significant differences in three of the treatments (Figure 16D); Saline-vehicle Day 10 (12502 \pm 2062 ) vs Day 1 (3765 \pm 939.8) $[t(7)=3.429, p=0.011]$, Saline-16-Ethy Day $10(10431 \pm 1178)$ vs Day $1(4908 \pm 828.5)$ $[t(7)=4.614, p=0.0024]$, Cocaine-vehicle Day 10 (18008 \pm 1462$)$ vs Day 1 (11444 \pm 776.6$)$ $[t(7)=3.89, p=0.0060)$. Cocaine-16-Ethy treated rats did not show any significant difference in stereotypic counts between Day 10 (11576 \pm 2809$)$ vs Day $1(12359 \pm 2261),(p=0.6344)$. 


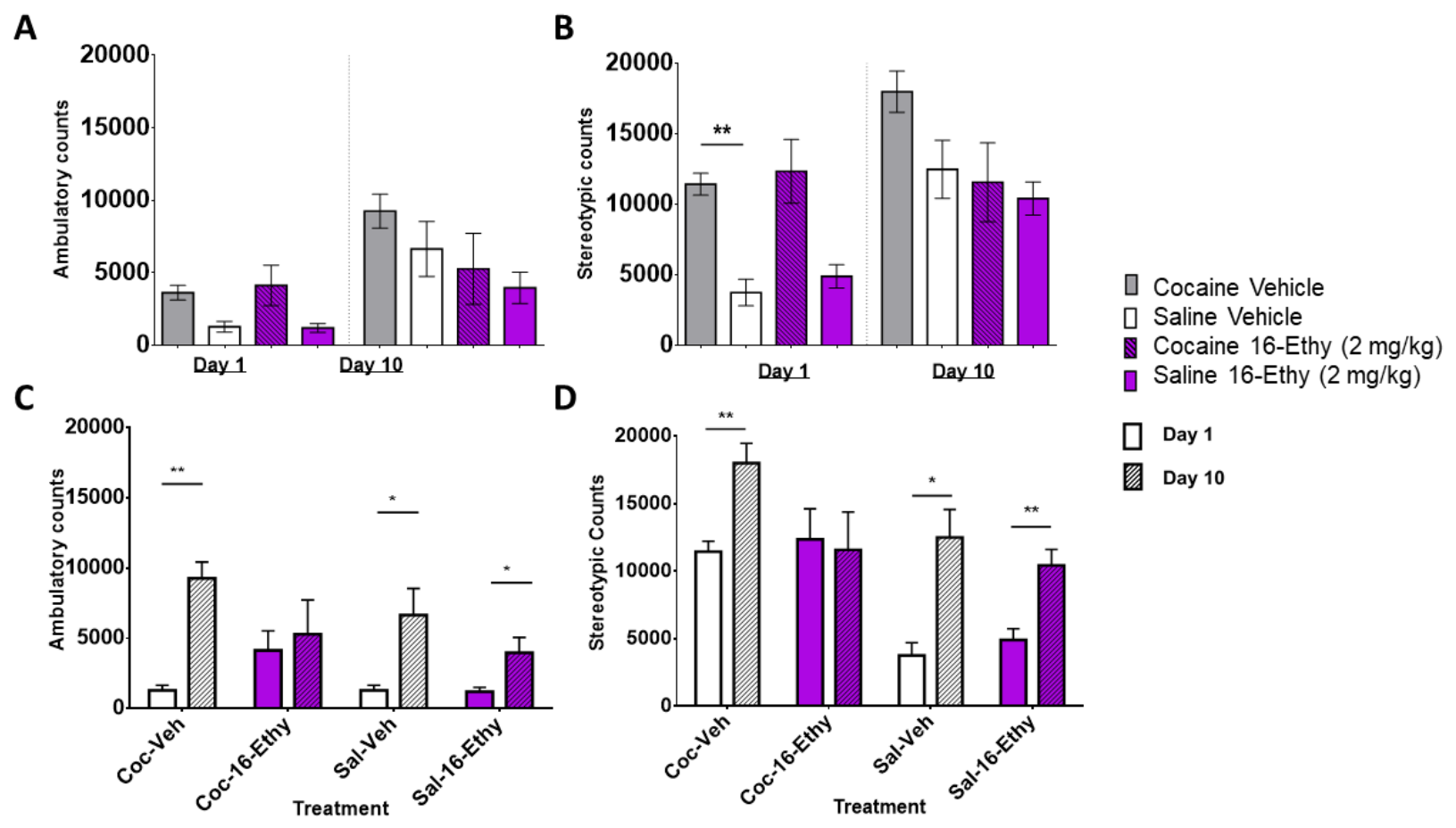

Figure 16: Comparison of locomotor activities recorded on Days 1 and 10 of the cocaine sensitisation experiment.

Rats received either cocaine or saline on Day 1 and pre-treated with 16-Ethy or vehicle before being administered cocaine on Day 10 . There were no significant differences in ambulatory counts in either Day 1 or 10 between treatments (A). Cocaine-vehicle treatment group showed a significant increase in stereotypic behaviour (B) on Day 1 compared to its control group (Saline-vehicle, $\mathrm{p}<0.05$ ). Within-treatment comparisons between Day 1 vs Day 10 identified significant increases in ambulatory (C) and stereotypic counts (D) in three treatments; Cocaine-Vehicle, Sal-Vehicle and Saline-16-Ethy but not Cocaine-16-Ethy. ${ }^{*} p<0.05,{ }^{* *} p<0.001$ (Repeated measures One-way ANOVA, Bonferroni post-test), $(n=8)$. 


\section{Discussion}

Previous research has demonstrated that Sal $A$ and its derivatives show promise in combating addiction. In the Kivell laboratory, 16-Ethy was found to be the most effective Sal A derivative to effectively attenuate cocaine-primed reinstatement at 0.1 and $0.3 \mathrm{mg} / \mathrm{kg}$. This test, a model of drug relapse, determined the effects of a 16-Ethy in interfering with the reinforcing and rewarding effects of cocaine. Since 16-Ethy attenuated drug taking at a lower concentration than Sal A $(0.3 \mathrm{mg} / \mathrm{kg})$, this indicated that 16 -Ethy was more potent. 16-Ethy also attenuated the behavioural motivation to continue drug seeking as seen in the progressive ratio self-administration model at $2 \mathrm{mg} / \mathrm{kg}$ which was not seen in Sal $A$ at the same dose. 16-Ethy is the only Sal A derivative to attenuate drug-seeking in this assay. To test whether 16-Ethy is a better candidate for clinical development than Sal A, a side effect profile needed to be assessed.

At $0.3 \mathrm{mg} / \mathrm{kg}, 16$-Ethy was shown not to have any sedative effects in locomotor activity tests, anxiogenic effects in EPM tests, pro-depressive effects in FST or aversive side effects in the CPA assay (Young., 2015; Culverhouse., 2016). Additionally, 16-Ethy did not show any longterm memory impairment at $0.3 \mathrm{mg} / \mathrm{kg}$, as demonstrated through a novel object recognition task (Welsh., 2017). However, a side effect profile had not been determined for the compound at the higher $2 \mathrm{mg} / \mathrm{kg}$ dose that was able to attenuate drug-seeking in the progressive ratio paradigm. Therefore, this thesis aimed to test the pro-depressive, aversive, anxiogenic and sedative effects of 16-Ethy at $2 \mathrm{mg} / \mathrm{kg}$. 


\subsection{Sedation - Locomotor activity testing}

Open field locomotor tests were used to identify any sedative properties of 16-Ethy at a dose of $2 \mathrm{mg} / \mathrm{kg}$. The sedative properties of a 16-Ethy were identified through ambulatory counts (photobeam breaks) generated from the animal's movements within an open field locomotor chamber. A reduction in ambulatory counts indicates sedative effects. This test was used not only as part of a general side effect profiling for the compound but also to determine whether attenuation of lever responses in self-administration models was as a result of the compound displaying anti-addictive characteristics or if the animal simply was not physically pressing the active lever in a sedated state. Two types of locomotor testing were used in this research, one with a 30 min habituation and one without.

For the habituated locomotor activity test, neither 16-Ethy or Sal A were found to have sedative effects compared to vehicle-treated rats. In fact, Sal A (2 mg/ $\mathrm{kg}$ ) was found to have significantly increased locomotor activity compared to vehicle-treated rats (Figure 11A). This was an interesting result, as previous experiments utilising Sal A ( $2 \mathrm{mg} / \mathrm{kg})$ had shown sedative effects in male Sprague-Dawley rats (Chartoff et al., 2008). Upon looking at the time course for ambulatory counts (Figure 11B), the greatest period of locomotor activity was seen during the first 30 min of the rat being placed in the open field chamber for habituation. Thereafter there was little to no movement observed.

There appeared to be a floor effect following the first $30 \mathrm{~min}$ in the chamber, so any sedative effects of the compound would go undetected. Therefore, another locomotor test was undertaken where the 30 min habituation period was removed and the rat was placed in the chamber after KOPr agonist pre-treatment. This test showed that $16-\mathrm{Ethy}(2 \mathrm{mg} / \mathrm{kg})$ had sedative effects compared to vehicle-treated rats (Figure 12A). Time course data showed that the sedative effect was only seen in the first 5 min (Figure 12B). Time course data showed that Sal A showed sedative effects within the first 5 \& $10 \mathrm{~min}$ following its administration, however, this did not contribute to an overall significant sedative effect compared to vehicletreated rats (Figure 12A).

These findings confirm previous research that indicated that KOPr agonist treatment elicits dose-dependent sedative effects. They do not display significant sedative effects at low doses 
but exhibit the effect at high doses. Sal A has previously shown to have sedative effects at 1 , 2, and $3.2 \mathrm{mg} / \mathrm{kg}$ in mice (Zhang et al., 2005; Chartoff., 2008) however these effects were not seen at low doses in mice or rats (Morani et al., 2012; Carlezon et al., (2006); Braida et al., (2009). Other Sal A analogues such as ethoxymethyl ether Sal B (EOM Sal B), $\beta$ tetrahydropyran Sal B ( $\beta$-THP Sal B) and Mesyl Sal B have all shown to have no significant sedative effects at low doses (0.1, 0.3, $1 \mathrm{mg} / \mathrm{kg}$, i.p) (Ewald et al., 2017; Simonson et al., 2015). Recently, another member of the Kivell laboratory found through rotarod motorcoordination tests, that C57BL/6 mice, administered 16-Ethy $(2 \mathrm{mg} / \mathrm{kg}$ ) had motor incoordination for 30 min following administration indicating sedative effects (unpublished data, Paton, PhD thesis, 2018). 


\subsection{Anxiety - Elevated plus maze}

The EPM was used as a measure of anxiety to measure the anxiogenic properties of KOPr agonists. The longer a rat spent exploring on the open arm of the maze, the less likely it was that the compound was anxiogenic, however, the longer the rat spent in the closed arm, and thereby the shorter the time spent in the open arm, the compound was thought to display anxiogenic properties. Previous research showed that 16 -Ethy at $0.3 \mathrm{mg} / \mathrm{kg}$ caused no change in open arm time in comparison to vehicle-treated rats (Culverhouse., 2016). These experiments show that 16-Ethy, at $2 \mathrm{mg} / \mathrm{kg}$ had no anxiogenic effects (Figure 13). Sal A was also administered at a higher dose of $2 \mathrm{mg} / \mathrm{kg}$ no anxiogenic effects were observed. This corroborates previous findings that highlighted that Sal A displayed anxiogenic effects at a low dose $(0.3 \mathrm{mg} / \mathrm{kg})$ but the same effects were not seen at a higher dose $(1 \mathrm{mg} / \mathrm{kg})$ (Culverhouse., 2016). In substantiation, Sal A $(0.1 \mathrm{mg} / \mathrm{kg}$ ) was shown to have anxiogenic effects but its analogues (EOM Sal B and $\beta$-THP Sal B) at higher doses did not (Ewald et al., 2017).

In contrast, Braida et al. (2009) found that Sal A (0.1-160 $\mu \mathrm{g} / \mathrm{kg}, \mathrm{s.c})$ had anxiolytic effects in the EPM, in male Sprague-Dawley rats. The traditional KOPr agonist U50,488H $(10 \mathrm{mg} / \mathrm{kg})$ has also been shown to have anxiogenic effects in Wistar rats (Gillett et al., 2013). However, previous research from the Kivell laboratory has shown $\mathrm{U} 50,488 \mathrm{H}$ did not effectively induce anxiogenesis in Sprague-Dawley rats (Culverhouse., 2016). The species of the animal has been shown to be important. For example, van der Staay et al. (2009) compared three strains of rats (Brown Norway, Lewis, Fischer 344, and Wistar Kyoto rats) and found that Fischer rats spent the most time in the open arm of the EPM. In contrast, Wistar Kyoto rats were more likely to display pro-depressive and anxiety-like behaviours compared to other strains (van der Staay et al., 2009).

Since $U 50,488 \mathrm{H}$ did not effectively induce anxiogenesis, we chose to use yohimbine, an indole alkaloid with alpha-2-adrenergic blocking activity, because it has previously been shown to reliably induce anxiogenesis at $2.5 \mathrm{mg} / \mathrm{kg}$ behaviour (Pellow et al., 1985). It should be noted that Pellow et al. (1985) conducted their experiments on two other rat strains, male hooded Lister rats and Wister rats. Therefore, we utilised yohimbine as a positive control in this experiment. Yohimbine $(2.5 \mathrm{mg} / \mathrm{kg})$, in this experiment, did not significantly reduce time 
spent in the open arm, however, there was a $43.5 \%$ reduction in time spent on the open arm suggesting a trend towards anxiogenic effects (Figure 13). In previous research, Culverhouse (2016) had used $n=12-29$ rats per treatment in order to find significant results in the same test. This experiment has only used an $n=7-10$, mainly due to time restraints, however, the power of this experiment would have been strengthened with a larger cohort of subjects.

\subsection{Pro-depression - Forced swim test}

The FST was originally developed as a preclinical assay to test for anti-depressant effects of novel drugs (Porsolt et al., 1977), however, some studies used the methodology and repurposed it to examine the pro-depressive effects of compounds (Carlezon et al., 2006; Morani et al., 2012). The test measures an animals mobile (swimming and climbing) and immobile behaviours in a chamber filled with water. An immobile state is thought to approximate more depressive-like behaviour since the animal does not actively try to escape the chamber. This behaviour is regarded as an indicator of behavioural despair. Prodepressive or anti-depressive effects were therefore gauged through the animals' movement within the chamber following KOPr agonist administration.

In this experiment, 16-Ethy at $2 \mathrm{mg} / \mathrm{kg}$ did not significantly increase or decrease immobility, swimming or climbing behaviour in comparison to rats treated with vehicle, indicating that 16-Ethy does not induce pro-depressive effects at a high dose (Figure 14). Likewise, neither EOM Sal B (0.1 and $0.3 \mathrm{mg} / \mathrm{kg}$ ) or $\beta$-THP Sal B (1.0 and $2 \mathrm{mg} / \mathrm{kg}$ ) induced pro-depressive effects (Ewald et al., 2017). However, Mesyl Sal B significantly increased immobility at $0.3 \mathrm{mg} / \mathrm{kg}$ (Kivell et al., 2018). Sal A at $2 \mathrm{mg} / \mathrm{kg}$ also did not show any significant pro-depressive effects when compared to vehicle-treated controls (Figure 14). This was a surprise, as previous studies have shown Sal A dose-dependently $(0.125-2 \mathrm{mg} / \mathrm{kg})$ displayed pro-depressive effects in rats following acute multiple treatments (Carlezon et al., 2006; Chartoff et al., 2010). It was shown that a single acute treatment at of Sal A at $0.3 \mathrm{mg} / \mathrm{kg}$ (Morani et al., 2012) had prodepressive effects. Therefore, it was presumed that Sal A at $2 \mathrm{mg} / \mathrm{kg}$ would show prodepressive effects and thereby act as a positive control in this experiment. When this didn't show pro-depressive effects, another positive control was required. 
Previous research has also shown the traditional KOPr agonist, U50,488H displays prodepressive effects in mice (Zhang et al., 2015). Another member of the Kivell laboratory carried out FST with $\mathrm{U} 50,488 \mathrm{H}(10 \mathrm{mg} / \mathrm{kg}$ ) in male Sprague-Dawley rats, however, the compound did not produce any pro-depressive effects (unpublished data., 2018). To add to the number of subjects and as a preliminary test, I also tried measuring $\mathrm{U} 50,488 \mathrm{H}$ in the FST, however, it did not show any pro-depressive effects when combined with the previous findings. Thus, I decided to not to continue using $\mathrm{U} 50,488 \mathrm{H}$ as it would not have been an appropriate use of animals or cost-effective. Therefore, without a dependable positive control, the reliability of these results are questionable. A possible explanation for the observations found may have to do with the fact that FST was always the last side effect profile paradigms tested. Consequently, all rats used in FST underwent a previous experimental procedure (locomotor activity or EPM) prior to FST and either received KOPr agonist or vehicle treatments for those tests. In comparison, all the rats that underwent FST in studies by both Carlezon et al. (2006) and Morani et al. (2012) were presumed to be experimentally naïve and were KOPr agonist naïve. A point of difference between the studies, however, was that Carlezon et al. (2016) administered 3 injections of Sal A 24 hours prior to testing, as opposed to a single acute administration used in the current FST protocol and by Morani et al. (2012).

The decision to use yohimbine $(2.5 \mathrm{mg} / \mathrm{kg})$ was made following the observation that it showed promising results in EPM. I wanted to test whether yohimbine, which has previously been shown to be anxiogenic, would show anti-depressant like effects since being placed in a water chamber should in theory cause anxiety and therefore increased mobile behaviour. Yohimbine at $2.5 \mathrm{mg} / \mathrm{kg}$ significantly reduced immobile behaviour and significantly increased climbing behaviour, therefore, expressing anti-depressant effects (Figure 14). These results confirmed previous studies which have shown yohimbine to potentiate anti-depressant effects at 2 mg/kg (Dhir A and Kulkarni S.k., 2007; Kawaura et al., 2011).

The major variations from how data in this experiment were analysed and those done previously in our lab was through the implementation of SMART software. In the past, the procedure mandated that each five-minute video was blindly analysed based on three movement types (immobile, swimming and climbing) within every five-second block of time. The use of SMART software allowed for the automation of data analysis. As this was the first 
time this technology was used for the whole experiment, part of this process involved the optimisation of the software to be able to accurately detect each movement (See Appendix 1: Setup and use of SMART software for FST video analysis).

Another factor that could have played a role in the results was the location where the forced swim test took place. Initially the test was conducted in the animal facility, however, when the room had multiple tests with various researchers in the room it became less than ideal to all be there at the same time. Thus for some of the cohorts, the FST was conducted in another room within the laboratory which had its own temperature climate. To allow for acclimatisation the rats were placed in the room at least one hour prior to testing. However, testing had returned to only being conducted within the animal facility, in a less congested part of the room. The final few experiments were done in the new Te Toki A Rata (TTR) building at Victoria University of Wellington.

The main advantage of the FST procedure is its easy operation and fast results. However, it does have some inherent flaws and its validity as a measure of depression has come into question over the years. One of the main issues is the precise meaning of immobility behaviour as an accurate measure and/or reflection of depression (Cryan \& Mombereau., 2004; Cryan, Valentino \& Lucki., 2005). This is important as it's not possible to ascertain behaviourally, if a compound is having pro-depressive effects or whether the animal is simply preserving energy while waiting for a possible escape, particularly if it knows it will be picked out after a time, as was the case during its habituation phase. This was termed learned immobility (De Pablo et al., 1989; Jefferys \& Funder., 1994; West, A.P., 1990). Other tests such as the chronic mild stress model and intracranial self-stimulation models have been looked into as possible substitutes for screening depressive behaviour (Carlezon et al., 2006; Harden et al., 2012).

Finally, for future endeavours in FST, I would advise that a taller cylinder be made. Initially, when first conducting the test it was seen that larger rats were able to rest their tails on the bottom of the water-filled cylinder. This could be a reason why vehicle, Sal A and 16-Ethy treated rats spent more time in immobile and swimming behaviours as opposed to climbing. Rats treated with yohimbine, however, spent more time climbing compared to KOPr agonists, not only because of the effect of the compound but also because they underwent the test 
when they were much younger and smaller. To avoid this, simply make sure that all experimental animals are age and size matched prior to testing. This experiment could also be done at an earlier stage Additionally, the water level was such that smarter rats were able to swim to the bottom and propel themselves to the top lip of the cylinder thus climb out. To mitigate both these problems, the water level was raised five centimetres, this minimised the number of rats that were able to escape therefore fulfilling the tests paradigm of learned despair. However, large rats were still able to reach the bottom of the cylinder with the tips of their tails. 


\subsection{Aversion - Conditioned place aversion}

The CPA paradigm is a measure of the aversive properties of a compound. If an animal spends less time in the drug-paired chamber, then the compound is thought have aversive side effects as the animal has associated the chamber to the compound of interest. However, if the animal spends more time in the drug-paired chamber on test day, then the compound is thought to be rewarding. Vehicle-treated rats show no changes in chamber preference over time. 16-Ethy $(2 \mathrm{mg} / \mathrm{kg}$ ) also showed no changes in time spent in the drug-paired chamber (Figure 15).

Previous research has shown that low doses of 16-Ethy $(0.3 \mathrm{mg} / \mathrm{kg})$, are not aversive using the same testing regime (Culverhouse., 2016). This has also been shown with EOM Sal B (0.1 $\mathrm{mg} / \mathrm{kg}$ ) and Mesyl Sal B $(0.3 \mathrm{mg} / \mathrm{kg})$, but not $\beta$-THP Sal B $(1.0 \mathrm{mg} / \mathrm{kg}$ ) analogues of Sal A (Ewald et al., 2017; Kivell et al., 2018). Compared to every other experimental test undertaken in this thesis, Sal A could not be done at the $2 \mathrm{mg} / \mathrm{kg}$ dose. This was because this experiment was the last to be conducted and was done under a strict time constraint. As such, a decision was made to administer Sal $A$ at a proven aversive dose $(0.3 \mathrm{mg} / \mathrm{kg})$ in a small number of rats and collate the data with that of the previous students (Culverhouse., 2016) so that this experiment could be completed as quickly as possible. Sal A at $0.3 \mathrm{mg} / \mathrm{kg}$, demonstrated aversive behaviour (Figure 15). This experiment did have a small number of subjects per treatment group $(n=7-11)$, increasing the number of subjects would reduce the variance and increase its statistical validity, however, it may not have changed the overall results of this experiment. 


\subsection{Cocaine locomotor effects - Behavioural sensitisation}

The repeated administration of a psychostimulant, such as cocaine results in a progressive amplification of locomotor responses through the process of behavioural locomotor sensitisation. This experiment aimed to evaluate the effects of 16-Ethy on the behavioural sensitisation to cocaine. It was hypothesised that 16-Ethy $(2 \mathrm{mg} / \mathrm{kg})$ would attenuate the behavioural locomotor sensitisation to cocaine, since low doses $(0.3 \mathrm{mg} / \mathrm{kg})$ were shown previously to attenuate the reinforcing and rewarding effects of cocaine in the cocaine-primed reinstatement model, and 16-Ethy attenuated responding at $2 \mathrm{mg} / \mathrm{kg}$ in the progressive ratio paradigm, a measure of motivation to continue drug seeking.

Previous research showed that 16 -Ethy at $0.3 \mathrm{mg} / \mathrm{kg}$ did not significantly attenuate cocaineinduced sensitisation (Young., 2015). This experiment found that rats treated with 16-Ethy at $2 \mathrm{mg} / \mathrm{kg}$, also did not significantly attenuate cocaine sensitisation (Figure 16). There is evidence that the experiment itself did work in that the cocaine and saline-treated rats that received vehicle pre-treatment on test day both displayed statistically significant cocaine sensitisation with a dramatic increase in ambulatory behaviour. However, it is evident that an experimental error occurred during the assigning of treatment groups during Day 1 . Compared to all the other treatment groups which show similar ambulatory behaviour on Day 1, the cocaine-Ethy group displayed much larger ambulatory behaviour (Figure 16C), therefore the validity of these results is in question. One possible reason for this error occurring is simply an error of judgement on my part following the experiment on Day 1. Instead of distributing the results so that all treatment groups had the same average ambulatory behaviour, I assigned those that displayed a higher ambulatory behaviour to the cocaine-Ethy group, thus, producing the difference between treatments on Day 1 . Experimental design, therefore, is an important factor, particularly in this experiment. If I were to carry out this experiment again, I would recommend that following Day 1 testing, to get the results randomised by someone else, therefore it would eliminate any bias or accidental groupings. This experiment had an $n=8$ rats per treatment group, and this did show statistical significance, however increasing the number of rats per treatment group would be beneficial in strengthening the statistical significance of the data. 


\subsection{Reward - Self-administration}

The rodent self-administration model is one of the most widely used and established methodologies to study the rewarding properties of drugs of abuse and thought to be the best model of drug-taking behaviour in a laboratory setting. Previous research has shown KOPr agonists having the ability to attenuate drug-primed reinstatement of drug-seeking (Ewald et al., 2018; Morani et al., 2009; Riley et al., 2014; Schenk et al., 1999). David Young (2015) conducted initial research into 16-Ethy and found that the compound significantly attenuated cocaine-reinstatement of drug-seeking behaviour ( 0.1 and $0.3 \mathrm{mg} / \mathrm{kg}$ ). However, 16-Ethy was also the only Sal A derivative to be able to effectively attenuate the motivation to continue drug seeking in the progressive ratio paradigm at a higher dose of $2 \mathrm{mg} / \mathrm{kg}$. Therefore, this experiment aimed to test the effects of 16-Ethy on rats that self-administered cocaine. It was hypothesised that 16-Ethy at $2 \mathrm{mg} / \mathrm{kg}$ would attenuate self-administration.

However, I could not get this experimental protocol to work consistently to enable evaluation of test drugs. There are myriad of variables and scenarios that could have led to this. This experiment was conducted in three distinct stages. The first stage of the experiment began in December 2016 and ended in March 2017. During this period, I followed the protocols used in David Young's Master's thesis for self-administration where during the training phase, rats were given five consecutive days to self-administer cocaine followed by two rest days. However, this did not seem to provide the same learned acquisition of self-administration seen by previous members of the Kivell laboratory.

One reason why the trained behaviour may not have worked during this period of time, and ultimately the subsequent times, was because of a large amount of experimenter stress. Due to the circumstances at the time, the experiment was conducted at night, and often finished in the early hours of the morning, however, it would have been ideal if the experiment was conducted during daylight hours. This was corrected in the subsequent trials. Experimenter stress could not be understated in animal behavioural work (Bolan et al., 2014) and may well have been the greatest barrier to successful self-administration. In addition to this, it was found that exposure to male but not female experimenters can cause rodents stress, therefore, despite adequate handling, there still remains an inherent predisposition to stress that could alter baseline responses (Sorge et al., 2014). 
During the first two stages of the experiments, headpieces used to tether rats onto the swivel that administered the drug intravenously, often came off. This lead to more rats having to be used and subsequently trained in the self-administration paradigm every time one was lost. All surgeries were graciously done by Diana Atigari, however, since I was not able to confidently complete surgeries independently, this did cause delays in when initial and secondary surgeries could be undertaken if the patency of the i.v. cannula was compromised by a leak or there was a blockage to the headpiece itself. It should be noted that in the beginning, a couple of rats had previously been used by Diana Atigari, and they still had patent lines for a long period, however, they were large and probably should not have been used after a certain point.

The second stage of the experiment began in May 2017 and ended in October 2017. It was clear that five days of self-administration with a two day rest period was not producing the desired learned behaviour. With a recommendation from my supervisor, I tried the experiment again, but this time adopting six days a week for self-administration training schedule with a one-day break, therefore the animal would be more likely to retain the behaviour by not having two consecutive rest days as before. During this time, more animals did graduate past the self-administration training phase and underwent the cocaine doseresponse paradigm.

However, the criteria for the dose-response proved to be one of the major hurdles during this period. The criteria included that the rats had to receive at least $10 \mathrm{mg} / \mathrm{kg}$ cocaine infusions per session, with $10 \%$ variation for 3 consecutive days or $20 \%$ variation for 2 days. Additionally, a fivefold increase in maximal response rates when compared to extinction responses. Throughout this experiment, the most difficult task across all three stages was trying to get the rats to respond to an adequate level so that the criteria would be met. However, more often than not, at least two of the three criteria would be met but not the third. This caused a lot of frustration as being a little lenient may have produced some results, however, I am confident that on my part, the protocol was strictly adhered to.

The final stage began in October 2017 and ended in January 2018. Despite the failure of the previous two attempts, with my supervisor's recommendation, we decided to give selfadministration one last try, since daily access to cocaine should have been addictive. This time 
though, we adopted a novel approach to self-administration by using a new delivery system, in this thesis termed as the backpack system. This methodology used because the headpiece delivery system from the previous two attempts was not reliable. Many headpieces came off and the process of putting them on was procedurally difficult and also highly stress-inducing, particularly during surgeries when a nerve could be hit and the whole animal moved despite being anaesthetised. This new delivery system avoided the head completely and involved placing a vascular access port termed the 'button' just behind the shoulder blades of the rats. This was a completely closed system loop which should have ensured that the patency of the i.v catheter remained viable for longer.

There were some differences compared to the headpiece system in testing for the patency of the catheter line. In the headpiece delivery system, blood would be drawn up through the line to test for patency, if no bloodline was observed then $0.15 \mathrm{~mL}$ of $50 \mathrm{mg} / \mathrm{kg}$ pentobarbital was flushed through. If the animal did not immediately experience sedation, this indicated the presence of a leak in the system. With the backpack system, however, nothing could be drawn back to test for the patency of the line, the pentobarbital was flushed directly in and its sedative effects were observed. The old headpiece delivery system had problems where I would have to replace the Tygon tubing within the tether attached to the rat when they broke. This would occur multiple times and since the equipment was antiquated, it was difficult to find replacements for the springs. However, when the tubing broke, it was easy to replace. This was not the case with the backpack system. The springs on the tethers were firmly attached to the tethered plug and the tubing, when damaged were not able to be replaced without dismantling the whole tether and thereby damaging it. Since the springs were so taut, when rats moved around within the chamber, in a matter of a minute, they could twist this tether, the torque of which completely dislodge the spring from the button, damaging both the spring and the tubing within it. Rats had to, therefore, be observed every 5 min throughout the 4-5 hour experiment.

The greatest obstacle that undermined the third attempt at self-administration was a complete upheaval and migration of the science faculty from the New Kirk building at Victoria University of Wellington to the newly constructed TTR building. There were large-scale disruptions throughout the building and our previous laboratory. Disruptions included the packing up of the surrounding laboratories, moving contractors, the removal of large 
equipment and the disassembly of structural components of the laboratory, such as walls and doors of neighbouring rooms, using loud machinery. The self-administration was already a sensitive paradigm, and small noise disruptions could be masked using white noise, however, this was not enough to mask the noise beyond the door of the animal room. The relocation of our laboratory equipment occurred during November and December 2017. On 31 January 2018, my supervisor and I determined that it was no longer feasible or practical to continue with my experiment. 


\subsection{Summary and future directions}

This thesis has explored the side effect profile of 16-Ethy at $2 \mathrm{mg} / \mathrm{kg}$. 16-Ethy was found to display sedative effects in non-habituated locomotor activity but not in a habituated paradigm. Compared to vehicle-treated rats, 16-Ethy $(2 \mathrm{mg} / \mathrm{kg})$ did not display prodepressive, anxiogenic or aversive properties, and did not attenuate cocaine sensitisation. Despite this, 16-Ethy still has shown promise as pharmacotherapy against drug addiction in previous research at low does.

However, the greatest missing piece of information required to further develop 16-Ethy as a pharmacotherapy was the effects on cocaine self-administration. 16-Ethy previously had demonstrated to be a more potent KOPr agonist at attenuating drug-seeking behaviours and motivation to continue drug seeking through self-administration at a low dose $(0.3 \mathrm{mg} / \mathrm{kg})$ compared to Sal A. The goal was to determine if 16-Ethy would also display similar effects at a high dose of $2 \mathrm{mg} / \mathrm{kg}$. The cocaine dose-response experiment would have not only demonstrated 16-Ethy's effect on cocaine self-administration (attenuation would move the whole curve down), it would have also highlighted what dose of cocaine that animals best responded to, which would have been vital in future experimentation.

This research could not get the experiment to work and so undertaking another selfadministration experiment would be the most important future direction to pursue. The facilities in the new TTR building should make the process far easier, for example having an overhead red light to illuminate the room whilst changing doses would be far more beneficial to the experimenter. As a recommendation, the backpack system should be the delivery system to use over the headpiece system as it is much easier for the animal and the experimenter doing the surgery. I would also recommend new equipment pieces such as swivels, as the previous ones were very old. Ultimately though, the results of a selfadministration experiment and any animal behavioural work rests on the state of the experimenter. The animals are easily affected by the stress of the experimenter. To mitigate stress in animals, handle them for at least three days prior to beginning each experiment. There was good virtue in continuing to pursue the self-administration experiment, however, during research, some things do not work out. The hypothesis still remains, that 16 -Ethy at 2 $\mathrm{mg} / \mathrm{kg}$ could attenuate cocaine self-administration, however, this remains to be pursued. 


\section{Supplementary information}

\section{Appendix 1: Setup and use of SMART software for FST video analysis}

Convert video files from camera (.AVCHD format) to .AVI files - this can be done through any online converter

Open SMART $\rightarrow$ on the pop up choose FST experiment $\rightarrow$ click experiment info $\rightarrow$ image source $\rightarrow$ single image source $\rightarrow$ digital video file

The following are the setting you alter on each tab in the ribbon user bar on the top of the screen

Calibration - here you are optimising the area of video tracking - it take a screenshot of your chose video and you use the scrollers to define area to be analysed (liek cropping the image). $\rightarrow$ move scrollers to the sides, top and bottom of the FST cylinder

Horizontal $=20 \mathrm{~cm}$

Vertical $=40.5 \mathrm{~cm}$

Keep the above values constant for all videos $\rightarrow$ you have to do this for each video that you analyse.

Arenas $\rightarrow$ leave as is

Zone definitions $\rightarrow$ drag red box and match it (superimpose) to the dimensions of the FST cylinder $\rightarrow$ click save icon $\rightarrow$ save as side view $\rightarrow$ close

Do the above 3 steps for each individual video

Detection settings $\rightarrow$ don't touch the setting on the left hand side $\rightarrow$ set threshold to 60 and accept

Time settings $\rightarrow$ play the video in the small playback window till you have place the rat in the FST cylinder and your hand and body is out of the video shot $\rightarrow$ then press "get from video" this is the starting point from where you video analysis will begin

Click preset time $\rightarrow$ Aquisition to 00:05:00:00 (this is the 5 minute run time of the test for analysis) $\rightarrow$ accept

Subjects $\rightarrow$ double click $\rightarrow$ enter details of the rat used in video e.g. type of treatment and rat number $\rightarrow$ accept

Then you can press the tiny green cross symbol and add all the details for each subsequent FST video that you will be analysing e.g. each rat number and their treatments

Scheduler $\rightarrow$ click appropriate experimental subject of the video (for analysis) then press the double green arrow and add to session (to delete the subject, click it and press delete)

The settings for Subjects, Scheduler and Data Acquisition remains the same for all videos that you analyse. 
Data Acquisition settings - this is perhaps the most important setting as you optimise each threshold to capture low and high activity. Based on previous videos below are the best settings but the thresholds can be changed based on sensitivity to the activities of your subjects.

Low activity threshold $=90.6$

High activity threshold $=220.3$

Activity smoothing $=0.0$

Click apply to all videos and save as default (you can also have this window pop up as your videos play so you can make sure the correct activities are being captured - it will show as a percentage and also show spikes with each activity being displayed in real time

Click Start on the time control window and tick the "in real time" box

After video analysis

Close of the boxes and click Run all trials $\rightarrow$ then "analysis" box - click analyse and then reports

You can export all the data as an excel file $\rightarrow$ ultimately all you need is the duration total for each video of subjects (measured in seconds) and the movement type (high or low activity) 


\section{Appendix 2: Chemicals and solutions for self-administration}

Reagents used for surgeries were purchased from Provet (Auckland, New Zealand). Pentobarbital $(500 \mathrm{mg} / \mathrm{mL})$, xylazine $(20 \mathrm{mg} / \mathrm{mL})$, ketamine $(100 \mathrm{mg} / \mathrm{mL})$, carprofen $(50$ $\mathrm{mg} / \mathrm{mL}$ ), terramycin powder, sodium lactate solution, Vetadine (1.6\% iodine, $\mathrm{w} / \mathrm{v}$ ), heparin $(5,000$ unit $/ \mathrm{mL})$ and penicillin $\mathrm{G}$ sodium $(1,000,000 \mathrm{IU})$. Sterile and filtered $0.9 \%$ saline $(0.9 \%$ $\mathrm{NaCl}, \mathrm{w} / \mathrm{v}$ ) was used to dilute all the stock solutions to appropriate working concentrations.

In order to make 30 unit $/ \mathrm{mL}$ and 3 unit $/ \mathrm{mL}$, heparin solutions, the 1000 unit $/ \mathrm{mL}$ stock solution of heparin was diluted in sterile $0.9 \%$ saline, the solution being filtered prior to use.

The working concentration for carprofen is $5 \mathrm{mg} / \mathrm{mL}$ and pentobarbital is $50 \mathrm{mg} / \mathrm{mL}$.

The penicillin/heparin solution used for flushing catheters was made by dissolving penicillin powder in 30 unit/mL to produce 100,000 unit/mL solution.

Heparinized cocaine solution that is used for self-administration tests was produced by dissolving cocaine hydrochloride (BDG Synthesis, Wellington, NZ) in $0.9 \%$ saline solution that contains 3 unit $/ \mathrm{mL}$ heparin to yield a final solution concentration of $1.65 \mathrm{~g} / \mathrm{L}$. To make a 20 $\mathrm{mg} / \mathrm{mL}$ solution used for cocaine-primed injections, cocaine hydrochloride was dissolved in $0.9 \%$ saline solution. 


\section{Appendix 3: Catheter preparation for surgery}

Catheters used for self-administration testing are prepared in advance to the surgery (at least two days to allow for the silicone to dry). using a handheld rotary sander (Dremel 3000) 22 gauge BD needles are (Becton Dickinson Ltd., NZ Auckland, New Zealand) are cut and blunted to a $3 \mathrm{~cm}$ length after which, it is rinsed thoroughly with $70 \%$ to remove any metal particulates due to the sanding. the metal piece is then inserted into a piece of silastic tubing $(0.5 \times 0.9$ $\mathrm{mm} \mathrm{ID,} \mathrm{C-P96115-02)} \mathrm{so} \mathrm{that} \mathrm{half} \mathrm{of} \mathrm{the} \mathrm{metal} \mathrm{is} \mathrm{covered.} \mathrm{Another} \mathrm{rinse} \mathrm{of} 70 \%$ ethanol is pushed through the catheter and then left to dry. Once dry a thin smooth layer of silicone is applied to the catheter, this is allowed to dry for at least 24 hours and then another coat of silicone is applied. After the final coat of silicone has been allowed to dry, a small silicone ball is added to the venous end of the catheter by rotating and pulling up some silicon from a blob of it. This silicone ball is on the opposite end of the metal end of the catheter and will act as an anchor for the catheter once it is inserted into the vein. The tubing is cut in an angle $4 \mathrm{~cm}$ down from the silicone ball, and this angled end is what gets inserted into the vein. 


\section{Appendix 4: Self-administration intra-jugular surgery (Headpiece system)}

Prior to surgery rats weighing 300-350 g were handled for at least three days. On the day of the surgery, the anaesthetized with a 2:1 ketamine/xylazine solution (90 and $9 \mathrm{mg} / \mathrm{kg}$; Provet NZ Pty. Ltd., Auckland, New Zealand) administered through intraperitoneal injection (i.p). The indicator that the rat is adequately anaesthetized is when the animal is completely limp and there is no kickback reflex when a strong pinching stimulus is applied to its hind foot. The rat is the subcutaneously injected (s.c) with the painkiller, Carprofen (5mg/kg; Provet, New Zealand). The right side of the chest (between the right arm and the neck) and the crown of the head (midline from the ears to just above the eyes) were shaved and the skin was cleaned using Vetadine (1.6\% iodine w/v: Provet, New Zealand) and $70 \%$ ethanol. Lacrilube (Provet, New Zealand) was swabbed onto each eye using a cotton swab to minimise the effect of the eyes drying out during the procedure.

A small incision is made directly above the right jugular vein (identified by throbbing through the skin) and the incision and underlying tissue is gently pulled apart to reveal the vein using scissors. Once the vein has been located, it is securely tied off using suture wire at the top end of the vein. A hole is cut through the skin at the back of the head and using scissors to create a gap subcutaneously, the catheter tube is manoeuvred behind the ear and around the neck to the exposed jugular vein. A small incision is made on the vein and after cutting the catheter tube on an angle, the tube is fed into the vein to a depth of approximately $4 \mathrm{~cm}$. Using the silicone ball as an anchor, the catheter is secured in the vein by tying it using suture wire. The patency of the catheter was tested by flushing 3 unit/mL heparin solution from a $1 \mathrm{~mL}$ syringe which was attached to the metal piece of the catheter and drawing back a little blood into the tubing, after which the metal end was capped using a closed-ended piece of tubing.

A long sagittal cut was made on the top of the head running from the midline where the ears are to just above the eyes in one motion using the scalpel down to the bone. The exposed skin and tissue was scraped away and the surface was rubbed with Terramycin powder to dry the bone and stop the bleeding. The head of the rat is then secured in a stereotaxic restraining device and four small holes were drilled into the skull in the four quadrants. Four jewellers 
screws were threaded into each hole but leaving a $2-3 \mathrm{~mm}$ gap between the head of the screw and the skull. The metal end of the catheter was placed sagittally in between the screws, with a portion of the metal end bent upwards at an angle (45-90 degrees from the skull). A slurry of Ostron liquid and Ostron (Henry Schein Shalfoon, Auckland, New Zealand) was put on top to secure the catheter, after which a larger upturned screw was placed behind the metal catheter end and secured with additional Ostron slurry. Once the Ostron dries it forms a hard acrylic resin headpiece. The chest and head wounds were sealed with superglue and Terramycin on top. To replace electrolytes lost during the surgery, $10 \mathrm{~mL}$ of sodium lactate solution (Provet, New Zealand) was injected s.c. into the hind flank of the rat (5 $\mathrm{mL}$ each side). 


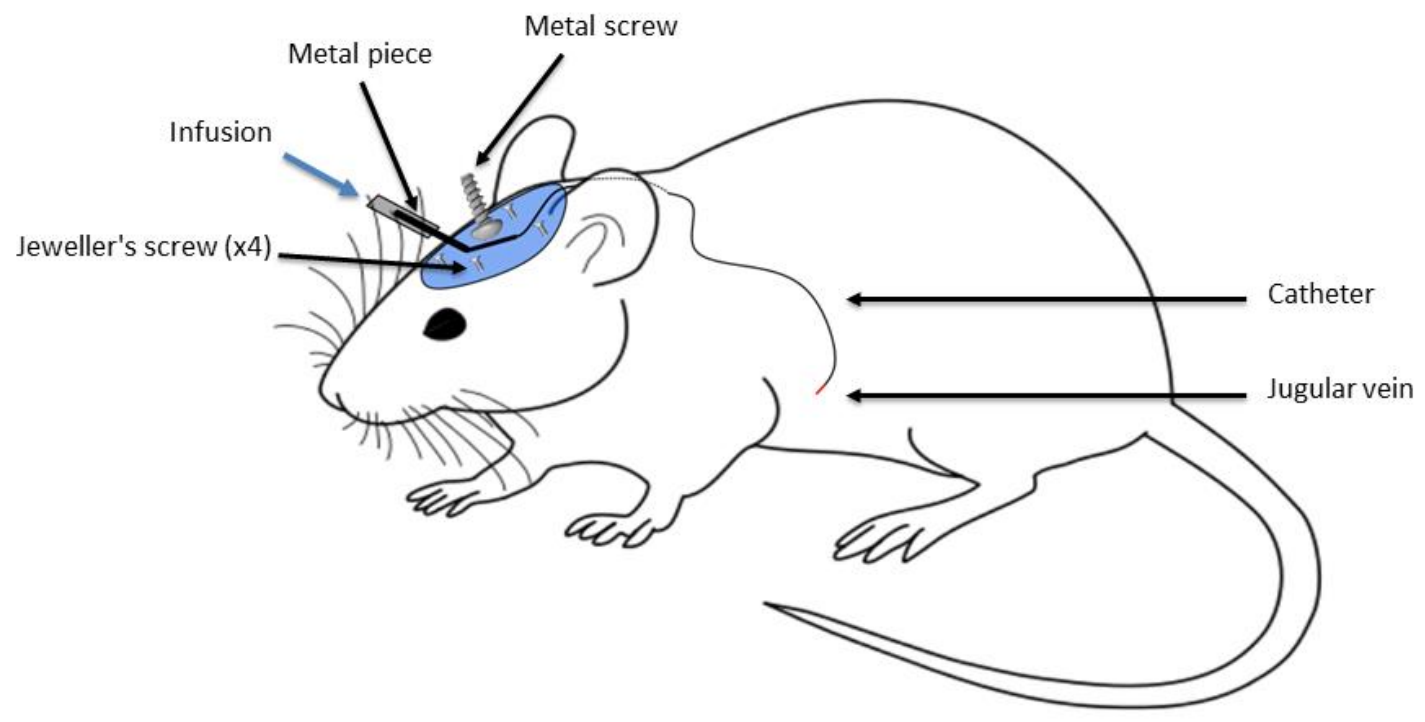

Figure 17: The headpiece system

Schematic of the placement of the headpiece and catheter for intravenous selfadministration. 


\section{Appendix 5: Self-administration intra-jugular surgery (Backpack system)}

Prior to surgery rats weighing 300-350 g were handled for at least three days. On the day of the surgery, the anaesthetized with a 2:1 ketamine/xylazine solution (90 and $9 \mathrm{mg} / \mathrm{kg}$; Provet NZ Pty. Ltd., Auckland, New Zealand) administered through intraperitoneal injection (i.p). The indicator that the rat is adequately anaesthetized is when the animal is completely limp and there is no kickback reflex when a strong pinching stimulus is applied to its hind foot. The rat is the subcutaneously injected (s.c) with the painkiller, Carprofen (5mg/kg; Provet, New Zealand).

The right side of the chest (between the right arm and the neck) and the mid-scapular region of the back (behind the shoulder blades) were shaved and the skin was cleaned using Vetadine (1.6\% iodine w/v: Provet, New Zealand) and 70\% ethanol. Lacrilube (Provet, New Zealand) was swabbed onto each eye using a cotton swab to minimise the effect of the eyes drying out during the procedure.

A small incision was made directly above the right jugular vein (identified by throbbing through the skin) and the incision and underlying tissue was gently pulled apart to reveal the vein using scissors. Once the vein has been located, it is securely tied off using suture wire at the top end of the vein. A hole was cut through the skin behind the shoulder blades. Using scissors, subcutaneous tissue is gently teased away to create a gap from the cut on the back to the incision at the vein, the catheter tube is then manoeuvred from the back to the incision above the right jugular vein. Ensure that the tubing is $4-5 \mathrm{~cm}$ extra-long to create a stress loop under the skin. A small incision was made on the vein and after cutting the catheter tube on an angle, the tube was fed into the vein to a depth of approximately $4 \mathrm{~cm}$. Using the silicone ball as an anchor, the catheter was secured in the vein by tying it using suture wire. The patency of the catheter was tested by flushing 3 unit/mL heparin solution from a $1 \mathrm{~mL}$ syringe which was attached to the metal piece of the catheter and drawing back a little blood into the tubing.

The vascular access port (VAB958S, Instech Labs) was soaked in sterile $0.9 \%$ saline to soften the felt portion of the port. Flush a small amount of saline through the port to eliminate any air. After the patency test, attach the tubing to the subcutaneous catheter attachment. The 
felt portion of the port was tucked under this skin of the incision on the back. Using forceps bring both sides of the incision together so that the felt is covered, then superglue the skin together.

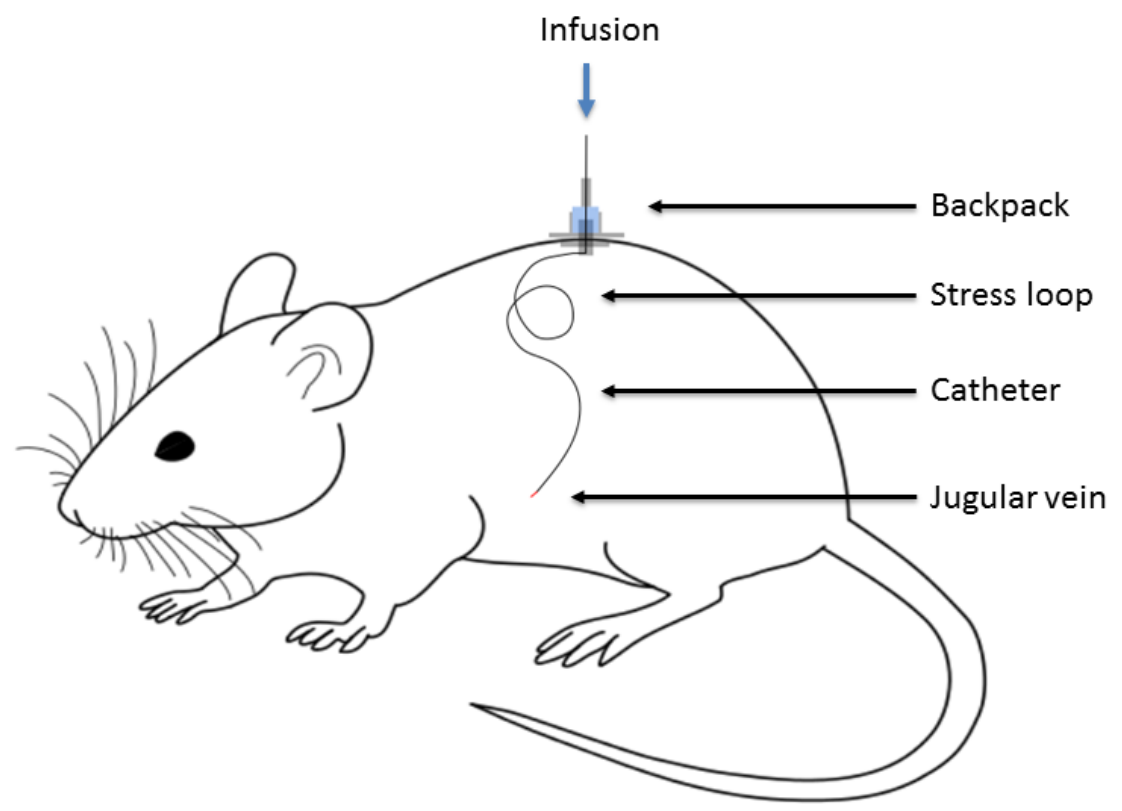

Figure 18: The backpack system

Schematic of the placement of the backpack and catheter for intravenous self-administration. 


\section{Appendix 6: Balanced Latin square design}

\begin{tabular}{|c|c|c|c|c|}
\hline Rat & $A$ & B & $\mathrm{C}$ & $\mathrm{D}$ \\
\hline 1 & Sal A (2 mg/kg) & $\begin{array}{l}\text { Yohimbine } \\
(2.5 \mathrm{mg} / \mathrm{kg})\end{array}$ & 16-Ethy (2 mg/kg) & Vehicle \\
\hline 2 & $\begin{array}{l}\text { Yohimbine } \\
(2.5 \mathrm{mg} / \mathrm{kg})\end{array}$ & 16-Ethy (2 mg/kg) & Vehicle & Sal A (2 mg/kg) \\
\hline 3 & $\begin{array}{c}\text { 16-Ethy (2 } \\
\mathrm{mg} / \mathrm{kg})\end{array}$ & Vehicle & Sal A (2 mg/kg) & $\begin{array}{l}\text { Yohimbine } \\
(2.5 \mathrm{mg} / \mathrm{kg})\end{array}$ \\
\hline 4 & Vehicle & Sal A & $\begin{array}{l}\text { Yohimbine } \\
(2.5 \mathrm{mg} / \mathrm{kg})\end{array}$ & 16-Ethy (2 mg/kg) \\
\hline 5 & Sal A (2 mg/kg) & $\begin{array}{l}\text { Yohimbine } \\
(2.5 \mathrm{mg} / \mathrm{kg})\end{array}$ & 16-Ethy (2 mg/kg) & Vehicle \\
\hline 6 & $\begin{array}{l}\text { Yohimbine } \\
(2.5 \mathrm{mg} / \mathrm{kg})\end{array}$ & 16-Ethy (2 mg/kg) & Vehicle & Sal A (2 mg/kg) \\
\hline 7 & $\begin{array}{c}\text { 16-Ethy (2 } \\
\mathrm{mg} / \mathrm{kg})\end{array}$ & Vehicle & Sal A (2 mg/kg) & $\begin{array}{l}\text { Yohimbine } \\
(2.5 \mathrm{mg} / \mathrm{kg})\end{array}$ \\
\hline 8 & Vehicle & Sal A & $\begin{array}{l}\text { Yohimbine } \\
(2.5 \mathrm{mg} / \mathrm{kg})\end{array}$ & 16-Ethy (2 mg/kg) \\
\hline
\end{tabular}

Table 4: Latin Square Design

Subjects that underwent multiple experiments (Locomotor activity, FST, EPM) and received multiple treatments were administered their treatments according to a Latin square design. All rats received all treatments. Between experiments/treatments a rest period of one week was provided to minimise carry over effects between treatments. 


\section{References}

Adamson, S. J., Deering, D. E., Sellman, J. D., Sheridan, J., Henderson, C., Robertson, R., . . Frampton, C. M. (2012). An estimation of the prevalence of opioid dependence in New Zealand. Int J Drug Policy, 23(1), 87-89. doi:10.1016/j.drugpo.2011.05.013

Akuta, N., Kumada, H., Fujiyama, S., Kawamura, Y., Sezaki, H., Hosaka, T., . . Ikeda, K. (2018). Recurrence rates of pruritus after the stop of nalfurafine hydrochloride in chronic liver disease: Preliminary prospective confirmatory trial. Hepatol Res, 48(10), 810-813. doi:10.1111/hepr.13075

Al-Hasani, R., McCall, Jordan G., Shin, G., Gomez, Adrian M., Schmitz, Gavin P., Bernardi, Julio M., . . . Bruchas, Michael R. (2015). Distinct Subpopulations of Nucleus Accumbens Dynorphin Neurons Drive Aversion and Reward. Neuron, 87, 1063-1077. doi:10.1016/j.neuron.2015.08.019

Bals-Kubik, R., Ableitner, A., Herz, A., \& Shippenberg, T. S. (1993). Neuroanatomical sites mediating the motivational effects of opioids as mapped by the conditioned place preference paradigm in rats. J Pharmacol Exp Ther, 264, 489-495.

Balster, R. L. (1991). Drug abuse potential evaluation in animals. British journal of addiction, 86, 1549-1558.

Beardsley, P. M., Howard, J. L., Shelton, K. L., \& Carroll, F. I. (2005). Differential effects of the novel kappa opioid receptor antagonist, JDTic, on reinstatement of cocaine-seeking induced by footshock stressors vs cocaine primes and its antidepressant-like effects in rats. Psychopharmacology, 183, 118-126. doi:10.1007/s00213-005-0167-4

Beguin, C., Potter, D. N., DiNieri, J. A., Munro, T. A., Richards, M. R., Paine, T. A., . . Cohen, B. M. (2007). N-Methylacetamide Analog of Salvinorin A: A Highly Potent and Selective -Opioid Receptor Agonist with Oral Efficacy. Journal of Pharmacology and Experimental Therapeutics, 324, 188-195. doi:10.1124/jpet.107.129023

Beguin, C., Richards, M. R., Wang, Y., Chen, Y., Liu-Chen, L. Y., Ma, Z., . . Cohen, B. M. (2005). Synthesis and in vitro pharmacological evaluation of salvinorin $A$ analogues modified at C(2). Bioorg Med Chem Lett, 15(11), 2761-2765. doi:10.1016/j.bmcl.2005.03.113

Belcheva, M. M., Clark, A. L., Haas, P. D., Serna, J. S., Hahn, J. W., Kiss, A., \& Coscia, C. J. (2005). $\mu$ and $\kappa$ Opioid Receptors Activate ERK/MAPK via Different Protein Kinase $C$ Isoforms and Secondary Messengers in Astrocytes. Journal of Biological Chemistry, 280, 27662-27669. doi:10.1074/jbc.M502593200

Benoit-Marand, M., Ballion, B., Borrelli, E., Boraud, T., \& Gonon, F. (2011). Inhibition of dopamine uptake by D2 antagonists: an in vivo study. Journal of Neurochemistry, 116, 449-458. doi:10.1111/j.1471-4159.2010.07125.x

Bera, I., \& Ghoshal, N. (2014). Positively Charged Nitrogen is Not Indispensable Requirement for Binding of Nitrogenous K-Opioid Agonists: Insights from Docking Studies. Letters in Drug Design \& Discovery., 11.

Berterame, S., Erthal, J., Thomas, J., Fellner, S., Vosse, B., Clare, P., . . Mattick, R. P. (2016). Use of and barriers to access to opioid analgesics: a worldwide, regional, and national study. The Lancet, 387, 1644-1656. doi:10.1016/S0140-6736(16)00161-6

Bohlen, M., Hayes, E. R., Bohlen, B., Bailoo, J. D., Crabbe, J. C., \& Wahlsten, D. (2014). Experimenter effects on behavioral test scores of eight inbred mouse strains under the influence of ethanol. Behavioural brain research, 272, 46-54.

doi:10.1016/j.bbr.2014.06.017 
Bolan, E. A., Kivell, B., Jaligam, V., Oz, M., Jayanthi, L. D., Han, Y., ... Shippenberg, T. S. (2007). D2 Receptors Regulate Dopamine Transporter Function via an Extracellular Signal-Regulated Kinases 1 and 2-Dependent and Phosphoinositide 3 KinaseIndependent Mechanism. Molecular Pharmacology, 71, 1222-1232. doi:10.1124/mol.106.027763

Bosch, P. J. (2013). The preclinical study of methamphetamine self-administration and the underlying molecular biology and proteomics changes in the reward system. (Doctor of Philospophy). In.

Bossert, J. M., Marchant, N. J., Calu, D. J., \& Shaham, Y. (2013). The reinstatement model of drug relapse: recent neurobiological findings, emerging research topics, and translational research. Psychopharmacology, 229, 453-476. doi:10.1007/s00213-0133120-y

Braida, D., Capurro, V., Zani, A., Rubino, T., Viganò, D., Parolaro, D., \& Sala, M. (2009). Potential anxiolytic- and antidepressant-like effects of salvinorin $A$, the main active ingredient of $<i>$ Salvia divinorum $</ i>$, in rodents. British Journal of Pharmacology, 157, 844-853. doi:10.1111/j.1476-5381.2009.00230.x

Braida, D., Limonta, V., Capurro, V., Fadda, P., Rubino, T., Mascia, P., ... Sala, M. (2008). Involvement of K-Opioid and Endocannabinoid System on Salvinorin A-Induced Reward. Biological Psychiatry, 63, 286-292. doi:10.1016/j.biopsych.2007.07.020

Braida, D., Limonta, V., Pegorini, S., Zani, A., Guerini-Rocco, C., Gori, E., \& Sala, M. (2007). Hallucinatory and rewarding effect of salvinorin A in zebrafish: K-opioid and CB1cannabinoid receptor involvement. Psychopharmacology, 190, 441-448. doi:10.1007/s00213-006-0639-1

Bruchas, M. R., \& Chavkin, C. (2010). Kinase cascades and ligand-directed signaling at the kappa opioid receptor. Psychopharmacology, 210, 137-147. doi:10.1007/s00213010-1806-y

Bruchas, Michael R., Schindler, Abigail G., Shankar, H., Messinger, Daniel I., Miyatake, M., Land, Benjamin B., ... Chavkin, C. (2011). Selective p38a MAPK Deletion in Serotonergic Neurons Produces Stress Resilience in Models of Depression and Addiction. Neuron, 71, 498-511. doi:10.1016/j.neuron.2011.06.011

Butelman, E. R., Caspers, M., Lovell, K. M., Kreek, M. J., \& Prisinzano, T. E. (2012). Behavioral effects and central nervous system levels of the broadly available kappa-agonist hallucinogen salvinorin A are affected by P-glycoprotein modulation in vivo. J Pharmacol Exp Ther, 341(3), 802-808. doi:10.1124/jpet.112.193227

Butelman, E. R., Mandau, M., Tidgewell, K., Prisinzano, T. E., Yuferov, V., \& Kreek, M. J. (2006). Effects of Salvinorin A, a -Opioid Hallucinogen, on a Neuroendocrine Biomarker Assay in Nonhuman Primates with High -Receptor Homology to Humans. Journal of Pharmacology and Experimental Therapeutics, 320, 300-306. doi:10.1124/jpet.106.112417

Butelman, E. R., Prisinzano, T. E., Deng, H., Rus, S., \& Kreek, M. J. (2009). Unconditioned behavioral effects of the powerful kappa-opioid hallucinogen salvinorin $A$ in nonhuman primates: fast onset and entry into cerebrospinal fluid. J Pharmacol Exp Ther, 328(2), 588-597. doi:10.1124/jpet.108.145342

Carlezon, W. A., Béguin, C., DiNieri, J. A., Baumann, M. H., Richards, M. R., Todtenkopf, M. S., ... Cohen, B. M. (2006). Depressive-Like Effects of the Kappa-Opioid Receptor Agonist Salvinorin A on Behavior and Neurochemistry in Rats. Journal of Pharmacology and Experimental Therapeutics, 316, 440-447. 
doi:10.1124/jpet.105.092304

Carlezon, W. A., Thome, J., Olson, V. G., Lane-Ladd, S. B., Brodkin, E. S., Hiroi, N., . . Nestler, E. J. (1998). Regulation of Cocaine Reward by CREB. Science, 282, 2272-2275. doi:10.1126/science.282.5397.2272

Cass, W. A., \& Gerhardt, G. A. (1994). Direct in vivo evidence that D2 dopamine receptors can modulate dopamine uptake. Neuroscience letters, 176, 259-263.

Cass, W. A., Gerhardt, G. A., Mayfield, R. D., Curella, P., \& Zahniser, N. R. (1992). Differences in dopamine clearance and diffusion in rat striatum and nucleus accumbens following systemic cocaine administration. Journal of neurochemistry, 59, 259-266.

Chartoff, E., Sawyer, A., Rachlin, A., Potter, D., Pliakas, A., \& Carlezon, W. A. (2012). Blockade of kappa opioid receptors attenuates the development of depressive-like behaviors induced by cocaine withdrawal in rats. Neuropharmacology, 62, 167-176. doi:10.1016/j.neuropharm.2011.06.014

Chartoff, E. H., Potter, D., Damez-Werno, D., Cohen, B. M., \& Carlezon, W. A. (2008). Exposure to the Selective K-Opioid Receptor Agonist Salvinorin A Modulates the Behavioral and Molecular Effects of Cocaine in Rats. Neuropsychopharmacology, 33, 2676-2687. doi:10.1038/sj.npp.1301659

Chavkin, C., Sud, S., Jin, W., Stewart, J., Zjawiony, J. K., Siebert, D. J., . . Roth, B. L. (2004). Salvinorin $A$, an active component of the hallucinogenic sage salvia divinorum is a highly efficacious kappa-opioid receptor agonist: structural and functional considerations. J Pharmacol Exp Ther, 308(3), 1197-1203. doi:10.1124/jpet.103.059394

Chefer, V. I., Bäckman, C. M., Gigante, E. D., \& Shippenberg, T. S. (2013). Kappa Opioid Receptors on Dopaminergic Neurons Are Necessary for Kappa-Mediated Place Aversion. Neuropsychopharmacology, 38, 2623-2631. doi:10.1038/npp.2013.171

Ciliax, B. J., Drash, G. W., Staley, J. K., Haber, S., Mobley, C. J., Miller, G. W., . . Levey, A. I. (1999). Immunocytochemical localization of the dopamine transporter in human brain. The Journal of comparative neurology, 409, 38-56.

Ciliax, B. J., Heilman, C., Demchyshyn, L. L., Pristupa, Z. B., Ince, E., Hersch, S. M., . . Levey, A. I. (1995). The dopamine transporter: immunochemical characterization and localization in brain. The Journal of neuroscience : the official journal of the Society for Neuroscience, 15, 1714-1723.

Cole, R. L., Konradi, C., Douglass, J., \& Hyman, S. E. (1995). Neuronal adaptation to amphetamine and dopamine: molecular mechanisms of prodynorphin gene regulation in rat striatum. Neuron, 14, 813-823.

Crawford, C. A., McDougall, S. A., Bolanos, C. A., Hall, S., \& Berger, S. P. (1995). The effects of the kappa agonist $U-50,488$ on cocaine-induced conditioned and unconditioned behaviors and Fos immunoreactivity. Psychopharmacology, 120, 392-399. doi:10.1007/BF02245810

Cryan, J. F., \& Mombereau, C. (2004). In search of a depressed mouse: utility of models for studying depression-related behavior in genetically modified mice. Mol Psychiatry, 9(4), 326-357. doi:10.1038/sj.mp.4001457

Cryan, J. F., Valentino, R. J., \& Lucki, I. (2005). Assessing substrates underlying the behavioral effects of antidepressants using the modified rat forced swimming test. Neurosci Biobehav Rev, 29(4-5), 547-569. doi:10.1016/j.neubiorev.2005.03.008

Culverhouse, A. (2015). Exploring the aversive and anxiogenic effects of novel kappa opioid receptor agonists in rats. (Masters Thesis). In. 
De Pablo, J. M., Parra, A., Segovia, S., \& Guillamon, A. (1989). Learned immobility explains the behavior of rats in the forced swimming test. Physiol Behav, 46(2), 229-237.

de Wit, H. (1996). Priming effects with drugs and other reinforcers. Experimental and Clinical Psychopharmacology, 4, 5-10. doi:10.1037/1064-1297.4.1.5

de Wit, H., \& Stewart, J. (1981). Reinstatement of cocaine-reinforced responding in the rat. Psychopharmacology, 75, 134-143.

Dhir, A., \& Kulkarni, S. K. (2007). Effect of Addition of Yohimbine (Alpha-2-Receptor Antagonist) to the Antidepressant Activity of Fluoxetine or Venlafaxine in the Mouse Forced Swim Test. Pharmacology, 80, 239-243. doi:10.1159/000104877

Di Chiara, G., \& Imperato, A. (1988). Drugs abused by humans preferentially increase synaptic dopamine concentrations in the mesolimbic system of freely moving rats. Proceedings of the National Academy of Sciences of the United States of America, 85, 5274-5278.

Dickinson, S. D., Sabeti, J., Larson, G. A., Giardina, K., Rubinstein, M., Kelly, M. A., . . . Zahniser, N. R. (1999). Dopamine D2 receptor-deficient mice exhibit decreased dopamine transporter function but no changes in dopamine release in dorsal striatum. Journal of neurochemistry, 72, 148-156.

Dogra, S., \& Yadav, P. N. (2015). Biased agonism at kappa opioid receptors: Implication in pain and mood disorders. Eur J Pharmacol, 763, 184-190. doi:10.1016/j.ejphar.2015.07.018

Ebner, S. R., Roitman, M. F., Potter, D. N., Rachlin, A. B., \& Chartoff, E. H. (2010). Depressivelike effects of the kappa opioid receptor agonist salvinorin $A$ are associated with decreased phasic dopamine release in the nucleus accumbens. Psychopharmacology, 210, 241-252. doi:10.1007/s00213-010-1836-5

Ewald, A. W. M., Bosch, P. J., Culverhouse, A., Crowley, R. S., Neuenswander, B., Prisinzano, T. E., \& Kivell, B. M. (2017). The C-2 derivatives of salvinorin A, ethoxymethyl ether Sal $B$ and $\beta$-tetrahydropyran Sal $B$, have anti-cocaine properties with minimal side effects. Psychopharmacology, 234, 2499-2514. doi:10.1007/s00213-017-4637-2

Feng, Y., He, X., Yang, Y., Chao, D., Lazarus, L. H., \& Xia, Y. (2012). Current research on opioid receptor function. Current drug targets, 13, 230-246.

Freeman, K. B., Naylor, J. E., Prisinzano, T. E., \& Woolverton, W. L. (2014). Assessment of the kappa opioid agonist, salvinorin $A$, as a punisher of drug self-administration in monkeys. Psychopharmacology, 231, 2751-2758. doi:10.1007/s00213-014-3436-2

Funk, D., Coen, K., \& Lê, A. D. (2014). The role of kappa opioid receptors in stress-induced reinstatement of alcohol seeking in rats. Brain and Behavior, 4, 356-367. doi:10.1002/brb3.222

Gillett, K., Harshberger, E., \& Valdez, G. R. (2013). Protracted withdrawal from ethanol and enhanced responsiveness stress: regulation via the dynorphin/kappa opioid receptor system. Alcohol (Fayetteville, N.Y.), 47, 359-365. doi:10.1016/j.alcohol.2013.05.001

Graham, D. L., Hoppenot, R., Hendryx, A., \& Self, D. W. (2007). Differential ability of D1 and D2 dopamine receptor agonists to induce and modulate expression and reinstatement of cocaine place preference in rats. Psychopharmacology, 191, 719730. doi:10.1007/s00213-006-0473-5

Grella, S. L., Funk, D., Coen, K., Li, Z., \& Lê, A. D. (2014). Role of the kappa-opioid receptor system in stress-induced reinstatement of nicotine seeking in rats. Behavioural Brain Research, 265, 188-197. doi:10.1016/j.bbr.2014.02.029

Griffiths, R. R., Findley, J. D., Brady, J. V., Dolan-Gutcher, K., \& Robinson, W. W. (1975). 
Comparison of progressive-ratio performance maintained by cocaine, methylphenidate and secobarbital. Psychopharmacologia, 43, 81-83.

Gupta, A., Décaillot, F. M., \& Devi, L. A. (2006). Targeting opioid receptor heterodimers: strategies for screening and drug development. The AAPS journal, 8, E153-159. doi:10.1208/aapsj080118

Harden, M. T., Smith, S. E., Niehoff, J. A., McCurdy, C. R., \& Taylor, G. T. (2012).

Antidepressive effects of the kappa-opioid receptor agonist salvinorin $A$ in a rat model of anhedonia. Behav Pharmacol, 23(7), 710-715. doi:10.1097/FBP.0b013e3283586189

Harding, W. W., Schmidt, M., Tidgewell, K., Kannan, P., Holden, K. G., Gilmour, B., . . Prisinzano, T. E. (2006). Synthetic studies of neoclerodane diterpenes from Salvia divinorum: semisynthesis of salvinicins $A$ and $B$ and other chemical transformations of salvinorin A. Journal of natural products, 69, 107-112. doi:10.1021/np050398i

Heidbreder, C. A., Babovic-Vuksanovic, D., Shoaib, M., \& Shippenberg, T. S. (1995). Development of behavioral sensitization to cocaine: influence of kappa opioid receptor agonists. J Pharmacol Exp Ther, 275, 150-163.

Heinsbroek, J. A., Furbish, A. B., \& Peters, J. (2018). A single, extinction-based treatment with a kappa opioid receptor agonist elicits a long-term reduction in cocaine relapse. Neuropsychopharmacology, 43, 1492-1497. doi:10.1038/s41386-017-0006-4

Hooker, J. M., Xu, Y., Schiffer, W., Shea, C., Carter, P., \& Fowler, J. S. (2008).

Pharmacokinetics of the potent hallucinogen, salvinorin $A$ in primates parallels the rapid onset and short duration of effects in humans. Neurolmage, 41, 1044-1050. doi:10.1016/j.neuroimage.2008.03.003

Hurd, Y. L., \& Herkenham, M. (1993). Molecular alterations in the neostriatum of human cocaine addicts. Synapse, 13, 357-369. doi:10.1002/syn.890130408

Jefferys, D., \& Funder, J. (1994). The effect of water temperature on immobility in the forced swimming test in rats. Eur J Pharmacol, 253(1-2), 91-94.

Johnson, S. M., \& Turner, S. M. F. (2010). Protecting motor networks during perinatal ischemia: the case for delta-opioid receptors. Annals of the New York Academy of Sciences, 1198, 260-270. doi:10.1111/j.1749-6632.2010.05434.x

Jordan, B., Cvejic, S., \& Devi, L. A. (2000). Opioids and Their Complicated Receptor Complexes. Neuropsychopharmacology, 23, S5-S18. doi:10.1016/S0893$133 \times(00) 00143-3$

Karberg, J. C., James, D. J., \& Statisticians, B. (2002). Substance Dependence, Abuse, and Treatment of Jail Inmates, 2002.

Kawaura, K., Miki, R., Urashima, Y., Kawahara, R., Soeda, F., Shirasaki, T., \& Takahama, K. (2012). Pharmacological mechanisms of antidepressant-like effect of tipepidine in the forced swimming test. Behavioural Brain Research, 226, 381-385. doi:10.1016/J.BBR.2011.09.031

Kebabian, J. W. (1978). Multiple classes of dopamine receptors in mammalian central nervous system: the involvement of dopamine-sensitive adenylyl cyclase. Life sciences, 23, 479-483.

Kelsey, J. E., Verhaak, A. M. S., \& Schierberl, K. C. (2015). The kappa-opioid receptor antagonist, nor-binaltorphimine (nor-BNI), decreases morphine withdrawal and the consequent conditioned place aversion in rats. Behavioural Brain Research, 283, $16-$ 21. doi:10.1016/J.BBR.2015.01.008

Kivell, B., Paton, K., Kumar, N., Morani, A., Culverhouse, A., Shepherd, A., . . Prisinzano, T. 
(2018). Kappa Opioid Receptor Agonist Mesyl Sal B Attenuates Behavioral

Sensitization to Cocaine with Fewer Aversive Side-Effects than Salvinorin A in Rodents (Vol. 23).

Kivell, B., Uzelac, Z., Sundaramurthy, S., Rajamanickam, J., Ewald, A., Chefer, V., . . . Shippenberg, T. S. (2014). Salvinorin A regulates dopamine transporter function via a kappa opioid receptor and ERK1/2-dependent mechanism. Neuropharmacology, 86, 228-240. doi:10.1016/j.neuropharm.2014.07.016

Knoll, A. T., Carlezon, W. A., \& Jr. (2010). Dynorphin, stress, and depression. Brain research, 1314, 56-73. doi:10.1016/j.brainres.2009.09.074

Knoll, A. T., Meloni, E. G., Thomas, J. B., Carroll, F. I., \& Carlezon, W. A. (2007). AnxiolyticLike Effects of -Opioid Receptor Antagonists in Models of Unlearned and Learned Fear in Rats. Journal of Pharmacology and Experimental Therapeutics, 323, 838-845. doi:10.1124/jpet.107.127415

Koob, G. F. (2008). A Role for Brain Stress Systems in Addiction. Neuron, 59, 11-34. doi:10.1016/J.NEURON.2008.06.012

Koob, G. F., \& Bloom, F. E. (1988). Cellular and molecular mechanisms of drug dependence. Science (New York, N.Y.), 242, 715-723.

Koob, G. F., \& Le Moal, M. (1997). Drug abuse: hedonic homeostatic dysregulation. Science (New York, N.Y.), 278, 52-58.

Li, J. G., Luo, L. Y., Krupnick, J. G., Benovic, J. L., \& Liu-Chen, L. Y. (1999). U50,488H-induced internalization of the human kappa opioid receptor involves a beta-arrestin- and dynamin-dependent mechanism. Kappa receptor internalization is not required for mitogen-activated protein kinase activation. The Journal of biological chemistry, 274, 12087-12094.

Little, K. Y., Krolewski, D. M., Zhang, L., \& Cassin, B. J. (2003). Loss of Striatal Vesicular Monoamine Transporter Protein (VMAT2) in Human Cocaine Users. American Journal of Psychiatry, 160, 47-55. doi:10.1176/appi.ajp.160.1.47

Liuchen, L. (2004). Agonist-induced regulation and trafficking of kappa; opioid receptors. Life Sciences, 75, 511-536. doi:10.1016/j.Ifs.2003.10.041

Mague, S. D., Pliakas, A. M., Todtenkopf, M. S., Tomasiewicz, H. C., Zhang, Y., Stevens, W. C., ... Carlezon, W. A. (2003). Antidepressant-Like Effects of kappa-Opioid Receptor Antagonists in the Forced Swim Test in Rats. Journal of Pharmacology and Experimental Therapeutics, 305, 323-330. doi:10.1124/jpet.102.046433

Maisonneuve, I. M., Archer, S., \& Glick, S. D. (1994). U50,488, a kappa opioid receptor agonist, attenuates cocaine-induced increases in extracellular dopamine in the nucleus accumbens of rats. Neuroscience letters, 181, 57-60.

Mansour, A., Khachaturian, H., Lewis, M. E., Akil, H., \& Watson, S. J. (1987). Autoradiographic differentiation of $\mathrm{mu}$, delta, and kappa opioid receptors in the rat forebrain and midbrain. The Journal of neuroscience : the official journal of the Society for Neuroscience, 7, 2445-2464.

Margolis, E. B., Lock, H., Chefer, V. I., Shippenberg, T. S., Hjelmstad, G. O., \& Fields, H. L. (2006). opioids selectively control dopaminergic neurons projecting to the prefrontal cortex. Proceedings of the National Academy of Sciences, 103, 2938-2942. doi:10.1073/pnas.0511159103

Mayfield, R. D., \& Zahniser, N. R. (2001). Dopamine D2 receptor regulation of the dopamine transporter expressed in Xenopus laevis oocytes is voltage-independent. Molecular pharmacology, 59, 113-121. 
McCurdy, C. R., Sufka, K. J., Smith, G. H., Warnick, J. E., \& Nieto, M. J. (2006). Antinociceptive profile of salvinorin $A$, a structurally unique kappa opioid receptor agonist.

Pharmacology Biochemistry and Behavior, 83, 109-113. doi:10.1016/j.pbb.2005.12.011

McLennan, G. P., Kiss, A., Miyatake, M., Belcheva, M. M., Chambers, K. T., Pozek, J. J., . . . Coscia, C. J. (2008). Kappa opioids promote the proliferation of astrocytes via Gbetagamma and beta-arrestin 2-dependent MAPK-mediated pathways. Journal of neurochemistry, 107, 1753-1765. doi:10.1111/j.1471-4159.2008.05745.x

Morani, A. S., Ewald, A., Prevatt-Smith, K. M., Prisinzano, T. E., \& Kivell, B. M. (2013). The 2methoxy methyl analogue of salvinorin $A$ attenuates cocaine-induced drug seeking and sucrose reinforcements in rats. Eur J Pharmacol, 720, 69-76. doi:10.1016/j.ejphar.2013.10.050

Morani, A. S., Kivell, B., Prisinzano, T. E., \& Schenk, S. (2009). Effect of kappa-opioid receptor agonists U69593, U50488H, spiradoline and salvinorin A on cocaine-induced drugseeking in rats. Pharmacology, biochemistry, and behavior, 94, 244-249. doi:10.1016/j.pbb.2009.09.002

Morani, A. S., Schenk, S., Prisinzano, T. E., \& Kivell, B. M. (2012). A single injection of a novel kappa opioid receptor agonist salvinorin $A$ attenuates the expression of cocaineinduced behavioral sensitization in rats. Behav Pharmacol, 23, 162-170. doi:10.1097/FBP.0b013e3283512c1e

Morón, J. A., Zakharova, I., Ferrer, J. V., Merrill, G. A., Hope, B., Lafer, E. M., . . Shippenberg, T. S. (2003). Mitogen-activated protein kinase regulates dopamine transporter surface expression and dopamine transport capacity. The Journal of neuroscience : the official journal of the Society for Neuroscience, 23, 8480-8488.

Morrow, P. (2018). The American opioid death epidemic-lessons for New Zealand? - New Zealand Medical Journal. The New Zealand Medical Journal.

Mucha, R. F., \& Herz, A. (1985). Motivational properties of kappa and mu opioid receptor agonists studied with place and taste preference conditioning. Psychopharmacology, 86, 274-280.

Nagase, H., Kawamura, K., Kawai, K., \& Hayakawa, J. (2010). Discovery of the First in Class Drug for Intractable Itch, Nalfurafine Hydrochloride. Journal of Synthetic Organic Chemistry, Japan, 68(12), 1261-1271. doi:10.5059/yukigoseikyokaishi.68.1261

Nakao, K., \& Mochizuki, H. (2009). Nalfurafine hydrochloride: a new drug for the treatment of uremic pruritus in hemodialysis patients. Drugs Today (Barc), 45(5), 323-329. doi:10.1358/dot.2009.45.5.1362067

Narendran, R., Lopresti, B. J., Martinez, D., Mason, N. S., Himes, M., May, M. A., . . Frankle, W. G. (2012). In Vivo Evidence for Low Striatal Vesicular Monoamine Transporter 2 (VMAT2) Availability in Cocaine Abusers. American Journal of Psychiatry, 169, 55-63. doi:10.1176/appi.ajp.2011.11010126

Narita, M., Kuzumaki, N., Miyatake, M., Sato, F., Wachi, H., Seyama, Y., \& Suzuki, T. (2006). Role of delta-opioid receptor function in neurogenesis and neuroprotection. Journal of Neurochemistry, 97, 1494-1505. doi:10.1111/j.1471-4159.2006.03849.x

Navarro, G., Moreno, E., Bonaventura, J., Brugarolas, M., Farré, D., Aguinaga, D., . . . McCormick, P. J. (2013). Cocaine Inhibits Dopamine D2 Receptor Signaling via Sigma1-D2 Receptor Heteromers. PLOS ONE, 8, e61245. doi:10.1371/JOURNAL.PONE.0061245

NCADD. (2015, 27/6/15). Alcohol, Drugs and Crime Retrieved from 
https://www.ncadd.org/about-addiction/alcohol-drugs-and-crime

Negus, S. S., Mello, N. K., Portoghese, P. S., \& Lin, C. E. (1997). Effects of kappa opioids on cocaine self-administration by rhesus monkeys. J Pharmacol Exp Ther, 282, 44-55.

NIDA. (2017). Trends \&amp; Statistics | National Institute on Drug Abuse (NIDA). National Institute on Drug Abuse.

Panlilio, L. V., \& Goldberg, S. R. (2007). Self-administration of drugs in animals and humans as a model and an investigative tool. Addiction (Abingdon, England), 102, 1863-1870. doi:10.1111/j.1360-0443.2007.02011.x

Paris, J. J., Reilley, K. J., \& McLaughlin, J. P. (2012). Kappa Opioid Receptor-Mediated Disruption of Novel Object Recognition: Relevance for Psychostimulant Treatment. Journal of Addiction Research \& Therapy, 01. doi:10.4172/2155-6105.S4-007

Park, K., Volkow, N. D., Pan, Y., \& Du, C. (2013). Chronic cocaine dampens dopamine signaling during cocaine intoxication and unbalances D1 over D2 receptor signaling. The Journal of neuroscience : the official journal of the Society for Neuroscience, 33, 15827-15836. doi:10.1523/JNEUROSCI.1935-13.2013

Pellow, S., Chopin, P., File, S. E., \& Briley, M. (1985). Validation of open:closed arm entries in an elevated plus-maze as a measure of anxiety in the rat. Journal of neuroscience methods, 14, 149-167.

Pfaus, J. G., Damsma, G., Nomikos, G. G., Wenkstern, D. G., Blaha, C. D., Phillips, A. G., \& Fibiger, H. C. (1990). Sexual behavior enhances central dopamine transmission in the male rat. Brain research, 530, 345-348.

Phillips, A. G., \& Fibiger, H. C. (1978). The role of dopamine in maintaining intracranial selfstimulation in the ventral tegmentum, nucleus accumbens, and medial prefrontal cortex. Canadian journal of psychology, 32, 58-66.

Plant, T. M., Zeleznik, A. J., Hull, E. M., \& Dominguez, J. M. (2015). Male Sexual Behavior. Knobil and Neill's Physiology of Reproduction, 2211-2285. doi:10.1016/B978-0-12397175-3.00049-1

Polter, A. M., Bishop, R. A., Briand, L. A., Graziane, N. M., Pierce, R. C., \& Kauer, J. A. (2014). Poststress block of kappa opioid receptors rescues long-term potentiation of inhibitory synapses and prevents reinstatement of cocaine seeking. Biological psychiatry, 76, 785-793. doi:10.1016/j.biopsych.2014.04.019

Porsolt, R. D., Le Pichon, M., \& Jalfre, M. (1977). Depression: a new animal model sensitive to antidepressant treatments. Nature, 266, 730-732. doi:10.1038/266730a0

Potter, D. N., Damez-Werno, D., Carlezon, W. A., Cohen, B. M., \& Chartoff, E. H. (2011). Repeated Exposure to the $\mathrm{k}$-Opioid Receptor Agonist Salvinorin A Modulates Extracellular Signal-Regulated Kinase and Reward Sensitivity. Biological Psychiatry, 70, 744-753. doi:10.1016/j.biopsych.2011.05.021

Prisinzano, T. E., Tidgewell, K., \& Harding, W. W. (2005). Kappa opioids as potential treatments for stimulant dependence. The AAPS journal, 7, E592-599. doi:10.1208/aapsj070361

Privette, T. H., \& Terrian, D. M. (1995). Kappa opioid agonists produce anxiolytic-like behavior on the elevated plus-maze. Psychopharmacology, 118, 444-450.

Redila, V. A., \& Chavkin, C. (2008). Stress-induced reinstatement of cocaine seeking is mediated by the kappa opioid system. Psychopharmacology, 200, 59-70. doi:10.1007/s00213-008-1122-y

Riley, A. P., Groer, C. E., Young, D., Ewald, A. W., Kivell, B. M., \& Prisinzano, T. E. (2014). Synthesis and k-Opioid Receptor Activity of Furan-Substituted Salvinorin A 
Analogues. Journal of Medicinal Chemistry, 57, 10464-10475. doi:10.1021/jm501521d

Rinaldi, R. C., Steindler, E. M., Wilford, B. B., \& Goodwin, D. (1988). Clarification and standardization of substance abuse terminology. JAMA, 259, 555-557.

Ritz, M. C., Lamb, R. J., Goldberg, S. R., \& Kuhar, M. J. (1987). Cocaine receptors on dopamine transporters are related to self-administration of cocaine. Science (New York, N.Y.), 237, 1219-1223.

Robinson, T. E., \& Berridge, K. C. (1993). The neural basis of drug craving: an incentivesensitization theory of addiction. Brain research. Brain research reviews, 18, 247-291.

Roth, B. L., Baner, K., Westkaemper, R., Siebert, D., Rice, K. C., Steinberg, S., . . Rothman, R. B. (2002). Salvinorin A: A potent naturally occurring nonnitrogenous opioid selective agonist. Proceedings of the National Academy of Sciences, 99, 11934-11939. doi:10.1073/pnas.182234399

Rusin, K. I., Giovannucci, D. R., Stuenkel, E. L., \& Moises, H. C. (1997). Kappa-opioid receptor activation modulates $\mathrm{Ca} 2+$ currents and secretion in isolated neuroendocrine nerve terminals. The Journal of neuroscience : the official journal of the Society for Neuroscience, 17, 6565-6574.

Schenk, S., Partridge, B., \& Shippenberg, T. S. (1999). U69593, a kappa-opioid agonist, decreases cocaine self-administration and decreases cocaine-produced drug-seeking. Psychopharmacology, 144, 339-346.

Schmidt, M. D., Schmidt, M. S., Butelman, E. R., Harding, W. W., Tidgewell, K., Murry, D. J., . . . Prisinzano, T. E. (2005). Pharmacokinetics of the plant-derived kappa-opioid hallucinogen salvinorin A in nonhuman primates. Synapse, 58(3), 208-210. doi:10.1002/syn.20191

Schmitz, Y., Benoit-Marand, M., Gonon, F., \& Sulzer, D. (2003). Presynaptic regulation of dopaminergic neurotransmission. Journal of neurochemistry, 87, 273-289.

Self, D. W., Barnhart, W. J., Lehman, D. A., \& Nestler, E. J. (1996). Opposite modulation of cocaine-seeking behavior by D1- and D2-like dopamine receptor agonists. Science (New York, N.Y.), 271, 1586-1589.

Shaham, Y., \& Miczek, K. A. (2003). Reinstatement-toward a model of relapse. Psychopharmacology, 168, 1-2. doi:10.1007/s00213-003-1469-z

Shippenberg, T. S., Zapata, A., \& Chefer, V. I. (2007). Dynorphin and the pathophysiology of drug addiction. Pharmacology \& therapeutics, 116, 306-321. doi:10.1016/j.pharmthera.2007.06.011

Simonson, B., Morani, A. S., Ewald, A. W. M., Walker, L., Kumar, N., Simpson, D., . . Kivell, B. M. (2015). Pharmacology and anti-addiction effects of the novel $k$ opioid receptor agonist Mesyl Sal B, a potent and long-acting analogue of salvinorin A. British Journal of Pharmacology, 172, 515-531. doi:10.1111/bph.12692

Solomon, R. L., \& Corbit, J. D. (1974). An opponent-process theory of motivation: I. Temporal dynamics of affect. Psychological Review, 81, 119-145. doi:10.1037/h0036128

Sonders, M. S., Zhu, S. J., Zahniser, N. R., Kavanaugh, M. P., \& Amara, S. G. (1997). Multiple ionic conductances of the human dopamine transporter: the actions of dopamine and psychostimulants. The Journal of neuroscience : the official journal of the Society for Neuroscience, 17, 960-974.

Sorge, R. E., Martin, L. J., Isbester, K. A., Sotocinal, S. G., Rosen, S., Tuttle, A. H., . . Mogil, J. S. (2014). Olfactory exposure to males, including men, causes stress and related 
analgesia in rodents. Nature Methods, 11, 629-632. doi:10.1038/nmeth.2935

Stevens Negus, S. (2004). Effects of the kappa opioid agonist U50,488 and the kappa opioid antagonist nor-binaltorphimine on choice between cocaine and food in rhesus monkeys. Psychopharmacology, 176, 204-213. doi:10.1007/s00213-004-1878-7

Stewart, J., \& Badiani, A. (1993). Tolerance and sensitization to the behavioral effects of drugs. Behav Pharmacol, 4, 289???312. doi:10.1097/00008877-199308000-00003

Sufka, K. J., Loria, M. J., Lewellyn, K., Zjawiony, J. K., Ali, Z., Abe, N., \& Khan, I. A. (2014). The effect of Salvia divinorum and Mitragyna speciosa extracts, fraction and major constituents on place aversion and place preference in rats. Journal of Ethnopharmacology, 151, 361-364. doi:10.1016/j.jep.2013.10.059

The role of dopamine in modulating the structure and function of striatal circuits, 183, 20696319 148-167 (2010).

Suzuki, T., Shiozaki, Y., Masukawa, Y., Misawa, M., \& Nagase, H. (1992). The role of mu- and kappa-opioid receptors in cocaine-induced conditioned place preference. Japanese journal of pharmacology, 58, 435-442.

Svingos, A. L., Chavkin, C., Colago, E. E. O., \& Pickel, V. M. (2001). Major coexpression of kappa-opioid receptors and the dopamine transporter in nucleus accumbens axonal profiles. Synapse, 42, 185-192. doi:10.1002/syn.10005

Swanson, L. W. (1982). The projections of the ventral tegmental area and adjacent regions: a combined fluorescent retrograde tracer and immunofluorescence study in the rat. Brain research bulletin, 9, 321-353.

Taussig, R., Iñiguez-Lluhi, J. A., \& Gilman, A. G. (1993). Inhibition of adenylyl cyclase by Gi alpha. Science (New York, N.Y.), 261, 218-221.

Taylor, D., \& Ho, B. T. (1977). Neurochemical effects of cocaine following acute and repeated injection. Journal of Neuroscience Research, 3, 95-101. doi:10.1002/jnr.490030203

Tejeda, H. A., Counotte, D. S., Oh, E., Ramamoorthy, S., Schultz-Kuszak, K. N., Bäckman, C. M., ... Shippenberg, T. S. (2013). Prefrontal Cortical Kappa-Opioid Receptor Modulation of Local Neurotransmission and Conditioned Place Aversion. Neuropsychopharmacology, 38, 1770-1779. doi:10.1038/npp.2013.76

Teksin, Z. S., Lee, I. J., Nemieboka, N. N., Othman, A. A., Upreti, V. V., Hassan, H. E., . . Eddington, N. D. (2009). Evaluation of the transport, in vitro metabolism and pharmacokinetics of Salvinorin A, a potent hallucinogen. Eur J Pharm Biopharm, 72(2), 471-477. doi:10.1016/j.ejpb.2009.01.002

Tempel, A., \& Zukin, R. S. (1987). Neuroanatomical patterns of the mu, delta, and kappa opioid receptors of rat brain as determined by quantitative in vitro autoradiography. Proceedings of the National Academy of Sciences of the United States of America, 84, 4308-4312.

Thompson, A. C., Zapata, A., Justice, J. B., Vaughan, R. A., Sharpe, L. G., \& Shippenberg, T. S. (2000). Kappa-opioid receptor activation modifies dopamine uptake in the nucleus accumbens and opposes the effects of cocaine. The Journal of neuroscience : the official journal of the Society for Neuroscience, 20, 9333-9340.

Ueno, Y., Mori, A., \& Yanagita, T. (2013). One year long-term study on abuse liability of nalfurafine in hemodialysis patients. Int J Clin Pharmacol Ther, 51(11), 823-831. doi:10.5414/cp201852

Valdés, L. J., Díaz, J. L., \& Paul, A. G. (1983). Ethnopharmacology of ska María Pastora (Salvia divinorum, Epling and Játiva-M.). Journal of ethnopharmacology, 7, 287-312. 
Valdez, G. R., \& Harshberger, E. (2012). Kappa opioid regulation of anxiety-like behavior during acute ethanol withdrawal. Pharmacology Biochemistry and Behavior, 102, 4447. doi:10.1016/j.pbb.2012.03.019

Valdez, G. R., Platt, D. M., Rowlett, J. K., Ruedi-Bettschen, D., \& Spealman, R. D. (2007). Agonist-Induced Reinstatement of Cocaine Seeking in Squirrel Monkeys: A Role for Opioid and Stress-Related Mechanisms. Journal of Pharmacology and Experimental Therapeutics, 323, 525-533. doi:10.1124/jpet.107.125484

van der Staay, F. J., Schuurman, T., van Reenen, C. G., \& Korte, S. M. (2009). Emotional reactivity and cognitive performance in aversively motivated tasks: a comparison between four rat strains. Behavioral and brain functions : $B B F, 5,50$. doi:10.1186/1744-9081-5-50

Van't Veer, A., \& Carlezon, W. A. (2013). Role of kappa-opioid receptors in stress and anxiety-related behavior. Psychopharmacology, 229, 435-452. doi:10.1007/s00213013-3195-5

Vargas-Perez, H., Ting-A-Kee, R. A., Heinmiller, A., Sturgess, J. E., \& van der Kooy, D. (2007). A test of the opponent-process theory of motivation using lesions that selectively block morphine reward. European Journal of Neuroscience, 25, 3713-3718. doi:10.1111/j.1460-9568.2007.05599.x

Vaughan, R. A., \& Foster, J. D. (2013). Mechanisms of dopamine transporter regulation in normal and disease states. Trends in pharmacological sciences, 34, 489-496. doi:10.1016/j.tips.2013.07.005

Volkow, Nora D., \& Morales, M. (2015). The Brain on Drugs: From Reward to Addiction. Cell, 162(4), 712-725. doi:https://doi.org/10.1016/j.cell.2015.07.046

Volkow, N. D., Wang, G.-J., Fischman, M. W., Foltin, R. W., Fowler, J. S., Abumrad, N. N., ... Shea, C. E. (1997). Relationship between subjective effects of cocaine and dopamine transporter occupancy. Nature, 386, 827-830. doi:10.1038/386827a0

Walf, A. A., \& Frye, C. A. (2007). The use of the elevated plus maze as an assay of anxietyrelated behavior in rodents. Nature protocols, 2, 322-328. doi:10.1038/nprot.2007.44

Walker, B. M., \& Koob, G. F. (2008). Pharmacological Evidence for a Motivational Role of kOpioid Systems in Ethanol Dependence. Neuropsychopharmacology, 33, 643-652. doi:10.1038/sj.npp.1301438

Walker, B. M., Valdez, G. R., McLaughlin, J. P., \& Bakalkin, G. (2012). Targeting dynorphin/kappa opioid receptor systems to treat alcohol abuse and dependence. Alcohol, 46, 359-370. doi:10.1016/J.ALCOHOL.2011.10.006

Walker, B. M., Zorrilla, E. P., \& Koob, G. F. (2011). Systemic k-opioid receptor antagonism by nor-binaltorphimine reduces dependence-induced excessive alcohol selfadministration in rats. Addiction biology, 16, 116-119. doi:10.1111/j.13691600.2010.00226.x

Wang, Y., Tang, K., Inan, S., Siebert, D., Holzgrabe, U., Lee, D. Y. W., . . L Liu-Chen, L.-Y. (2004). Comparison of Pharmacological Activities of Three Distinct Ligands (Salvinorin A, TRK-820 and 3FLB) on Opioid Receptors in Vitro and Their Antipruritic and Antinociceptive Activities in Vivo. Journal of Pharmacology and Experimental Therapeutics, 312, 220-230. doi:10.1124/jpet.104.073668

Wayne W. Harding, Kevin Tidgewell, Nathan Byrd, Howard Cobb, Christina M. Dersch, Eduardo R. Butelman, ... Thomas E. Prisinzano*. (2005). Neoclerodane Diterpenes as a Novel Scaffold for $\mu$ Opioid Receptor Ligandst. doi:10.1021/JM048963M 
Wee, S., \& Koob, G. F. (2010). The role of the dynorphin-k opioid system in the reinforcing effects of drugs of abuse. Psychopharmacology, 210, 121-135. doi:10.1007/s00213010-1825-8

Wee, S., Orio, L., Ghirmai, S., Cashman, J. R., \& Koob, G. F. (2009). Inhibition of kappa opioid receptors attenuated increased cocaine intake in rats with extended access to cocaine. Psychopharmacology, 205, 565-575. doi:10.1007/s00213-009-1563-y

Weeks, J. R. (1962). Experimental morphine addiction: method for automatic intravenous injections in unrestrained rats. Science (New York, N.Y.), 138, 143-144.

Welsh, S. (2017). The effect of novel kappa opioid peptide receptor agonists on learning and memory in rats (Masters Thesis). In.

West, A. P. (1990). Neurobehavioral studies of forced swimming: the role of learning and memory in the forced swim test. Prog Neuropsychopharmacol Biol Psychiatry, 14(6), 863-877.

Whitfield, T. W., Schlosburg, J. E., Wee, S., Gould, A., George, O., Grant, Y., . . Koob, G. F. (2015). $\mathrm{k}$ Opioid receptors in the nucleus accumbens shell mediate escalation of methamphetamine intake. The Journal of neuroscience : the official journal of the Society for Neuroscience, 35, 4296-4305. doi:10.1523/JNEUROSCI.1978-13.2015

Wiers, C. E., Shumay, E., Volkow, N. D., Frieling, H., Kotsiari, A., Lindenmeyer, J., . . . Bermpohl, F. (2015). Effects of depressive symptoms and peripheral DAT methylation on neural reactivity to alcohol cues in alcoholism. Translational Psychiatry, 5, e648-e648. doi:10.1038/tp.2015.141

Wood, P. L., \& Rao, T. S. (1991). Morphine stimulation of mesolimbic and mesocortical but not nigrostriatal dopamine release in the rat as reflected by changes in 3methoxytyramine levels. Neuropharmacology, 30, 399-401.

Wu, L. G., \& Saggau, P. (1997). Presynaptic inhibition of elicited neurotransmitter release. Trends in neurosciences, 20, 204-212.

Yoshida, M., Yokoo, H., Mizoguchi, K., Kawahara, H., Tsuda, A., Nishikawa, T., \& Tanaka, M. (1992). Eating and drinking cause increased dopamine release in the nucleus accumbens and ventral tegmental area in the rat: measurement by in vivo microdialysis. Neuroscience letters, 139, 73-76.

Young, D. (2015). Pre-clinical Anti-Addictive and Side-effect profiles of Novel Kappa-opioid Agonists. (Masters Thesis). In.

Zakharova, E., Collins, S. L., Åberg, M., Kumar, A., Fernandez, J. B., \& Izenwasser, S. (2008). Depletion of serotonin decreases the effects of the kappa-opioid receptor agonist U69593 on cocaine-stimulated activity. Eur J Pharmacol, 586, 123-129. doi:10.1016/j.ejphar.2008.02.065

Zhang, L.-S., Wang, J., Chen, J.-C., Tao, Y.-m., Wang, Y.-h., Xu, X.-j., . . Liu, J.-g. (2015). Novel $\mathrm{K}$-opioid receptor agonist MB-1C-OH produces potent analgesia with less depression and sedation. Acta Pharmacologica Sinica, 36, 565-571. doi:10.1038/aps.2014.145

Zhang, Y., Butelman, E. R., Schlussman, S. D., Ho, A., \& Kreek, M. J. (2005). Effects of the plant-derived hallucinogen salvinorin $A$ on basal dopamine levels in the caudate putamen and in a conditioned place aversion assay in mice: agonist actions at kappa opioid receptors. Psychopharmacology, 179, 551-558. doi:10.1007/s00213-0042087-0

Zhou, Y., \& Leri, F. (2016). Neuroscience of opiates for addiction medicine: From stressresponsive systems to behavior. Prog Brain Res, 223, 237-251. doi:10.1016/bs.pbr.2015.09.001 